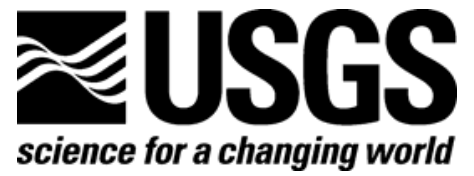

\title{
Performance Audit of the U.S. Geological Survey, Energy Resource Program Inorganic Geochemistry Laboratory
}

By James A. Luppens, Louis G. Janke, Jamey D. McCord, John H. Bullock, Lisa Brazeau, and Ronald H. Affolter

Open-File Report 2007-1136 


\section{U.S. Department of the Interior \\ DIRK KEMPTHORNE, Secretary}

\section{U.S. Geological Survey \\ Mark D. Myers, Director}

\section{U.S. Geological Survey, Reston, Virginia 2007}

For product and ordering information:

World Wide Web: http://www.usgs.gov/pubprod

Telephone: 1-888-ASK-USGS

For more information on the USGS - the Federal source for science about the Earth, its natural and living resources, natural hazards, and the environment:

World Wide Web: http://www.usgs.gov

Telephone: 1-888-ASK-USGS

Suggested citation:

Luppens, J.A, Janke, L.G. McCord, J.D., Bullock, J.H. Brazeau, L., Affronter, R.H., 2007, Performance Audit of the U.S. Geological Survey, Energy Resource Program Inorganic Geochemistry Laboratory: U.S. Geological Survey, Open-File Report 2007-1136

Any use of trade, product, or firm names is for descriptive purposes only and does not imply endorsement by the U.S. Government.

Although this report is in the public domain, permission must be secured from the individual copyright owners to reproduce any copyrighted material contained within this report. 


\section{Contents}

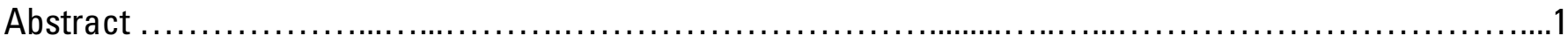

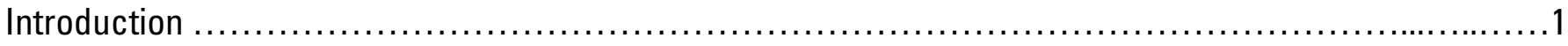

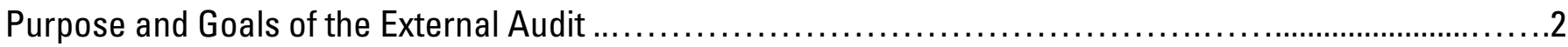

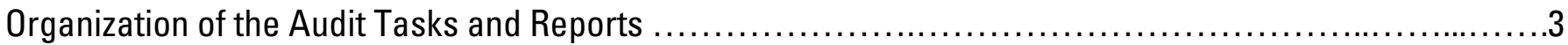

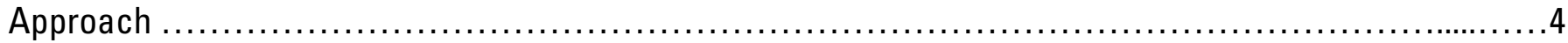

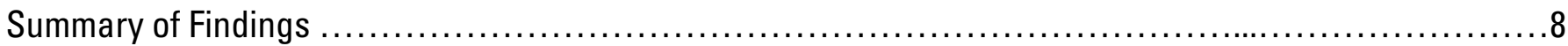

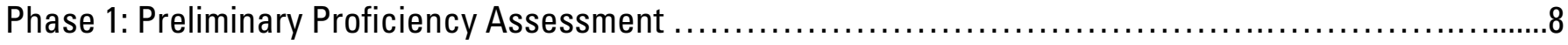

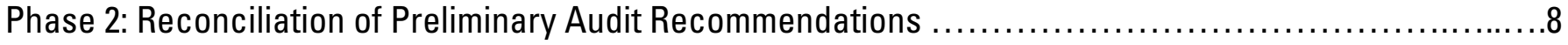

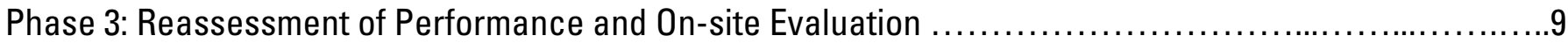

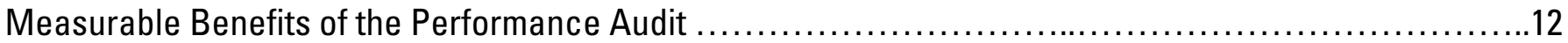

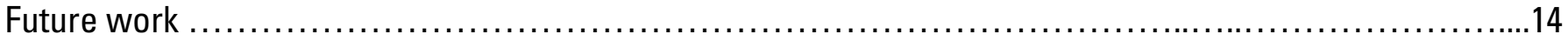

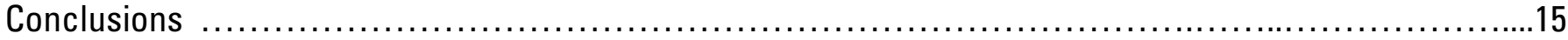

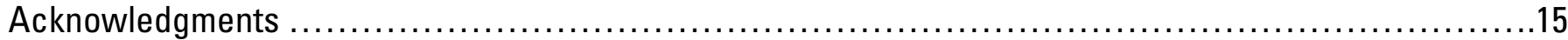

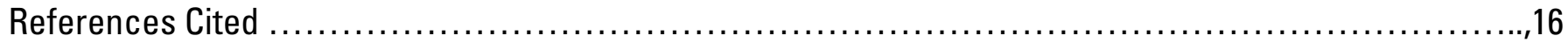

Appendix A - Phase 1: Preliminary Evaluations of Quality System and Recommendations..................17

Appendix A.1: Preliminary Evaluation of Quality System; Initial Report................................18

Appendix A.2: Preliminary Evaluation of Quality System; Final Report....................................

Appendix B - Phase 3: Reassessment Analyses, and On-site Audit Final Report .........................44

Appendix B.1: Evaluation of Reassessment Results from Chlorine Determinations.......................45

Appendix B.2: Evaluation of Reassessment Results for Major Oxides...................................5

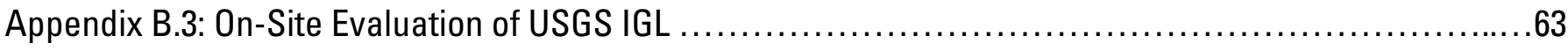

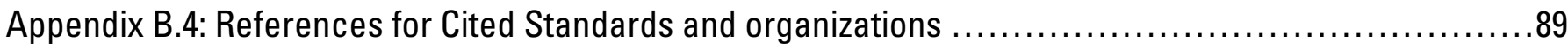

\section{Figures}

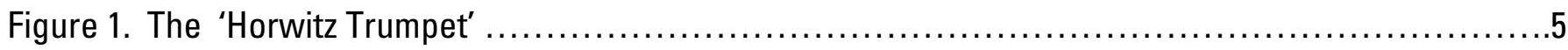

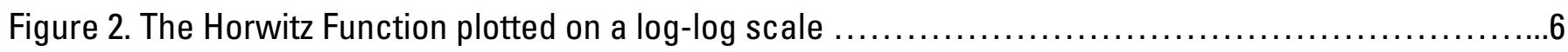

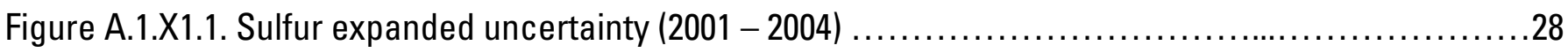

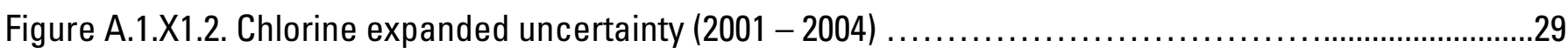

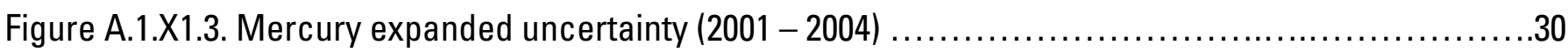

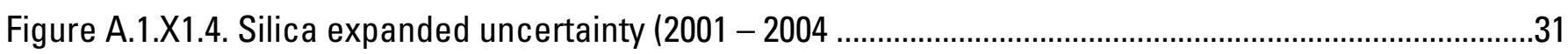

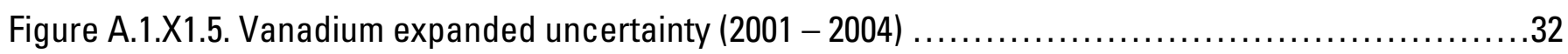

Figure B.2.1. The comparison of reported and corrected silica oxide values .......................... 55

Figure B.2.2. The comparison of reported and corrected Aluminum oxide values ........................56

Figure B.2.3. The comparison of reported and corrected Iron oxide values ............................57 
Figure B.2.4. The comparison of reported and corrected Calcium oxide values .58

Figure B.2.5. The comparison of reported and corrected Magnesium oxide values ......................59

Figure B.2.6. The comparison of reported and corrected Sodium oxide values .........................60

Figure B.2.7. The comparison of reported and corrected Potassium oxide values ........................61

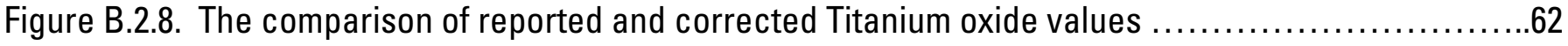

\section{Tables}

Table 1. IGL CANSPEX'M results before and after performance audit analyses ...........................13

Table 2. Summary of CANSPEX ${ }^{\mathrm{TM}}$ results before and after IGL performance audit ......................... 14

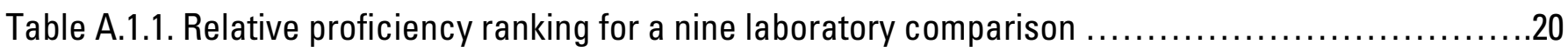

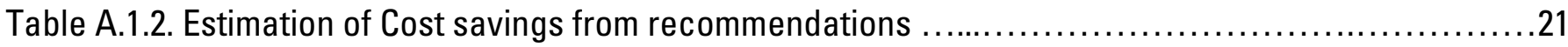

Table A.1.3. Recommended purchases of certified reference and reference materials ...................... 1

Table A.1.4. Acceptance values of certified reference and reference materials .........................22

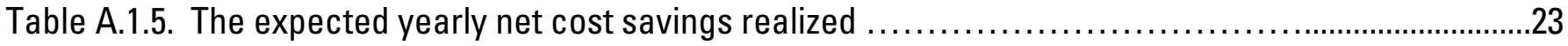

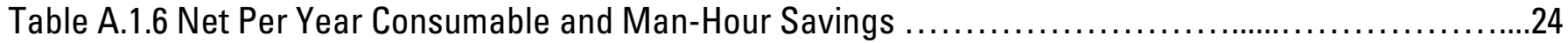

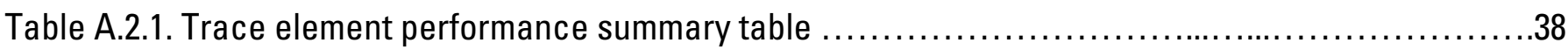

Table A.2.2. Major and minor element performance summary table ...........................................39

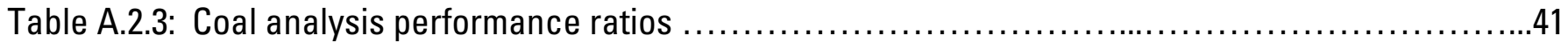

Table A.2.X1.1. Estimated cost savings over a four year period for all recommendations ...................43

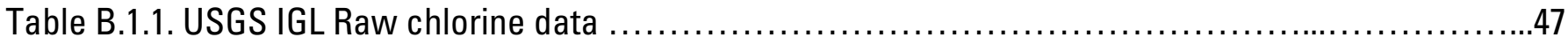

Table B.1.2. USGS IGL Chlorine results corrected for calibration and control bias .........................48

Table B.2.1. Expected major oxide totals for the CRM samples ….................................. 51

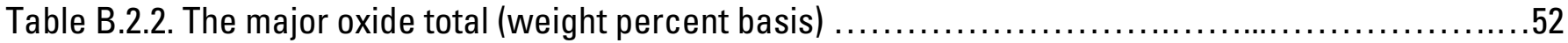

Table B.2.3. Comparison of Precision and Accuracy of Corrected Oxide vs. Reported Oxides ...............53

Table B.3.1. ASTM standards for collection of mine samples and commercial samples .....................65

Table B.3.2. Riffle slot sizes for particle sizes at each stage of sample reduction ........................66

Table B.3.3. The number of standards required by the type of calibration curve ….......................73

Table B.3.4. The point at which the \pm 2 s uncertainty reaches $20 \%$ of the chlorine value ...............................82

Table B.3.5. The point at which the \pm 2 s uncertainty reaches $20 \%$ of the mercury value $\ldots \ldots \ldots \ldots \ldots \ldots \ldots . . . . \ldots 5$

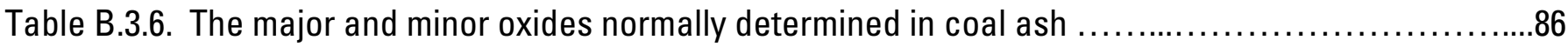

Table B.3.7. The relevant applicable standards and expected percent uncertainty...................................87 


\title{
Performance Audit of the U.S. Geological Survey, Energy Resource Program Inorganic Geochemistry Laboratory
}

By James A. Luppens ${ }^{1}$, Louis G. Janke², Jamey D. McCord ${ }^{3}$, John H. Bullock ${ }^{3}$, Lisa Brazeau, and Ronald H. Affolter ${ }^{3}$

\begin{abstract}
A performance audit of the U.S. Geological Survey (USGS), Energy Resource Program (ERP) Inorganic Geochemistry Laboratory (IGL) was conducted between August, 2003 and October, 2005. The goals were to ensure that a high level of analytical performance was maintained and identify any areas that could be enhanced. The audit was subdivided into three phases. Phase 1 was a preliminary assessment of current performance based on recent performance on CANSPEX ${ }^{\mathrm{TM}}$ samples. IGL performance was also compared to laboratories world-wide with similar scope. Phase 2 consisted of the implementation of the recommended changes made in Phase 1. Phase 3 of the audit consisted of a reassessment effort to evaluate the effectiveness of the recommendations made in the Phase 1 and an on-site audit of the laboratory facilities. Phases 1 and 3 required summary reports that are included in Appendices A and B of this report. The audit found that the IGL was one of the top two laboratories compared for trace element analyses. Several recommendations to enhance performance on major and minor elemental parameters were made and implemented. Demonstrated performance improvements as a result of the recommended changes were documented. Several initiatives to sustain the performance improvements gained from the audit have been implemented.
\end{abstract}

\section{Introduction}

The U.S. Geological Survey (USGS), Geologic Discipline, Energy Resources Program (ERP) addresses the challenge of increasing demand for affordable energy from environmentally acceptable energy sources by conducting basic and applied research on geologic energy resources and on the environmental, economic, and human health impacts of their production and use. The ERP provides reliable and impartial scientific information and comprehensive analyses of oil, natural gas, and coal resources of the nation and the world. The results of USGS

\footnotetext{
${ }^{1}$ U.S. Geological Survey, Reston, VA 20192, USA

${ }^{2}$ Quality Associates International ${ }^{\circledR}$ LDT; Douglas, Ont., Canada, KOJ $1 S 0$

${ }^{3}$ U.S. Geological Survey, Denver, CO 80225, USA
} 
data and USGS research are used to shape policies regarding domestic and foreign energy resources and to manage energy resources on Federal lands.

An integral component of that energy research program is the ERP Inorganic Geochemistry Laboratory (IGL) located in Denver, CO. The IGL is responsible for the analysis of major, minor, and trace elements in coal, overburden, water, and related samples from diverse sources not only from coal regions in the US, but also from around the world. Samples come from projects such as the National Coal Resource Assessment (NCRA), World Coal Quality Inventory (WoCQI), National Coal Quality Inventory (NaCQI), and various research studies on coal and coal by-products as well as associated studies on environmental and health impacts. The IGL's primary focus is the analysis of major, minor, and trace elements in coal and related samples. Recently, water analyses from studies involving leachate samples from coal combustion by-products, coal bed methane (CBM) produced water samples, and air samples have also become a significant part of the IGL's capabilities. Routine coal analyses that include proximate, ultimate, equilibrium moisture and ash fusion temperatures are performed under contract by Geochemical Testing, Somerset, PA.

The data generated and the expertise of IGL personnel developed over years of analyzing such a unique and varied energy-related sample suite is a critical support component of the ERP's programs. Furthermore, the IGL not only provides production analyses, but also devotes a significant amount of time improving existing techniques and developing new standard procedures in cooperation with ASTM International Committee D05 on Coal and Coke to meet the needs of ongoing and future scientific studies. Increased emphasis throughout the coal industry on understanding the impacts of production and usage of coal, including the effects of mercury, arsenic, and other toxic elements, will ensure that the major, minor, and trace element results generated by the IGL will have increased visibility and importance.

\section{Purpose and Goals of the External Audit}

Although the term "audit" often has negative implications, it should always be designed and perceived as a constructive practice. A basic principle of sound quality management is a formal audit by an external examiner at appropriate intervals to verify that operations comply with the elements of good laboratory practice. Periodic outside reviews are required regardless of a laboratory's current performance. The ultimate goal is to demonstrate and maintain a high level of confidence that the IGL continues to produce data that are of the requisite accuracy. Because USGS data are used world-wide, it is vital that the IGL Quality Management System (QMS) complies with the elements of good laboratory practice specified in ISO/IEC 17025, "General requirements for the competence of testing and calibration laboratories" (ISO/IEC, 2005), to maintain international credibility as a lead agency in coal quality assessment. Compliance with national standards such as ASTM D 4182 and ASTM D 4621 (ASTM International, 2006), which reflect the requirements of ISO/IEC 17025, makes certain that the USGS continues to address the interests and needs of the coal industry.

As part of a continuing effort to demonstrate government accountability, the ERP awarded a contract to conduct an operating audit of the IGL to Quality Associates International ${ }^{\circledR}$ LDT (QAI) in July, 2003. The fundamental scope of the audit by QAI was to evaluate performance of the IGL to ensure that its operations were consistent with ISO 17025 (ISO, 2005), ASTM D4621-99, and D4182-97 (ASTM International, 2006). Where appropriate, the audit was required to make recommendations for incorporation into the QMS that will optimize the continuing production of reliable results from major, minor and trace element analyses when 
employing industry consensus standards and in-house methods. To ensure a comprehensive assessment of all analytical values reported by the IGL, the scope of the audit was expanded to include an abridged evaluation of the performance of Geochemical Testing, Somerset, PA, which is the contract laboratory currently used for basic coal quality parameters including proximate and ultimate analyses. The specific goals of the audit were:

- Compare recent IGL performance with similar laboratories around the world.

- Produce consistent, high quality data.

- Lower operational costs.

- Create a working environment that optimizes staff involvement in quality assurance that fosters a constructive process for continuous improvement rather than just a simple, onetime "score card".

- Position the laboratory to become a recognized competent practitioner of analyses based on a performance based testing program, an approach that is being adopted by major standards writing organizations around the world.

Performance based testing (PBT) provides the ability to continually demonstrate the production of credible analytical results through comparison with accepted performance benchmarks. An effective way to accomplish such comparisons is through the continuing use of samples with known values that can be to traceable to certified reference materials. Simply stated, the essential objectives of PBT are to demonstrate both proof of competency and proof of value. Thus, attainment of proficiency in PBT practices is the ultimate goal for the IGL.

\section{Organization of the Audit Tasks and Reports}

This external audit was structured differently than the traditional approach where an auditor simply conducts an on-site inspection and writes a report summarizing the findings of that visit. In this case, the audited laboratory is then left on its own to address, implement, and verify any recommendations. The approach taken for this audit was more interactive and comprehensive, consisting of three phases. The purpose of this report is to organize all the reports generated during the IGL performance audit into one document and provide a summary of the audit process and results. The complete results and conclusions can be found within the body of the individual audit reports presented in Appendices A and B.

Phase 1 consisted of a preliminary assessment of the recent IGL performance and submitting recommendations to address specific identified deficiencies. The purpose of this task was to verify that the QMS utilized at the IGL produces reliable major, minor and trace elemental analytical results from energy-related samples that the IGL routinely analyzes. Analytical results from other coal laboratories around the world were also studied to see how the IGL operations and results compared with those from organizations with similar scope and sample throughput. Reports were prepared by QAI summarizing the preliminary findings of Phase 1 audit. These reports included a summary of findings, list of significant deficiencies, recommended corrective measures and recommended improvements, and an overall assessment of the IGL's ability to produce reliable analytical results.

Phase 2 of the performance audit consisted of a period in which the IGL implemented all of the recommended changes identified in Phase 1. This included the purchase of additional certified reference materials (CRMs), modifications to sample preparation and analytical procedures, and acquisition of new equipment and instrumentation. This phase also included a trial period to ensure that the IGL personnel had fully implemented all of the recommendations 
and that the new instruments were fully functional. No audit reports were generated during this phase.

Phase 3 of the audit consisted of a reassessment task to evaluate the effectiveness of the implementation of the recommendations from the Phase 1 reports. An on-site audit of the IGL laboratory facilities was also conducted to verify that recommendations made during the performance audit had been properly implemented as well as providing a summary of best practices methodology as an aid to developing a comprehensive QMS. Phases 1 and 3 required summary reports that are included in Appendices A and B of this report.

\section{Approach}

In developing an approach for conducting the audit, two basic concepts needed to be addressed. First, is there a universally recognized laboratory audit standard, and second, is there a universally accepted benchmark for comparing laboratory results?

Fortunately, ISO/IEC Guide 17025 (ISO, 2005) provides a comprehensive framework for laboratory performance evaluation. This guide contains all of the requirements that testing laboratories have to meet in order to demonstrate that they are able to generate technically valid results. The methodology for the IGL laboratory audit followed ISO 17250 which provides the following guidelines:

- Specifies the requirements for technical competence.

- Facilitates the acceptance of results and cooperation between countries.

- Includes all quality elements present in the ISO 9000 series.

- Emphasizes certification using ISO 9000 alone does not demonstrate the competence of the laboratory to produce technically valid results.

- Specifies requirements for management reviews.

During the preliminary phase of the audit, the approach to benchmarking and laboratory comparisons evolved. To provide an initial assessment of the IGL analytical capabilities, a comparison of the performance of the USGS with Australian and Canadian Government test facilities for silica $(\mathrm{SiO} 2)$, vanadium $(\mathrm{V})$, sulfur $(\mathrm{S})$, chlorine $(\mathrm{Cl})$, and mercury $(\mathrm{Hg})$ was made and is summarized in table A 1.1 (Appendix A 1). The coal indicators compared were chosen because they influence opportunities and limitations for coal utilization. The major, minor, and trace elements selected are benchmark indicators of the ability to achieve complete recovery and acceptable consistency of results. $\mathrm{Hg}, \mathrm{Cl}$, and $\mathrm{S}$ are important environmental parameters. $\mathrm{SiO}_{2}$ is the single-most dominant constituent in both coal ash and fly ash, and V provides a good gauge of a laboratory's ability to perform trace element analyses. This preliminary comparison included 9 laboratories from both the United States and the world that regularly perform analysis of coal and coal-derived ash. The use of proficiency graphs provided a method of identifying suspect analytical trends that might require remediation.

The Horwitz function, which provides a powerful performance benchmark to quantify laboratory performance, was utilized for the complete comparison of all analytical parameters for the final Phase 1 report (Appendix A.2). Dr. William Horwitz is a pioneer and leading advocate of interlaboratory method performance studies (Chemistry International, 2000). In such studies, the organizer normally distributes a set of test materials to the participant laboratories that analyze them blind by a strictly defined method. The results are returned to the organizer, who calculates two fundamental measures of the performance of the analytical method, the repeatability (within laboratory standard deviation) and the reproducibility (between laboratory standard deviation). 
Over 10,000 analytical methods subjected to a collaborative trial were examined by Dr. Horwitz. He noticed that as the concentration of the analyte decreased over two orders of magnitude, the reproducibility relative standard deviation (RSD) increased by a factor of two. Therefore, at 100 percent concentration of analyte the RSD was about 2 percent, at 1 percent the RSD was about 4 percent, and at 0.01 percent or 100 parts per million (ppm), the RSD was about 8 percent. This pattern persisted at least down to part per billion (ppb) levels. These findings gave rise to the famous 'Horwitz Trumpet' (fig. 1), which depicts the relationship expressed as a two-sided one-sigma confidence interval (Thompson, 2004). The Horwitz function or "curve" is expressed by the following equation:

$$
\begin{aligned}
\mathbf{R S D}=\mathbf{C}^{\mathbf{- 0 . 1 5 0 5}}, \text { where: } \\
\mathrm{RSD}=\text { Relative standard deviation } \\
\mathrm{C}=\text { Concentration of analyte (weight fraction) }
\end{aligned}
$$

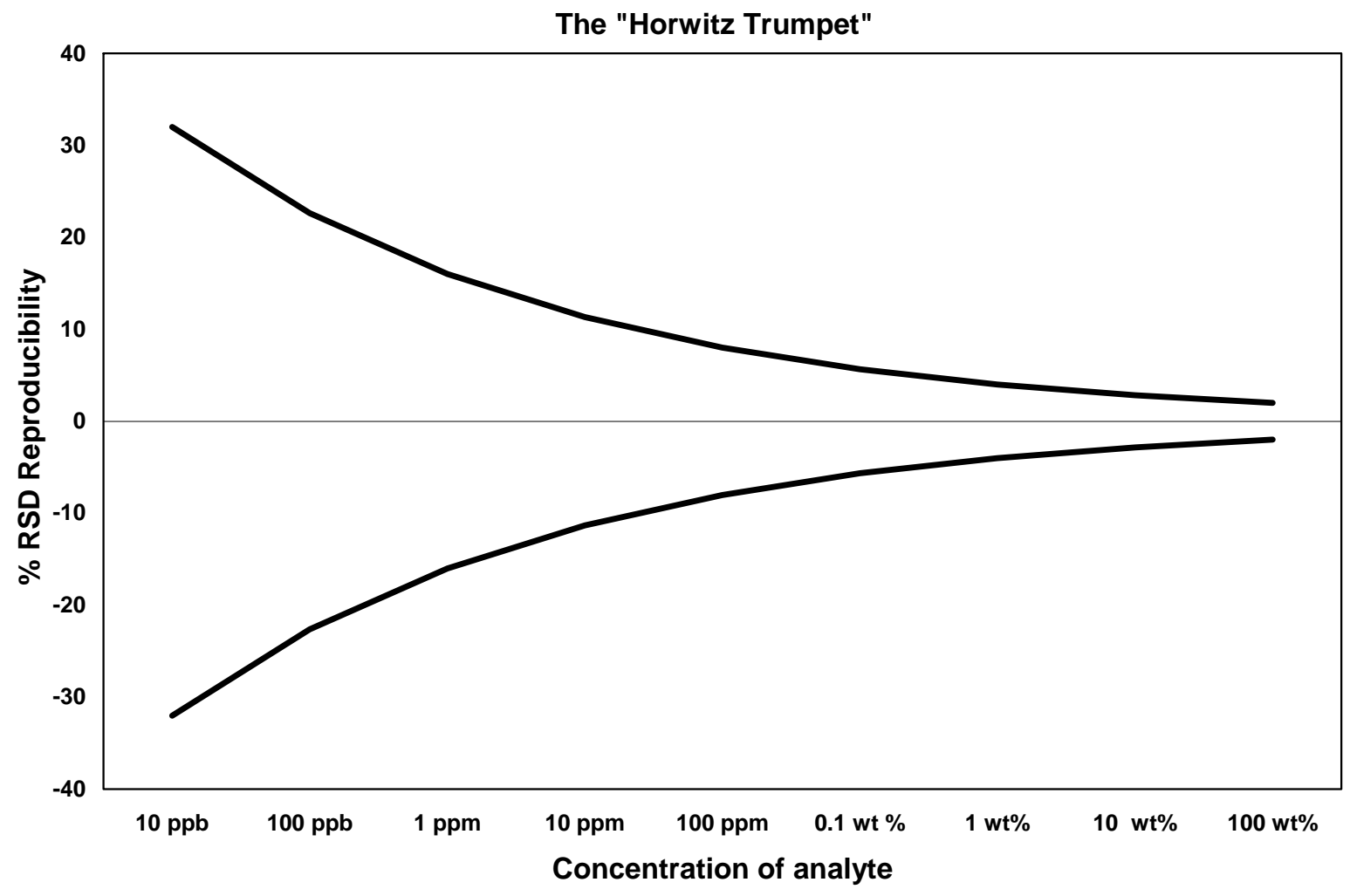

Figure 1. The famous 'Horwitz Trumpet' that depicts the relationship expressed as a two-sided, one-sigma confidence interval (after Horwitz and others, 1980). The trumpet shape of the two curves reflects the inverse relationship between analyte concentrations and the RSD (relative standard deviation).

This function expresses the reproducibility relative standard deviations that can be expected for any concentration level when competent laboratories use optimized test procedures to analyze any matrix for any analyte. It may be used to set aim uncertainties against which to 
plan new standard test methods and to assess the performance of existing test methods (ASTM International, 2006b). The Horwitz function has gained wide acceptance as a powerful evaluation tool as evidenced by the following:

- It is recognized by the International Union of Pure and Applied Chemists (Pocklington, W. D., 1990, Chemistry International, 2000) and employed by the International Association of Geoanalysts GeoPT proficiency testing scheme (International Association of Geoanalysts, 2001) as a fundamental benchmark for comparing laboratory results.

- It can be employed to compare laboratory results with certified or reference values as well as known values from proficiency test programs.

- It was developed from over 10,000 independent certification, method validation and proficiency studies covering a wide range of materials, concentration, and measurement techniques.

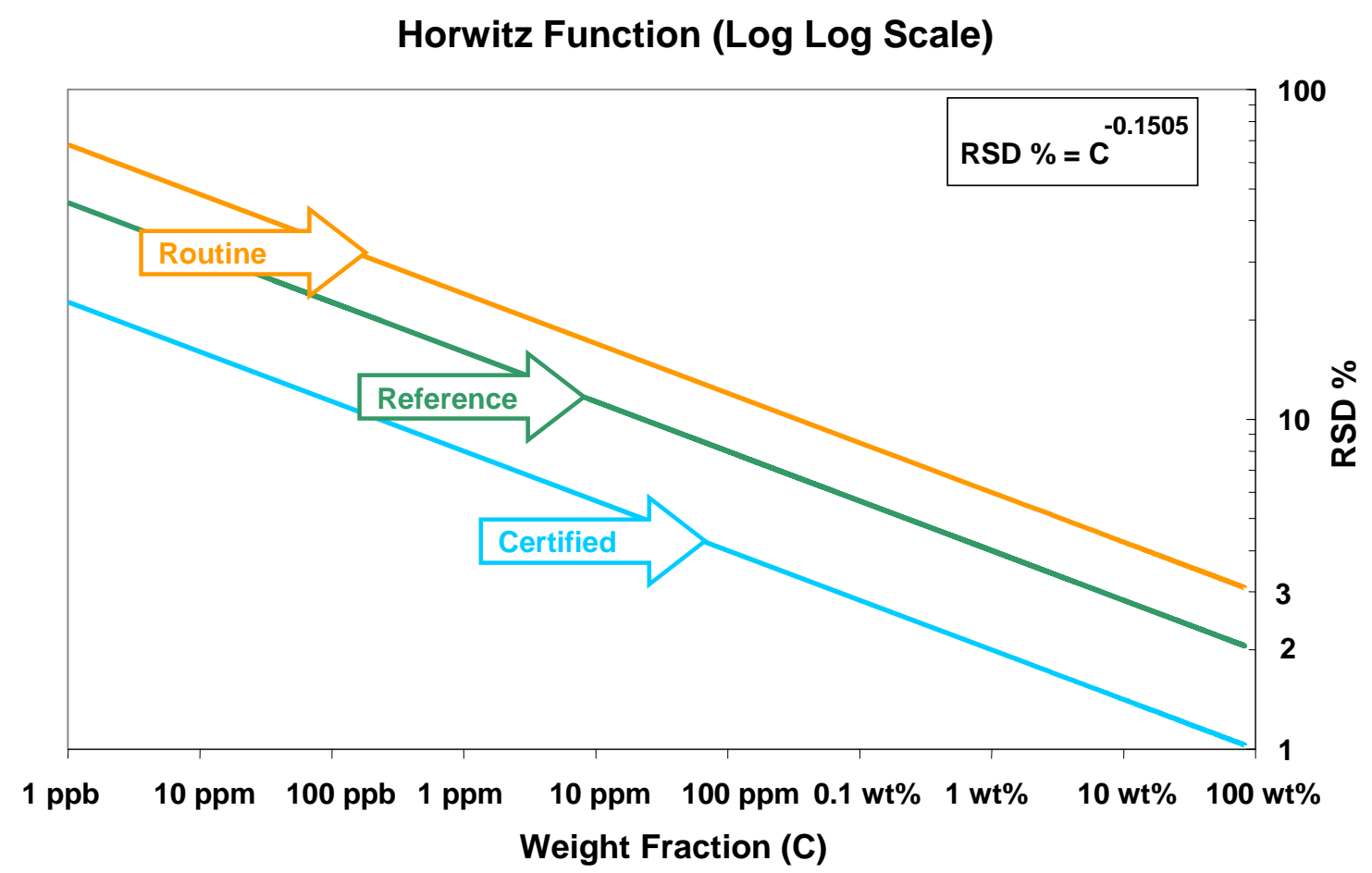

Figure 2. The Horwitz Function plotted on a log-log scale (RSD is the relative standard deviation). Certified analyses represent a performance ratio of 1.0 or less. Reference analyses represent a performance ratio of 2.0 or less but greater than 1.0. Routine analyses represent a performance ratio 3.0 or less but greater than 2.0. Ratios greater than 3.0 indic ate either the laboratory or the method employed by the laboratory are not capable of consistently producing acceptable results. The Reference line in this figure is equivalent to the Horwitz curve in fig. 1.

To facilitate use of the Horwitz function in evaluating laboratory performance, it is useful to plot the function on a log-log scale (fig. 2). The "reference" line on fig. 2 corresponds to the 
Horwitz curves plotted on fig. 1. Dividing the standard deviation of a method ILS or of laboratory proficiency testing program (PTP) results over a series of samples, by that predicted by the function, yields a Horwitz performance ratio. A low Horwitz performance ratio is an indicator of highly reliable analytical results.

QAI recognized several levels of performance: Class 1, appropriate for "certified" analysis, constitutes a Horwitz performance ratio of 1 or less; Class 2, appropriate for "referee" (reference) analysis, constitutes a performance ratio of less than or equal to 2 but greater than 1.; and Class 3, appropriate for "routine" analysis, constitutes a performance ratio of less than or equal to 3 but greater than 2 . Ratios greater than 3 indicate the laboratory or the method employed by the laboratory are not capable of consistently producing acceptable results.

This report includes a series of performance tables designed to provide the ability to determine the capability of a laboratory "at a glance". The Horwitz PTP performance ratio for each laboratory as well as the Horwitz method ILS performance ratio for the best state of the art ASTM International standard for each parameter is shown in tables A.1.1, A.1.2, and A.1.3 in Appendix A.2. A "blue" performance ratio in the tables indicates the laboratory or method is capable of producing certified results (maximum relative analytical error of 1 percent at 100 percent concentration). A "green" performance ratio in the tables indicates the laboratory or method is capable of producing reference results (maximum relative analytical error of 2 percent at 100 percent concentration). An "orange" performance ratio in the tables indicates the laboratory or method is capable of producing routine results (maximum relative analytical error of 3 percent at 100 percent concentration). Performance ratios greater than a maximum relative analytical error of 3 percent (at 100 percent concentration) are shown in black. The minimum goal of a laboratory should be to achieve a performance ratio at least equivalent to the reference standard. It is possible for a laboratory to achieve a lower performance ratio (better results) than the reference standard by establishing more rigorous control over environmental, sample preparation, and/or instrumental conditions than specified in a given standard.

The use of CANSPEX ${ }^{\mathrm{TM}}$ results throughout the preliminary phase of this proficiency audit was essential for making recommendations for improvements that were initiated and monitored in subsequent phases. The IGL has participated in the CANSPEX ${ }^{\mathrm{TM}}$ intralaboratory PTP since 1999. CANSPEX ${ }^{\mathrm{TM}}$ is a proficiency testing service that assists a laboratory at becoming more competent in performing measurements. Participation in PTPs is a key element of good laboratory practice cited in ISO 17025, "General Requirements for the Competence of Testing and Calibration Laboratories" (ISO, 2005). Proficiency testing programs should be employed by an analytical laboratory to determine the "health" of their quality system. In PTPs, analytical performance is measured against samples of known composition (but without any identification information) that are submitted to the participating laboratories at periodic intervals. These PTPs normally assimilate results from their participants and return nothing more than a statistical analysis of the data. This approach is no longer adequate in the testing environment of today. CANSPEX ${ }^{\mathrm{TM}}$ provides the laboratory specific information on those factors that are affecting both short and long term quality control. Currently 114 laboratories from 20 countries take part in the CANSPEX ${ }^{\mathrm{TM}}$ program. For the sake of objectivity, laboratory comparisons for this audit covered the period of time for which the IGL facility has been reporting results to CANSPEX ${ }^{\mathrm{TM}}$. 


\section{Summary of Findings}

The overall approach utilized for this performance audit of the IGL was successful and achieved all of the original major goals of the process. The adoption of the phased method audit not only furnished an assessment of the current laboratory performance, but also provided a mechanism for implementing and verifying the effectiveness of the recommendations. The overall constructive process further strengthened the IGL's analytical capabilities while, at the same time, provided improved laboratory safety conditions and offered a net decrease in operating costs.

\section{Phase 1: Preliminary Proficiency Assessment}

Phase 1 actually consisted of two separate tasks with formal reports generated for each activity. The initial audit report dated June 01, 2004 (Appendix A.1) was effective in identifying significant areas that needed improvement and in prescribing preliminary recommendations for corrective measures to be implemented by the IGL. The final audit report dated September 10, 2004 (Appendix A.2) supported and refined the recommendations of the initial report. The findings of the Phase 1 preliminary assessment results are summarized below:

- The USGS IGL is one of the two top laboratories included in this assessment for the determination of trace analytes in coal-derived ash.

- Table A.1.1 (Appendix A.1) clearly indicated that there were several performance issues at the IGL that needed to be addressed.

- Inconsistent results for some major and minor elements parameters were documented leading to a recommendation to modify the sample digestion protocol. This modification will not only sustain a high level of performance for trace element analyses, but also improve reliability, reduce costs, and increase the safety of performing major and minor parameter analyses by eliminating the perchloric acid digestion procedure. Actually, this recommendation should also provide modest improvements to the performance on trace element analyses as well.

- An expanded panel of Certified Reference Materials (CRMs) and Reference Materials (RMs) will also improve reliability of mercury and sulfur analyses.

- Converting to ASTM D 6721 (ASTM International, 2006) for chlorine analysis with the purchase of a direct combustion instrument will extend the range, significantly improve the quality of the results, and reduce the cost of chlorine analyses (figs. A.1.2 and A.1.5).

- Even with all the recommended capital purchases, an estimated net decrease in operating expenses of about $\$ 100,000$ over a four year period (table A.2.X1.1, Appendix A.2) is projected. ). Savings are attained from both a reduction of consumables and in manpower requirements.

- The USGS contract laboratory, Geochemical Testing, achieved one of the highest levels of performance in this assessment for contract parameters (table A.2.3, Appendix A.2).

\section{Phase 2: Reconciliation of Preliminary Audit Recommendations}

Following the preliminary audit, Phase 2 was devoted to implementation of the recommendations generated from Phase 1 . Some of the recommendations were straightforward and involved minor expenditures while others required significant financial commitments.

The use of the additional recommended reference materials should improve the reliability of sulfur and mercury analyses. The suite of available CRMs and RMs was expanded through 
the purchase of the suggested materials. This was accomplished promptly and with minimal expense.

A significant methodology modification was the conversion to the acid mix prescribed in ASTM D 6349 and D 6357 (ASTM International, 2006) followed by hot block digestion for the dissolution of coal-derived ash. This recommendation required the purchase of several hot block units from Environmental Express, Mt. Pleasant, S.C. The hot block digestion replaced two separate digestions (graphite sinter and Teflon acid digestion) that had been employed by the IGL to carry out major, minor and trace element analyses. Changing to this single digestion procedure not only significantly reduced operator time and consumables, but also improved the safety of the preparation procedure. The hot block digestion eliminated the need for perchloric acid, which demands extreme safety precautions requiring a specialized fume hood.

Furthermore, since a fluxing agent is not required, the solids loading on the Inductively Coupled Plasma Mass Spectrometry (ICP-MS) and Inductively Coupled Plasma - Atomic Emission Spectrometer (ICP-AES) systems are significantly reduced. One final benefit is that the hot blocks can also be employed for the acid extraction of mercury by ASTM D6414 (ASTM International, 2006).

The most significant recommended change in terms of cost expenditures was the adoption of ASTM D6721 (ASTM International, 2006) standard for chlorine by the direct combustion method. A TOX-100 analyzer, which is capable of meeting the requirements of ASTM D6721 (ASTM International, 2006), was purchased from COSA Instrument Corporation, Norwood, NJ. The Eschka ignition method, which had been employed by the IGL for the preparation of coal samples for chlorine analysis (ASTM D2361, ASTM International, 2006), is known to yield highly erratic and inconsistent recovery (and demonstrated by the Chlorine Expanded Uncertainty Proficiency graph (fig. A.1.X1.2, Appendix A.1; and table A.2.3, Appendix A.2).

An additional benefit of the Phase 1 recommendations was the potential for significant cost savings in addition to improved analytical performance. A revised estimation of the substantial anticipated cost savings for all of the recommended changes is found in table A.2.X1.1 (Appendix A.2). Savings are attained both in a reduction of consumables and in labor requirements.

\section{Phase 3: Reassessment of Performance and On-site Evaluation}

After the recommended changes were implemented and the sample preparation and analytical equipment was received, commissioned, and a reasonable training and trial testing period was completed, a reassessment of the performance of the IGL was conducted as part of Phase 3 of the performance audit. Specifically, reassessment of the performance results from chlorine determinations and the digestion procedures for major oxides were completed. Additionally, an on-site audit of the IGL facilities in Denver, CO USA was completed in September, 2005.

Twenty samples distributed through CANSPEX ${ }^{\mathrm{TM}}$ from 2000 to 2004 were submitted to the USGS IGL as "blind" samples (the expected chlorine concentration was not known to the laboratory). Appendix B.1 presents the findings of the chlorine reassessment. The chlorine analyses are summarized in tables B.1.1 and B.1.2 (Appendix B.1). The chlorine results produced, employing ASTM D 6721 (ASTM International, 2006) for these samples, exhibited a marked improvement in accuracy without any degradation in precision, particularly for samples with less than $500 \mu \mathrm{g} / \mathrm{g}$ of chlorine. The 20 samples selected cover a wide range of coal rank 
and grade and represent coals from 9 different countries. Most importantly, no other CANSPEX ${ }^{\mathrm{TM}}$ laboratory achieved as high a level of performance for chlorine as the IGL for these 20 CANSPEX ${ }^{\mathrm{TM}}$ samples. Only one of the 20 IGL results was ranked in the "suspect" range. The IGL result for this sample analysis, combined with similar results from other laboratories using the same method, suggests that the certified value for chlorine for this sample may need to be reassessed.

Appendix B.2 presents the findings of the major, minor, and trace element reassessment. Evaluation of CANSPEX ${ }^{\mathrm{TM}}$ results in Phase 1 resulted in a recommendation that the IGL convert from a sinter-acid digestion procedure (including use of perchloric acid) for decomposition and dissolution of coal derived ash to the mixed-acid decomposition and dissolution recommended in ASTM D6349 (ASTM International, 2006). During the reassessment in Phase 3, the IGL performed the mixed-acid digestion on four separate test portions of 21 CANSPEX $^{\mathrm{TM}}$ samples covering the period of 1999 to 2004. Of the 21 samples subjected to the recommended mixedacid digestion procedure, 18 were samples prepared by QAI. The remaining three were CRMs from three independent certifying bodies: the Canadian Certified Reference Materials Program (CCRMP), the National Institute of Standards and Technology (NIST) USA, and the USGS. These CRMs are employed world wide for the calibration and control of procedures employed for the determination of major oxides. The homogeneity of all three CRMs is verified by the respective certifying agencies. To eliminate any objections concerning the homogeneity of the QAI samples, this evaluation was limited to results from the three CRMs. The CRMs used were USGS GSP-2 (granodiorite), CCRMP SY-4 (diorite gneiss), and NIST 1633b (coal fly ash). All three chosen CRMs pose especially difficult analytical challenges. From the results presented in table B.2.3 (Appendix B.2), it is evident that there are significantly more quality exceptions for the sinter-acid procedure than for the recommended mixed-acid digestion procedure. This validates the Phase 1 recommendation to adopt a mixed acid, hot block digestion for dissolution of coal-derived ash.

There were a particularly significant number of exceptions between the previously used sinter-acid and the recommended mixed-acid digestion procedures for the NIST 1633b sample in table B.2.3 (Appendix B.2). Of the three CRM samples, NIST 1633b is the only sample that contains combustible carbon. The amount of unburned carbon is in the order of 3.4 weight percent. The NIST $1633 \mathrm{~b}$ test portions treated by the sinter-acid digestion procedure were not preignited at a temperature sufficient to remove this combustible carbon. The IGL confirmed the sinter-acid digestion solutions contained a visible gray residue, which is an indicator of the presence of unburned carbon. This residue not only has the potential to absorb soluble oxides, but also to create erratic flow of the sample through the ICP nebulizer. When all three CRM samples were preignited at a temperature that not only eliminates combustible carbon but also decomposes mineral carbonates, sulfides, and hydrates prior to treatment by the recommended mixed-acid digestion procedure, no visible residue was observed. Based on the above observation, it was emphasized that all samples should be preignited as recommended in the section on preparation of ash in ASTM D6349 (ASTM International, 2006).

Finally, both table B.2.3 and the graphs (figs B.2.1-8) in Appendix B.2 provide strong evidence that a significant shift in nebulization is occurring from sample to sample during the ICP analysis. It was recommended that this effect be monitored and reconciled by using one or more internal standards added to each analysis solution.

An on-site evaluation of the IGL was conducted on September 12-14, 2005 and a report was completed (Appendix B.3). The purpose of this evaluation was two-fold. The first goal was 
to observe the laboratory operations first hand and to verify that recommendations made during the performance audit had been properly implemented as well as to making additional recommendations as appropriate. The on-site audit confirmed recommendations for analytical practices intended to improve the efficiency and reliability of test results have been implemented and are being monitored on an on-going basis to substantiate the effectiveness of the recommendations. The recent implementation of a blind testing program should provide the recommended ongoing, real time monitoring of laboratory performance.

The second goal was to assist the IGL in the finalization of IGL standard operating procedures (SOPs) for every significant analytical procedure as part of developing a total quality management system. Because there was not sufficient time to perform a detailed analysis of each analytical process, much of the on-site report contains a summary of best practices. The recommendations and examples included in this report do not necessarily constitute current or future practices or procedures employed at the IGL. The USGS management and IGL staff is currently reviewing the recommendations and examples to decide whether they can be in whole or in part incorporated into current SOPs without adversely impacting the quality of results produced. The full report of the On-site Evaluation (Appendix B.3) can be referenced for specific information. For the sake of brevity, only the principal topics that were addressed are listed below:

Collection of Coal Samples

Collection of Ash Samples

Sample Preparation, Storage and Handling

- Preparation of coal samples for analysis

- Preparation of ash samples for analysis

Quality Control

- Instrument maintenance

- Validated operators

- Instrument conditioning

- Acceptance limits for calibration and control samples

- Calibration and calibration verification

Establishment and Use of Control charts, Method Specific SOPs

Moisture

- International, Regional and National standards

- Type of purging atmosphere (accuracy)

- Dryness of purging atmosphere (precision and accuracy)

- Insufficient drying time (precision and accuracy

- Concurrent drying coals of significantly different rank (precision)

- Cooling and weighing of samples (precision and accuracy)

Ash

- International, Regional and National standards

- Incineration of the sample (precision) final soak temperature (precision and accuracy)

- Concurrent ashing coals of significantly different rank (precision)

- Cooling and weighing of samples (precision and accuracy)

Sulfur

- International, Regional and National standards

- Verification of the operating conditions (precision and accuracy) 
- Analyzer calibration (Precision and Accuracy)

- Premature Termination of sulfur Analysis Cycle (Precision and Accuracy)

Chlorine

- International, Regional and National standards

- Situation and handling of instrument components and samples (precision and accuracy)

- Preparation of the apparatus (precision and accuracy)

- Analyzer calibration (precision and accuracy) determination chlorine content (precision and accuracy)

- Limits of application of standard methods (precision and accuracy)

- Bomb decomposition as a reparation technique (precision and accuracy)

Mercury

- International, Regional and National standards

- Acid extraction/wet oxidation as a preparation technique (precision and accuracy)

- Sample Digestion

- Analyzer calibration (precision and accuracy)

- Limit of application of standard methods (precision and accuracy)

- Bomb decomposition as a preparation technique (precision and accuracy)

- Direct combustion for the analysis of mercury (precision and accuracy)

Major and Minor Elements

- International, Regional and National standards for major an minor oxides

- Analyzer calibration (precision and accuracy)

Trace Elements

- International, Regional and National standards for trace constituents

- Analyzer calibration (precision and accuracy)

Many of the quality control measures discussed in Appendix B.3 are already in place. Perhaps the biggest challenge highlighted in the on-site report is the issue of sampling, handling, and preparation. The most fundamental principle of sampling is to try to ensure that each sample collected is representative of the intended purpose. Other sample issues include the concept of minimum sample size (dependent on size consist of the material being sampled) and improper sample packaging leading to loss of moisture or sample oxidation.

No amount of analytical competence and/or quality control can rectify and overcome samples that were improperly collected, handled, or prepared. While these problems are largely outside the IGL's direct scope of responsibility, it was recommended that there needs to be close coordination between the sample collectors/submitters and the IGL personnel. Practices employed to collect samples should be compared with the procedures cited in Appendix B.3. If it is not possible to implement comparable procedures, the IGL should implement procedures that can identify sources and causes of sample variability that could detract from the reliability of analytical results.

\section{Measurable Benefits of the Performance Audit}

Even though the Phase 3 reassessment program documented significant improvements as a result of specific recommendations, it seemed appropriate to ascertain if improvement in the overall performance of the IGL was being sustained following the laboratory audit. To accomplish this, a trend analysis that compared pre-and post-audit analytical performance was conducted. 
A relatively straightforward analysis was devised whereby performance ratios were calculated for individual parameters for each CANSPEX ${ }^{\mathrm{TM}}$ sample during the period prior to the audit and all CANSPEX ${ }^{\mathrm{TM}}$ samples analyzed following the audit. Parameter results were classified either "acceptable" or "suspect". Acceptable results are those performance ratios with a precision and accuracy that fall within CANSPEX ${ }^{\mathrm{TM}}$ three standard deviation limits. Suspect results are those with a precision or accuracy or both that fall outside CANSPEX ${ }^{\mathrm{TM}}$ three standard deviation limits. A tally of all individual ratio results was made. Table 1 contains the pre- and post-audit results for each individual parameter. Table 2 provides a summary both numerically and as percentages.

Table 1. Compilation of IGL CANSPEXTM results before and after the performance audit. Acceptable results are those with a precision and accuracy that fall within the CANSPEX 3 standard deviation limits. Suspect results are those with a precision or accuracy or both that fall outside the CANSPEX 3 standard deviation limits. [BA = Before Audit; AA = After Audit]

\begin{tabular}{|c|c|c|c|c|c|c|c|c|c|c|}
\hline Parameter & \multicolumn{3}{|c|}{ Coal } & \multicolumn{2}{c|}{ Ash } & \multicolumn{2}{c|}{ S } & \multicolumn{2}{c|}{ CI } & \multicolumn{2}{c|}{ Hg } \\
\hline Rating & BA total & AA total & BA & AA & BA & AA & BA & AA & BA & AA \\
\hline Acceptable & 19 & 21 & 6 & 6 & 5 & 6 & 3 & 4 & 5 & 5 \\
\hline Suspect & 5 & 1 & 3 & 0 & 1 & 0 & 0 & 0 & 1 & 1 \\
\hline
\end{tabular}

\begin{tabular}{|c|c|c|c|c|c|c|c|c|c|c|c|c|c|c|c|c|c|c|c|c|c|c|c|c|}
\hline \multirow{2}{*}{$\begin{array}{c}\text { Parameter } \\
\text { Rating } \\
\end{array}$} & \multicolumn{2}{|c|}{ Mineral Oxides } & \multicolumn{2}{|c|}{$\mathrm{SiO}_{2}$} & \multicolumn{2}{|c|}{$\mathrm{Al}_{2} \mathrm{O}_{3}$} & \multicolumn{2}{|c|}{$\mathrm{Fe}_{2} \mathrm{O}_{3}$} & \multicolumn{2}{|c|}{$\mathrm{CaO}$} & \multicolumn{2}{|c|}{ MgO } & \multicolumn{2}{|c|}{$\mathrm{Na}_{2} \mathrm{O}$} & \multicolumn{2}{|c|}{$\mathrm{K}_{2} \mathrm{O}$} & \multicolumn{2}{|c|}{$\mathrm{P}_{2} \mathrm{O}_{5}$} & \multicolumn{2}{|c|}{$\mathrm{TiO}_{2}$} & \multicolumn{2}{|c|}{$\mathrm{BaO}$} & \multicolumn{2}{|c|}{ Sro } \\
\hline & 3 A total & AA total & BA & AA & BA & $\mathrm{AA}$ & BA & AA & BA & AA & BA & $\mathrm{AA}$ & BA & AA & BA & $\mathrm{AA}$ & $\mathrm{BA}$ & AA & $\mathrm{BA}$ & AA & $\mathrm{BA}$ & AA & BA & AA \\
\hline & & & 0 & 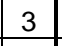 & 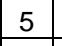 & 4 & 4 & 5 & 2 & e & 0 & 4 & 2 & 4 & 4 & 7 & 1 & 0 & 4 & 4 & 0 & 6 & 5 & 6 \\
\hline Suspect & 24 & 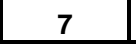 & 5 & 2 & 2 & 1 & 2 & 0 & 3 & 0 & 1 & 1 & 4 & 1 & 2 & 1 & 0 & 0 & 2 & 1 & 1 & 0 & 2 & 0 \\
\hline
\end{tabular}

\begin{tabular}{|c|c|c|c|c|c|c|c|c|c|c|c|c|c|c|c|c|c|c|c|c|c|c|c|c|c|c|}
\hline \multirow{2}{*}{$\begin{array}{c}\text { Parameter } \\
\text { Rating } \\
\end{array}$} & \multicolumn{2}{|c|}{ Trace Components } & \multicolumn{2}{|c|}{ As } & \multicolumn{2}{|c|}{$\mathrm{Be}$} & \multicolumn{2}{|c|}{ Cd } & \multicolumn{2}{|c|}{ Co } & \multicolumn{2}{|c|}{$\mathrm{Cr}$} & \multicolumn{2}{|c|}{$\mathrm{Cu}$} & \multicolumn{2}{|c|}{ Mn } & \multicolumn{2}{|c|}{$\mathrm{Ni}$} & \multicolumn{2}{|c|}{$\mathbf{P b}$} & \multicolumn{2}{|c|}{ Sb } & \multicolumn{2}{|c|}{ v } & \multicolumn{2}{|c|}{$\mathrm{Zn}$} \\
\hline & BA total & AA total & BA & AA & BA & AA & BA & AA & BA & AA & BA & AA & BA & AA & BA & AA & BA & AA & BA & AA & BA & AA & BA & AA & BA & AA \\
\hline ble & 73 & & 0 & 5 & $r$ & 5 & 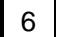 & 4 & 7 & 4 & 7 & 5 & 0 & 5 & 0 & 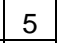 & 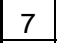 & 5 & 4 & 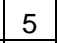 & $t$ & 5 & 6 & 5 & 4 & 4 \\
\hline$c t$ & 5 & 2 & 0 & 0 & 0 & 0 & 0 & 0 & 0 & 1 & ( & 0 & 0 & 0 & & 0 & 0 & 0 & 1 & 0 & 0 & 0 & 1 & 0 & 2 & 1 \\
\hline
\end{tabular}

On a parameter-by-parameter basis, the approach used to develop tables 1 and 2 is not considered statistically rigorous as the sample populations were limited for the post audit samples and not all of the recommended changes were implemented precisely at the same time. However, this relatively simple analysis shows significant collective trends in performance improvement, especially in those problem areas identified in the preliminary assessment in Phase 1 of the audit. The results expressed as percentages (table 2) are especially helpful for demonstrating the post-audit performance gains. Performance on both the coal parameters including sulfur and chlorine as well as major and minor oxides analyses improved significantly showing a dramatic decrease in the percentage of suspect results from 21 to 5 percent and from 35 to 12 percent respectively (table 2). Most importantly, excellent performance on the analysis of trace elements was not only maintained through the effected changes, but modest performance improvements were also realized with percentage of acceptable results before and after rising from 94 percent to 97 percentage respectively. 
Table 2. Summary of IGL CANSPEXTM results before and after the performance audit analyses from table 1 expressed both numerically and as percentages. Acceptable results are those with a precision and accuracy that fall within the CANSPEX 3 standard deviation limits. Suspect results are those with a precision or accuracy or both that fall outside the CANSPEX 3 standard deviation limits.

\begin{tabular}{|c|c|c|c|c|}
\hline Parameter & \multicolumn{3}{|c|}{ Coal (Ash, Sulfur, Chlorine, Mercury) } \\
\hline \multirow{3}{*}{ Rating } & \multicolumn{2}{|c|}{ Number of Results } & \multicolumn{2}{c|}{ Percentages } \\
\cline { 2 - 5 } & $\begin{array}{c}\text { Before } \\
\text { Audit }\end{array}$ & $\begin{array}{c}\text { After } \\
\text { Audit }\end{array}$ & $\begin{array}{c}\text { Before } \\
\text { Audit }\end{array}$ & $\begin{array}{c}\text { After } \\
\text { Audit }\end{array}$ \\
\hline Acceptable & 19 & 21 & $79 \%$ & $95 \%$ \\
\hline Suspect & 5 & 1 & $21 \%$ & $5 \%$ \\
\hline
\end{tabular}

\begin{tabular}{|c|c|c|c|c|}
\hline Parameter & \multicolumn{4}{|c|}{ Major/Minor Oxides } \\
\hline \multirow{3}{*}{ Rating } & Number of Results & \multicolumn{2}{c|}{ Percentages } \\
\cline { 2 - 5 } & $\begin{array}{c}\text { Before } \\
\text { Audit }\end{array}$ & $\begin{array}{c}\text { After } \\
\text { Audit }\end{array}$ & $\begin{array}{c}\text { Before } \\
\text { Audit }\end{array}$ & $\begin{array}{c}\text { After } \\
\text { Audit }\end{array}$ \\
\hline Acceptable & $\mathbf{4 5}$ & $\mathbf{5 1}$ & $65 \%$ & $\mathbf{8 8 \%}$ \\
\hline Suspect & $\mathbf{2 4}$ & $\mathbf{7}$ & $\mathbf{3 5 \%}$ & $\mathbf{1 2 \%}$ \\
\hline
\end{tabular}

\begin{tabular}{|c|c|c|c|c|}
\hline Parameter & \multicolumn{4}{|c|}{ Trace Elements } \\
\hline \multirow{2}{*}{ Rating } & Number of Results & \multicolumn{2}{c|}{ Percentages } \\
\cline { 2 - 5 } & $\begin{array}{c}\text { Before } \\
\text { Audit }\end{array}$ & $\begin{array}{c}\text { After } \\
\text { Audit }\end{array}$ & $\begin{array}{c}\text { Before } \\
\text { Audit }\end{array}$ & $\begin{array}{c}\text { After } \\
\text { Audit }\end{array}$ \\
\hline Acceptable & 73 & 57 & $94 \%$ & $97 \%$ \\
\hline Suspect & 5 & 2 & $6 \%$ & $3 \%$ \\
\hline
\end{tabular}

\section{Future Work}

While the recently completed performance audit of the IGL represents attainment of an important benchmark, it is not a final goal by itself, but simply a significant step in the process of continuous improvement in quality assurance. Furthermore, this performance audit is not a onetime process. As part of a best practices philosophy of management, additional external performance audits will be performed at appropriate intervals per ISO 17025 regardless of perceived analytical performance.

A major additional step towards enabling the IGL to become recognized as a competent practitioner of analyses based on a performance based testing was the implementation of a "double blind" testing program in fiscal year 2006. A double-blind check sample is one that laboratory personnel do not know is an external check sample. Blind samples have the same characteristics of routine samples and are delivered along with normal samples batches without special notice. The current double-blind audit program consists of the submittal of at least two samples per month of coal and coal ash to the IGL and a monthly, real-time summary evaluation 
report of the analytical results by QAI. Any discrepancies are immediately identified and timely remedial action is taken. Thus, a double-blind program, conducted by a third party, provides realtime, objective assessment of laboratory competency through traceability to recognized reference materials and certified reference materials. As a result, double-blind results are the ultimate test of analytical design performance.,

\section{Conclusions}

The format and results of the external performance audit of the IGL by Quality Associates International ${ }^{\circledR}$ LDT proved very successful. The phased approach and constructive nature of the process with tools to measure performance should be considered as a blueprint for subsequent external laboratory reviews. The significant results and findings of this audit are:

1) Participation in an external, proficiency testing program is a valuable component in the development of a successful quality assurance system.

2) The USGS IGL was one of the two top laboratories included in this performance assessment for the determination of trace analytes in coal derived ash.

3) Inconsistent results for some major and minor parameters were identified. Several recommendations were made to correct deficiencies including expanding the use of certified reference materials, purchasing new preparation and analytical equipment, and modifying the sample digestion procedures. The adoption of the audit recommendations resulted in not only improvements in analytical reliability, increased productivity, and lowered consumable costs, but also a safer working environment.

4) The USGS contract laboratory (Geochemical Testing) achieved one of the highest levels of performance in this assessment for contract parameters.

5) Performance comparisons on CANSPEX ${ }^{\mathrm{TM}}$ sample performance both pre- and post-audit confirmed significant performance gains, especially for major and minor oxides and elemental parameters while sustaining proficiency on trace element analyses.

6) A working environment that optimizes staff involvement in quality assurance was enhanced.

7) A double-blind-testing program was recently implemented. This program will provide an additional level of analytical competence verification by providing frequent monitoring and documentation of performance to help sustain gains made by the audit.

8) A commitment to continuous improvement of quality assurance and performance as an ongoing practice was reconfirmed.

A laboratory that is committed to an operating environment founded on the principles of a performance based testing approach should not view audits with apprehension, but look at the process as additional opportunities for verification of analytical proficiency.

\section{Acknowledgments}

The authors wish to thank Curtis Palmer, USGS, Reston, VA and Margaret Ellis, USGS, Denver, Colo., for their helpful reviews of this work. 


\section{References Cited}

ASTM International, 2006, Annual Book of ASTM Standards, Section 5, Petroleum Products, Lubricants and Fossil Fuels: v. 05.05 Gaseous fuels; coal and coke: ASTM International, West Conshohocken, Pennsylvania, $705 \mathrm{p}$.

ASTM International, 2006b, E2165-01 Standard Practice for Establishing an Uncertainty Budget for the Chemical Analysis of Metals, Ores, and Related Materials: ASTM International Document Summary, http://www.astm.org/cgibin/SoftCart.exe/DATABASE.CART/REDLINE PAGES/E2165.htm?L+mystore+qhid4467.

Chemistry International, 2000, William Horwitz receives Robert Boyle Medal from Royal Society of Chemistry: Chemistry International, Vol. 22, No. 6, November 2000, http://www.iupac.org/publications/ci/2000/november/awards_horwitz.html

Horwitz, W., Kamps, L.R., and Boyer, K.W., 1980, Quality assurance in the analysis of foods for trace constituents: Journal of Association of Analytical Chemistry, 1980, v. 63, no. 6, p. 13441354.

International Association of Geoanalysts, 2001, Ninth International proficiency test of analytical geochemistry laboratories: International Association of Geoanalysts, GEOPT9/OU-6; http://geoanalyst.org/geopt9.html

ISO, 2005, 17025:2005(E), General Requirements for the competence of testing and calibration laboratories: ISO (the International Organization for Standardization) and IEC (the International Electrotechnical Commission), Geneva, Switzerland, 36 p., http://www.iso.org/iso/en/ISOOnline.frontpage

Pocklington, W. D., 1990, Harmonized protocols for the adoption of standardized analytical methods and for the presentation of their performance characteristics: International Union of Pure and Applied Chemists, Journal of Pure \& Applied Chemistry, v. 62, no.1, pp. 149-162, http://www.iupac.org/publications/pac/1990/pdf/6201x0149.pdf. 


\section{Appendix A.}

\section{Phase 1: Preliminary Evaluations of Quality System and Recommendations}

Appendix A.1: Preliminary Evaluation of Quality System and Recommendations; Initial Report, June 01, 2004

Appendix A.2: Preliminary Evaluation of Quality System and Recommendations, Final Report, 2 September 10, 2004

The following appendices do not conform to USGS form and style. They also contain multiple reference citations to standard methods and other contacts. To facilitate review of the documents the reference was not provided every time a standard test method or organizational contacts were cited. Information regarding these citations is provided Appendix B.4. 


\section{Appendix A.1 \\ Phase 1: Preliminary Evaluation of Quality System and Recommendations; Initial Report}

Performance Audit of U.S. Geological Survey Inorganic Geochemistry and Contract Laboratories

Requisition \#3-2920-1052

June 01, 2004

Louis Janke, President

Quality Associates International ${ }^{\circledast}$, LDT.

P.0. Box 117

Douglas, ON KOJ 1 SO

Canada

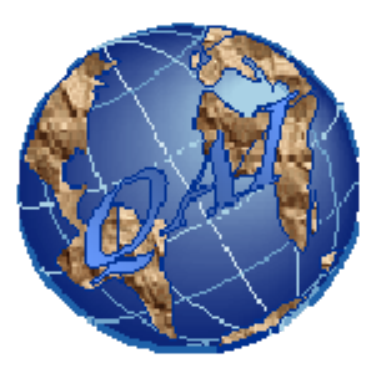




\section{Introduction}

The data generated and the expertise of Inorganic Geochemistry Laboratory (IGL) personnel remains a critical support component of the Energy Resources Program's (ERP's) programs. Increased emphasis throughout the coal industry on understanding the impacts of production and usage of coal including the effects of mercury, arsenic, and other toxic elements will ensure that the major, minor and trace element results generated by the IGL will have increased visibility and importance.

Since that sample suite analyzed is literally worldwide, the primary goal of the Quality Management System (QMS) should be to ensure the USGS continues to maintain a high level of confidence that the Denver laboratory continues to produce data that are of the requisite accuracy for not only the US but also the global coal community.

To meet this goal the objectives of this USGS quality system review can be summarized as follows:

- Produce high quality data

- Lower operational costs

- Create a working environment that optimizes staff involvement in quality improvement

- Positions the laboratory to become a recognized competent practitioner of performance based testing an approach to the assessment and maintenance of laboratory competency that is being adopted by major standards writing organizations worldwide including ASTM International and ISO.

\section{Executive Summary}

To provide an initial assessment of the IGL analytical capabilities, a comparison of the performance of USGS with Australian and Canadian Government test facilities for sulfur (S), chlorine $(\mathrm{Cl})$, mercury $(\mathrm{Hg})$, silica $(\mathrm{SiO} 2)$ and vanadium $(\mathrm{V})$ is summarized in table A.1.1. The coal indicators were selected as they dictate opportunities and limitations for the utilization of coal. The major, minor, and trace elements were selected because they are benchmark indicators of the ability to achieve complete recovery and acceptable consistency of results. $\mathrm{Hg}, \mathrm{Cl}$, and $\mathrm{S}$ are all important environmental parameters. $\mathrm{SiO}_{2}$ is the single-most dominant constituent in both in coal ash and fly ash and V provides good gauge of a laboratory's ability to perform trace element analyses. This preliminary comparison includes 9 laboratories from the USA and around the world that regularly perform analysis of coal and coal-derived ash. Results employed for the comparison were obtained from the Quality Associates International Ltd. (QAI) CANSPEX ${ }^{\mathrm{TM}}$ proficiency improvement program.

CANSPEX ${ }^{\mathrm{TM}}$ is proficiency test service that assists a laboratory at becoming more competent in performing measurements. Participation in proficiency testing programs (PTP) is a key element of good laboratory practice cited in ISO 17025, General Requirements for the Competence of Testing and Calibration Laboratories. PTPs should be employed by a testing laboratory to determine the "health" of their quality system. Most PTPs assimilate results from their participants and return nothing more than a statistical analysis of the data. In the testing 
environment of today, this approach is no longer adequate. CANSPEX ${ }^{\mathrm{TM}}$ provides the laboratory specific information on those factors that are affecting both short and long-term quality control. Currently 95 laboratories from 18 countries take part in the CANSPEX ${ }^{\mathrm{TM}}$ program.

For the sake of objectivity, this comparison (table A.1.1.) covered the period of time for which the IGL facility has been reporting results to CANSPEX ${ }^{\mathrm{TM}}$. A rank of 1 indicates the laboratory is the most proficient of the 9 laboratories, a rank of 9 indicates the laboratory is the least proficient. The proficiency graphs (figs. A.1.X1.1-5) appear in Appendix X1 of this report.

Geochemical Testing, which performs contract analysis for the USGS, is also included in this comparison. An evaluation of the performance of Geochemical Testing for the contract parameters Proximate-Ultimate-Btu, Forms of sulfur, Ash Fusion Temperatures along with any recommendations shall be provided to the USGS by the end of July, 2004. In addition, a complete set of graphs shall be supplied for the full suite of measurements conducted by the USGS.

Table A.1.1. Relative proficiency ranking for a nine laboratory comparison. A rank of 1 indicates the laboratory is the most proficient of the 9 laboratories, a rank of 9 indicates the laboratory is the least proficient.

\begin{tabular}{|c|c|c|c|c|}
\hline \multicolumn{5}{|c|}{ Relative Proficiency Ranking 9 Laboratory Comparison } \\
\hline Parameter & Australia & Canada & USGS & U.S. Commercial Lab \\
\hline Silica & 6 & 4 & 9 & 5 \\
\hline Vanadium & 5 & 8 & 6 & 1 \\
\hline Sulfur & 5 & 1 & 8 & 4 \\
\hline Chlorine & 4 & 3 & 9 & 7 \\
\hline Rank Sum & $\mathbf{2 0}$ & $\mathbf{1 6}$ & $\mathbf{3 2}$ & $\mathbf{1 7}$ \\
\hline Mercury & 3 & & 4 & 8 \\
\hline Rank Sum & $\mathbf{2 3}$ & & $\mathbf{3 6}$ & $\mathbf{2 5}$ \\
\hline
\end{tabular}

The results from table A.1.1 clearly indicates that there are performance issues at the IGL that need to be addressed. Based on this comparison, QAI has developed recommendations to be implemented by the Denver laboratory that will promote achievement of the objectives cited in the introduction. Once the recommendations have been instituted, a final assessment shall be conducted to identify and quantify improvements. This approach will allow the Denver laboratory to reach the primary goal of consistently producing data that are of the requisite accuracy for not only the US, but also for the global coal community at a level of proficiency commensurate with that demonstrated by peer agencies worldwide.

\section{Recommendations}

The recommendations provided in this report require a total capital investment of approximately $\$ 43,000$. In addition to significantly increasing the reliability of results, it is anticipated that the USGS will recover the capital investment within 1 year and realize an increased man-hour and consumable margin equivalent to $\$ 85,000$ over a period of 4 years. These estimates are 
summarized in the Table A.1.2. Each recommendation appears in a separate section of this report.

Table A.1.2. Estimation of cost savings from recommendations.

\begin{tabular}{|l|l|l|l|l|l|l|}
\hline Recommendation & Description & Year $\mathbf{1}$ & Year 2 & Year 3 & Year 4 & Totals \\
\hline $1,2,3$ & CRM/RM & $\$ 1,185$ & $\$ 645$ & $\$ 645$ & $\$ 645$ & $\mathbf{\$ 3 , 1 2 0}$ \\
\hline 2 & TOX Cl Analyzer & $(\$ 26,850)$ & $\$ 13,150$ & $\$ 13,150$ & $\$ 13,150$ & $\mathbf{\$ 1 2 , 6 0 0}$ \\
\hline 3,4 & Test Hot Block & $\$ 15,250$ & $\$ 18,250$ & $\$ 18,250$ & $\$ 18,250$ & $\mathbf{\$ 7 0 , 0 0 0}$ \\
\hline Resource & Net (Expense) Savings & $\mathbf{( \$ 1 0 , 4 1 5 )}$ & $\mathbf{\$ 3 2 , 0 4 5}$ & $\mathbf{\$ 3 2 , 0 4 5}$ & $\mathbf{\$ 3 2 , 0 4 5}$ & $\mathbf{\$ 8 5 , 7 2 0}$ \\
\hline
\end{tabular}

CRM Certified Reference Material

RM Reference Material

Net Negative yearly costs shown in parentheses

\section{Recommendation 1: Sulfur}

1) The USGS can increase the proficiency of sulfur analysis by obtaining the Certified Reference Material (CRM) and Reference Material (RM) coals listed in blue in table A.1.3.

Table A.1.3. Recommended purchases of certified reference and reference materials.

\begin{tabular}{|c|c|c|c|c|c|c|c|c|c|c|}
\hline Sample & $\begin{array}{c}\text { Available } \\
\text { From }\end{array}$ & $\underset{\text { Bottle }}{\text { Weight (g) }}$ Per & $\begin{array}{c}\text { S wt } \\
\%\end{array}$ & Cl & \begin{tabular}{|c|}
$\mathbf{H g}$ \\
$\mathrm{ng} / \mathrm{g}$
\end{tabular} & Cost & $\begin{array}{c}\text { Current } \\
\text { Use }\end{array}$ & $\begin{array}{c}\text { Current } \\
\text { Cost }\end{array}$ & $\begin{array}{c}\text { Forecast } \\
\text { Use }\end{array}$ & $\begin{array}{c}\text { Forecast } \\
\text { Cost }\end{array}$ \\
\hline $\begin{array}{l}\text { SARM } \\
20\end{array}$ & SABS & 250 & 0.51 & NTV & 250 & $\$ 350$ & 0 & $\$ 0$ & 0.5 & $\$ 175$ \\
\hline $1632 c$ & NIST & 50 & 1.46 & 1139 & 94 & $\$ 380$ & 2 & $\$ 760$ & 1 & $\$ 380$ \\
\hline 2684b & NIST & 50 & 3.08 & NTV & 97 & $\$ 160$ & 0 & $\$ 0$ & 1 & $\$ 160$ \\
\hline ES-2 & QAI & 90 & 4.45 & 465 & 116 & $\$ 120$ & 0 & $\$ 0$ & 1.5 & $\$ 180$ \\
\hline ES-6 & QAI & 90 & 0.51 & 90 & 24 & $\$ 120$ & 0 & $\$ 0$ & 1.5 & $\$ 180$ \\
\hline 2002-3 & QAI & 90 & 1.90 & 4935 & 131 & $\$ 120$ & 0 & $\$ 0$ & 1.5 & $\$ 180$ \\
\hline CLB-1 & USGS & 60 & 1.49 & 1082 & 151 & $\$ 75$ & 2 & $\$ 150$ & 2 & $\$ 150$ \\
\hline $1633 b$ & NIST & 75 & 0.2075 & NTV & 141 & $\$ 300$ & 1 & $\$ 300$ & 1 & $\$ 300$ \\
\hline 2774 & Alpha & 60 & NTV & NTV & NTV & $\$ 120$ & 2 & $\$ 240$ & $\mathbf{0}$ & $\$ 0$ \\
\hline 2780 & Alpha & 60 & NTV & NTV & NTV & $\$ 120$ & 2 & $\$ 240$ & $\mathbf{0}$ & $\$ 0$ \\
\hline 2782 & Alpha & 100 & NTV & NTV & NTV & $\$ 120$ & 2 & $\$ 240$ & 0 & $\$ 0$ \\
\hline 1635 & NIST & 50 & NTV & NTV & NTV & $\$ 180$ & 1 & $\$ 180$ & 0 & $\$ 0$ \\
\hline 0.93 & Leco & 60 & 0.93 & NTV & NTV & $\$ 120$ & 2 & $\$ 240$ & 0 & $\$ 0$ \\
\hline
\end{tabular}

Per Year Consumable, Man-Hour Savings $\quad \mathbf{\$ 6 4 5}$

Certified Values are in blue bold.

Reference values in blue normal.

NTV no traceable value.

SARM 20 is available from Brammer Standards in Texas. 
2) In addition to the cost savings specified in table A.1.3, the CRM/ RM suite of samples offers the following technical advantages.

The use of CRMs from different sources National Institute of Standards and Technology (NIST), South African Bureau of Standards (SABS), and USGS) will minimize certifying agency specific biases in USGS standardization and calibrations. The suite of CRM and RM samples selected includes values for critical emission species $\mathrm{S}, \mathrm{Cl}$, and $\mathrm{Hg}$ over a wide range of concentrations. The SABS SARM 20 is certified for an extensive range of trace elements (23) including U and Th, as well as several rare earths. SARM 20 provides approximate values for an additional 13 trace. The NIST, SARM, ES, and 2002-3 samples have a very high degree of inter-traceability. They been analyzed simultaneously in a minimum of 3 different interlaboratory studies each involving a different group of laboratories. The CLB-1 sample was run through one of the same interlaboratory studies as the NIST, ES and 2002-3 samples.

3) Use SARM 20, NIST 2684b, ES-2 2002-3 and CLB-1 for calibration of the sulfur analyzer. Use NIST 1632c and ES-6 to determine whether the analyzer remains in a state of control.

4) To achieve a high level of proficiency, use the acceptance values listed in table A.1.4 for calibration and control samples.

Table A.1.4. Acceptance values of certified reference and reference materials.

\begin{tabular}{|l|c|c|}
\hline $\begin{array}{l}\text { CRM/RM } \\
\text { Samples }\end{array}$ & $\begin{array}{c}\text { Reference } \\
\text { Value }\end{array}$ & $\begin{array}{c}\text { Acceptance } \\
\text { Limits }\end{array}$ \\
\hline SARM 20 & 0.5100 & 0.038 \\
\hline NIST 2684b & 3.0760 & 0.076 \\
\hline ES-2 & 4.4500 & 0.097 \\
\hline $2002-3$ & 1.9000 & 0.059 \\
\hline CLB-1 & 1.4900 & 0.052 \\
\hline NIST 1632c & 1.4620 & 0.052 \\
\hline ES-6 & 0.5100 & 0.038 \\
\hline
\end{tabular}

5) The USGS should require that the same materials be employed for all contracted out sulfur analysis.

\section{Recommendation 2: Chlorine}

1) To increase the proficiency of chlorine analysis the USGS needs to convert from the Eschka ignition method to ASTM method D 6721. This entails the purchase of a direct combustion analyzer at' a cost of approximately $\$ 40,000$. A direct combustion analyzer that meets the requirements of ASTM D 6721 is available from COSA instruments located in Norwood, New Jersey. Purchase of a demo or used analyzer could significantly reduce capital outlay. A summary of the expected recovery of this capital investment and extended cost savings is summarized in table 5 . 
Table A.1.5. The expected yearly net cost savings realized by purchase of a direct combustion instrument for chlorine analyses per ASTM D6721 versus current Eshka method.

\begin{tabular}{|c|c|c|c|c|c|c|}
\hline Method & Consumables & $\begin{array}{c}\text { Analyst Time } \\
\text { (Min.) }\end{array}$ & Samples & $\begin{array}{c}\text { Man } \\
\text { hours }\end{array}$ & Man \$\$ & $\begin{array}{l}\text { Total } \\
\text { Costs } \\
\end{array}$ \\
\hline ASTM 6721 & $\$ 500$ & 5 & 1500 & 125 & $\$ 3,750$ & $\$ 4,250$ \\
\hline Eshka & $\$ 2,400$ & 20 & 1500 & 500 & $\$ 15,000$ & $\$ 17,400$ \\
\hline \multicolumn{6}{|c|}{ Net Per Yearly Consumable and Man-Hour Savings } & $\$ 13,150$ \\
\hline
\end{tabular}

In addition to the cost savings specified in table A.1.5, ASTM D 6721 offers the following technical advantages.

- Method D 6721 is based on microcoulometry, which is considered a primary analytical method. Standardization is carried out with a pure chemical compound and does not require the use of CRM or RM coals.

- Analysis and repeat analysis simply involves weighing a portion of sample and introducing it in the analyzer without pretreatment. As a result, the number of steps required to carry out the analysis of chlorine is significantly reduced in comparison to other techniques. This immediately reduces the number of sources of error with a subsequent improvement in the reliability of results.

- Unlike bomb combustion and low temperature ignition, the method operates at temperatures that achieve complete recovery of chlorine from non-combustible as well as combustible materials.

- Much smaller quantities of sample (20 mg to $40 \mathrm{mg}$ ) in comparison to other techniques (150 $\mathrm{mg}$ to $500 \mathrm{mg}$ ) are required to obtain reliable results.

2) To ensure a high degree of precision employ a 5-place analytical balance to weigh all standardization and analysis samples.

3) Conduct analysis of NIST 1632c, ES-2, ES-6, and CLB-1 with each batch of chlorine samples and keep a record of the results obtained vs. the values listed in table A.1.4 in an Excel spreadsheet.

\section{Recommendation 3: Mercury}

1) The USGS can increase and ensure continued proficiency of mercury analysis by employing the certified Reference material (CRM) and reference material (RM) coals selected for sulfur as recovery control samples.

2) At the very least, analyze SARM 20 and one other CRM sample (NIST 1632c, 2684b, $1633 \mathrm{~b}$ ) with each batch of mercury samples. In addition, it is good practice to include one of the RM samples ES-2, ES-6, or 2002-3 in each analysis batch, preferably with a mercury value near the expected value of the test samples. Carry out analysis of all CRM and RM samples in duplicate. Calculate the recovery for each sample tested. Do not normalize test sample values to CRM or RM values. 
3) Should there be a need for the USGS to contract out mercury analysis, use a laboratory with the capability to conduct measurements in compliance with ASTM D 6722 for coals of the following rank, medium volatile bituminous, low volatile bituminous, semi-anthracite, and anthracite. The USGS should require that the same materials employed as CRMs and RMS by the USGS be used for all contracted out mercury analysis. NIST $2692 \mathrm{~b}$ should not be employed as a calibration or control sample as several studies have shown that this CRM is biased high.

\section{Recommendation 4: Majors, Minors and Trace Elements}

To increase the proficiency of major, minor and trace element results the USGS needs to convert to a preparation technique based on fusion or hot block acid digestion. The most effective approach for the USGS would appear to be hot block acid digestion. This entails the purchase of a hot block with a cost of approximately $\$ 3,000$. A hot block that has proven suitable for coal ash is available from Environmental Express, Mt. Pleasant, South Carolina. A summary of the expected recovery of this capital investment and extended cost savings is summarized in table A.1.6.

Table A.1.6. Net per year consumable and man-hour savings using recommended digestion.

\begin{tabular}{|c|c|c|c|c|c|c|}
\hline & Consumables & $\begin{array}{c}\text { Analyst } \\
\text { Time } \\
\text { (Min.) }\end{array}$ & $\begin{array}{c}\text { Total } \\
\text { Samples } \\
\text { per Year }\end{array}$ & $\begin{array}{c}\text { Total } \\
\text { Man } \\
\text { hours }\end{array}$ & $\begin{array}{c}\text { Total Man } \\
\text { Hour Costs }\end{array}$ & Total Costs \\
\hline Recommended Hot Block & $\$ 750$ & 15 & 1500 & 375 & $\$ 11,250$ & $\$ 12,000$ \\
\hline Peroxide Fusion: Graphite Crucibles & $\$ 1,500$ & 15 & 1500 & 375 & $\$ 11,250$ & $\$ 12,750$ \\
\hline Teflon Acid Digest & $\$ 2,500$ & 20 & 1500 & 500 & $\$ 15,000$ & $\$ 17,500$ \\
\hline Net Per Year Consumable and Man-Hour Savings Using Hot Block Digestion & $\mathbf{\$ 1 8 , 2 5 0}$ \\
\hline
\end{tabular}

In addition to the cost savings specified the hot block digestion offers the following technical advantages.

- The hot block digestion replaces two separate digestions graphite sinter and Teflon acid digestion currently employed by the USGS to carry out major, minor and trace analysis.

- The hot block digestion eliminates the need for perchloric acid, which requires extreme safety precautions and can only be used in a specialized fume hood.

- The hot block can also be employed for the acid extraction of mercury by ASTM D 6414.

- Since a fluxing agent is not required the solids loading on the ICP-MS and ICP AES systems is significantly reduced.

\section{Hot block digestion of the ash}

The use of Teflon tubes and a heating block improves the efficiency and precision of ash dissolution when compared with heating the sample in a Teflon beaker on a hot plate. A recommended procedure employing a heating block is described below.

Transfer $200 \mathrm{mg}$ to $500 \mathrm{mg}$ of ignited ash to a $60 \mathrm{~mL}$ Teflon tube. Add $20 \mathrm{~mL}$ aqua regia and 20 $\mathrm{mL}$ of $\mathrm{HF}$ to the tube. Place the tube in a room temperature hot block. Ramp the hot block to 
$100^{\circ} \mathrm{C}$ and hold at this temperature for 30 minutes. Ramp the hot block to $150^{\circ} \mathrm{C}$. Maintain this temperature while the mixture evaporates to dryness. Do not bake the sample.

After the solution has evaporated to dryness, rinse the tube walls with deionized water. Heat this solution at $150^{\circ} \mathrm{C}$ to dryness. Do not bake the sample. Remove the tube from the hot block. Cool to room temperature. Add $1 \mathrm{~mL}$ of $\mathrm{HNO}_{3}$ and $40 \mathrm{~mL}$ of deionized water to the tube. Heat the contents in the hot block at $110^{\circ} \mathrm{C}$ for one hour. Transfer to a $100 \mathrm{~mL}$ polypropylene volumetric flask. Dilute to volume with water and mix. Examine the final test solution and record the presence and color of any undissolved residue. Prepare a blank by using the above procedure but omitting the ash.

Residue left after dissolution indicates the presence of undissolved mineral or organic matter. In the case of a fly ash ignited at $500{ }^{\circ} \mathrm{C}$ prior to dissolution, the undissolved material can be made up of refractory carbon compounds that are not readily decomposed in the ignition step or digested by the acids. These carbon compounds can retain trace elements. Ignition of the fly ash at a higher temperature can decompose these refractory compounds but can also lead to loss of trace elements that are volatile above $500{ }^{\circ} \mathrm{C}$.

To demonstrate the digestion process is remaining in an acceptable state of control, digest a sample prepared from an ash containing little or no organic carbon with each batch of samples.

Once the USGS has commissioned this preparation method, Quality Associates International Ltd. shall provide a minimum of 6 blind ash samples for a proficiency test.

\section{Appendix A.1.X1. Proficiency Graphs}

\section{An Uncertainty Primer}

Because human beings are fallible, all devices from something as simple as a tape measure to something as complex as a mass spectrometer designed and employed to conduct measurements can, and do produce, variable results. This variation in the results is called uncertainty. The smaller the uncertainty, the more reliable are the conclusions that can be extracted from the measurement system. The following example should help to clarify this point.

A polling agency conducts a poll of voters in a randomly selected state on the outcome of an upcoming election. From this poll, they establish that $54 \%$ of the voters intend to vote YES. They then compare this state's results with the remaining states for the past 4 elections and conclude that this result could vary from $47 \%$ to $61 \%$ or an uncertainty of $\pm 7 \%$. The key point is that this poll indicates the YES's could lose the election.

Another agency conducts a more extensive poll of voters in all 50 states. They establish that 56 $\%$ of voters intend to vote YES. By comparing the variation between the individual states the agency concludes the result could vary from $53 \%$ to $59 \%$ or an uncertainty of $\pm 3 \%$. The clear indication is that YES's are going to win the election. The poll also provides current state-bystate results, which would allow the YES's to focus their efforts to push the outcome closer to the $59 \%$ value. 
In the end, the poll with the lower uncertainty not only increases confidence in the outcome of the election, but also optimizes use of party resources. Now suppose we wait a month and ask the agencies to conduct the exercise again. Most individuals would recognize that it is very unlikely the poll results are going to be exactly the same. In the case of the first agency, the randomly selected state changes and the result is $56 \%$ expect to vote YES with an uncertainty of $\pm 11 \%$. In the case of the second agency, the result is $57 \%$ expect to vote YES with an uncertainty of \pm 4 $\%$.

Not only are the conclusions from the two polls the same, but also it is evident that the measurement system employed by the second agency with a range of uncertainty $( \pm 3 \%$ to \pm 4 $\%$ ) is more stable than the measurement system employed by the first with a range of uncertainty $( \pm 7 \%$ to $\pm 11 \%)$.

The graphs in this appendix display the uncertainty of measurements conducted for different test parameters by different laboratories covering periods of up to 4 years. The uncertainties are displayed as box plots that illustrate the average uncertainty as well as the maximum and minimum expected uncertainties as defined by the ends of the boxes.

The proficiency box-plots are highlighted as follows.

$\begin{array}{lll}\text { USGS } & \text { Blue } & \text { Lab 685 } \\ \text { Geochemical } & \text { Green } & \text { Lab } 588 \\ \text { Canada } & \text { Red } & \text { Lab 551 } \\ \text { Australlia } & \text { Orange } & \text { Lab 620 }\end{array}$

\section{Lab classification}

$\begin{array}{ll}\text { Com } & \text { Commercial lab } \\ \text { Edu } & \text { University lab } \\ \text { Gen } & \text { Utility lab } \\ \text { Gov } & \text { Government lab } \\ \text { Prd } & \text { Coal producer }\end{array}$

\section{Country code}
AUS: Australia
ISR: Israel
CAN: Canada
USA: United States of America
GER: Germany

Analytical Instruments: ICPAES: Inductively Coupled Plasma Argon Emission Spectroscopy;
ICPMS: Inductively Coupled Plasma Mass Spectroscopy; ICPOES: Inductively Coupled Plasma
Optical Emission Spectroscopy; XRF: X-Ray Fluorescence; IC: Ion Chromatography; ISE: Ion
Selective Electrode
Figures A.1.X1.1-5 present proficiency graphs for sulfur, chlorine, mercury, silica, and
vanadium. There are two box-plots for each laboratory. One for the entire period covered by the 
graph indicated as (Lab-3 or Lab-4) and one for the past year (indicated as Lab-1). The primary method employed by the laboratory over the period of the graph and during the past year appears under the country code. 


\section{Sulfur Expanded Uncertainty 2001-2004}

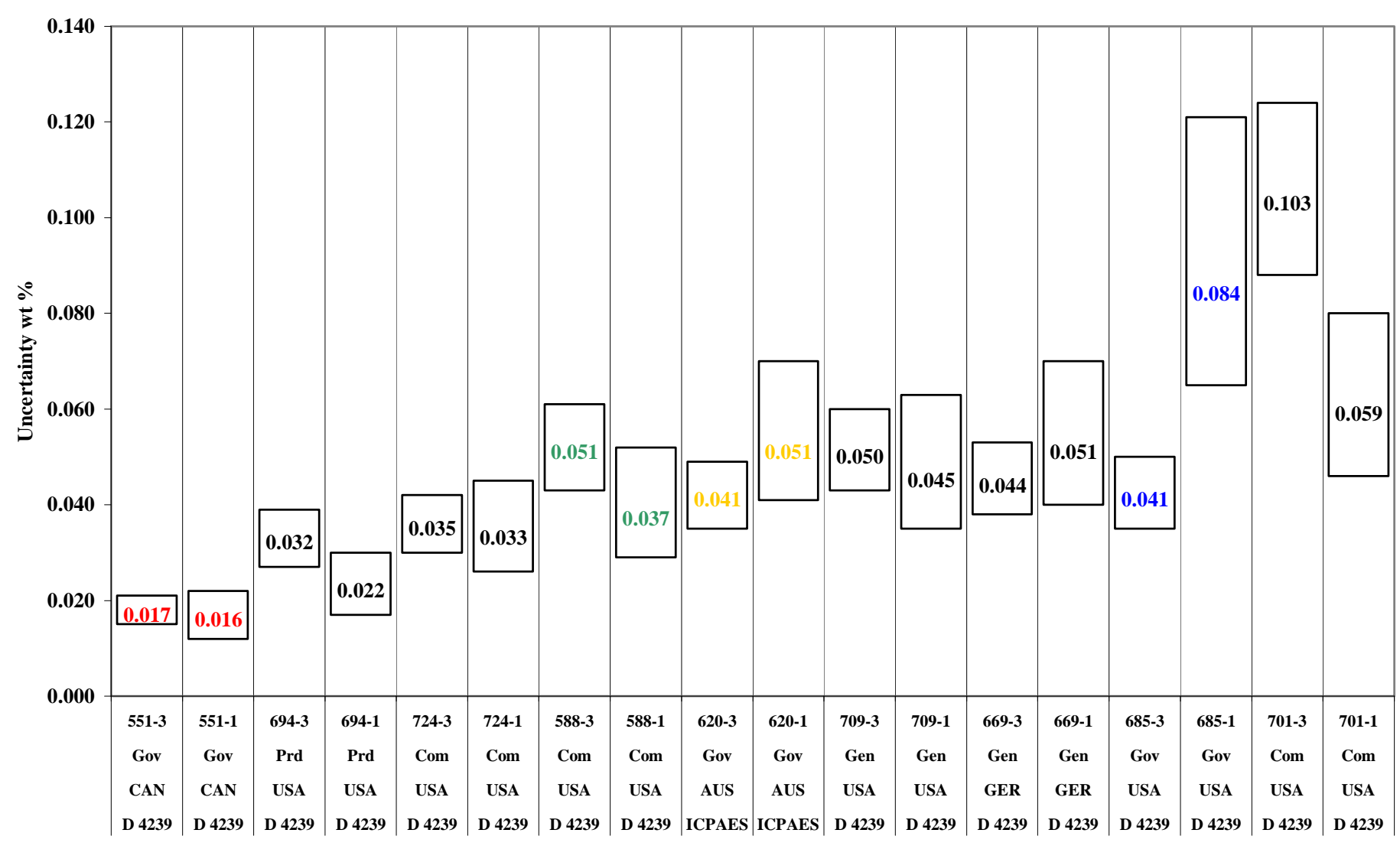

\begin{tabular}{|c|c|c|}
\hline USGS & Blue & Lab 685 \\
\hline Geochemical & Green & Lab 588 \\
\hline
\end{tabular}

Canada Red Lab 551

Australlia Orange Lab 620

Country code

\section{Lab classification}

Com Commercial lab

Edu University lab

Gen Utility lab
AUS
Australia
CAN
Canada
GER
Germany
ISR
Israel
USA

Analytical Instruments: ICPAES: Inductively Coupled Plasma Argon Emission Spectroscopy; ICPMS: Inductively Coupled Plasma Mass Spectroscopy; ICPOES: Inductively Coupled Plasma Optical Emission Spectroscopy; XRF: X-Ray Fluorescence; IC: Ion Chromatography; ISE: Ion Selective Electrode

Figure A.1.X1.1. Sulfur expanded uncertainty $(2001-2004)$ 


\section{Chlorine Expanded Uncertainty 1999-2004}

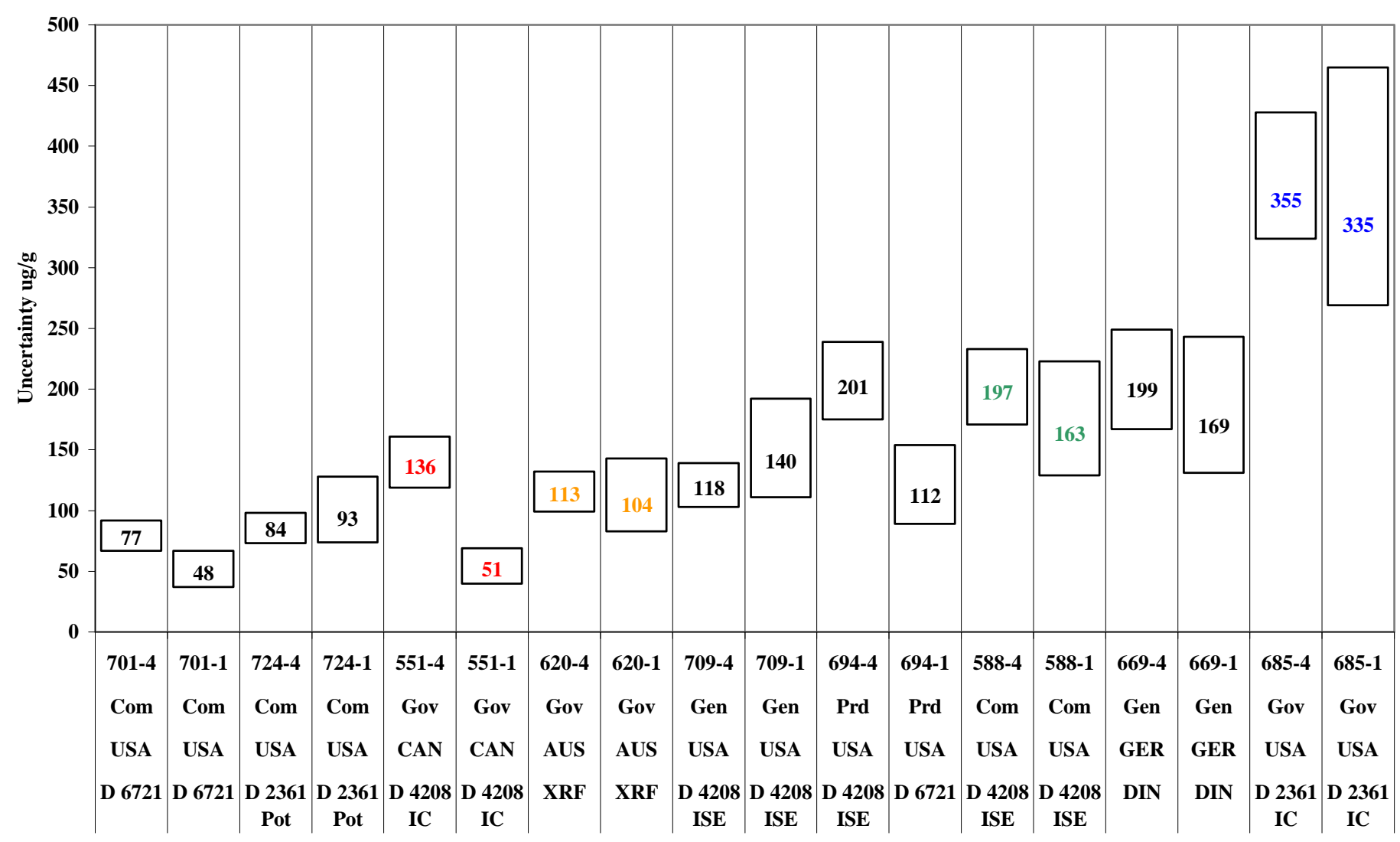

\begin{tabular}{|c|c|c|c|c|}
\hline USGS & Blue & Lab 685 & Gov & Government lab \\
\hline Geochemical & Green & Lab 588 & Prd & Coal producer \\
\hline
\end{tabular}

Canada Red Lab 551

Australlia Orange Lab 620

\section{Lab classification}

Com Commercial lab

Edu University lab

Gen Utility lab

\section{Country code}

$\begin{array}{ll}\text { AUS } & \text { Australia } \\ \text { CAN } & \text { Canada } \\ \text { GER } & \text { Germany (DIN) } \\ \text { ISR } & \text { Israel } \\ \text { USA } & \text { United States of America }\end{array}$

Analytical Instruments: ICPAES: Inductively Coupled Plasma Argon Emission Spectroscopy; ICPMS: Inductively Coupled Plasma Mass Spectroscopy; ICPOES: Inductively Coupled Plasma Optical Emission Spectroscopy; XRF: X-Ray Fluorescence; IC: Ion Chromatography; ISE: Ion Selective Electrode

Figure A.1.X1.2. Chlorine expanded uncertainty (2001 - 2004) 


\section{Mercury Expanded Uncertainty 1999-2004}

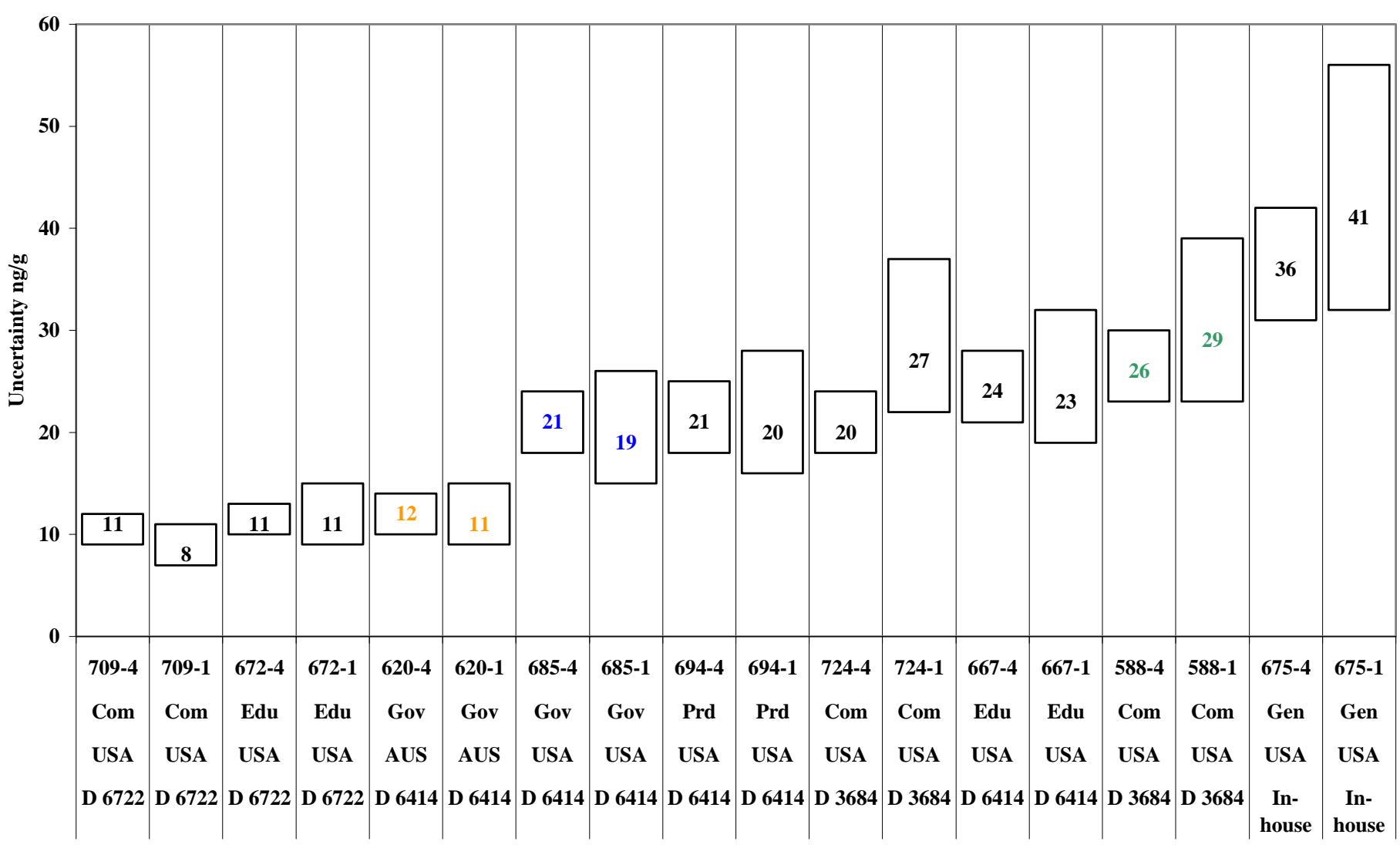

\begin{tabular}{|c|c|c|c|c|}
\hline USGS & Blue & Lab 685 & Gov & Government lab \\
\hline Geochemical & Green & Lab 588 & Prd & Coal producer \\
\hline
\end{tabular}

Canada Red Lab 551

Australlia Orange Lab 620

\section{Lab classification}

Com Commercial lab

Edu University lab

Gen Utility lab

\section{Country code}

$\begin{array}{ll}\text { AUS } & \text { Australia } \\ \text { CAN } & \text { Canada } \\ \text { GER } & \text { Germany } \\ \text { ISR } & \text { Israel } \\ \text { USA } & \text { United States of America }\end{array}$

Analytical Instruments: ICPAES: Inductively Coupled Plasma Argon Emission Spectroscopy; ICPMS: Inductively Coupled Plasma Mass Spectroscopy; ICPOES: Inductively Coupled Plasma Optical Emission Spectroscopy; XRF: X-Ray Fluorescence; IC: Ion Chromatography; ISE: Ion Selective Electrode

Figure A.1.X1.3. Mercury expanded uncertainty (2001 - 2004) 


\section{Silica Expanded Uncertainty 1999-2004}

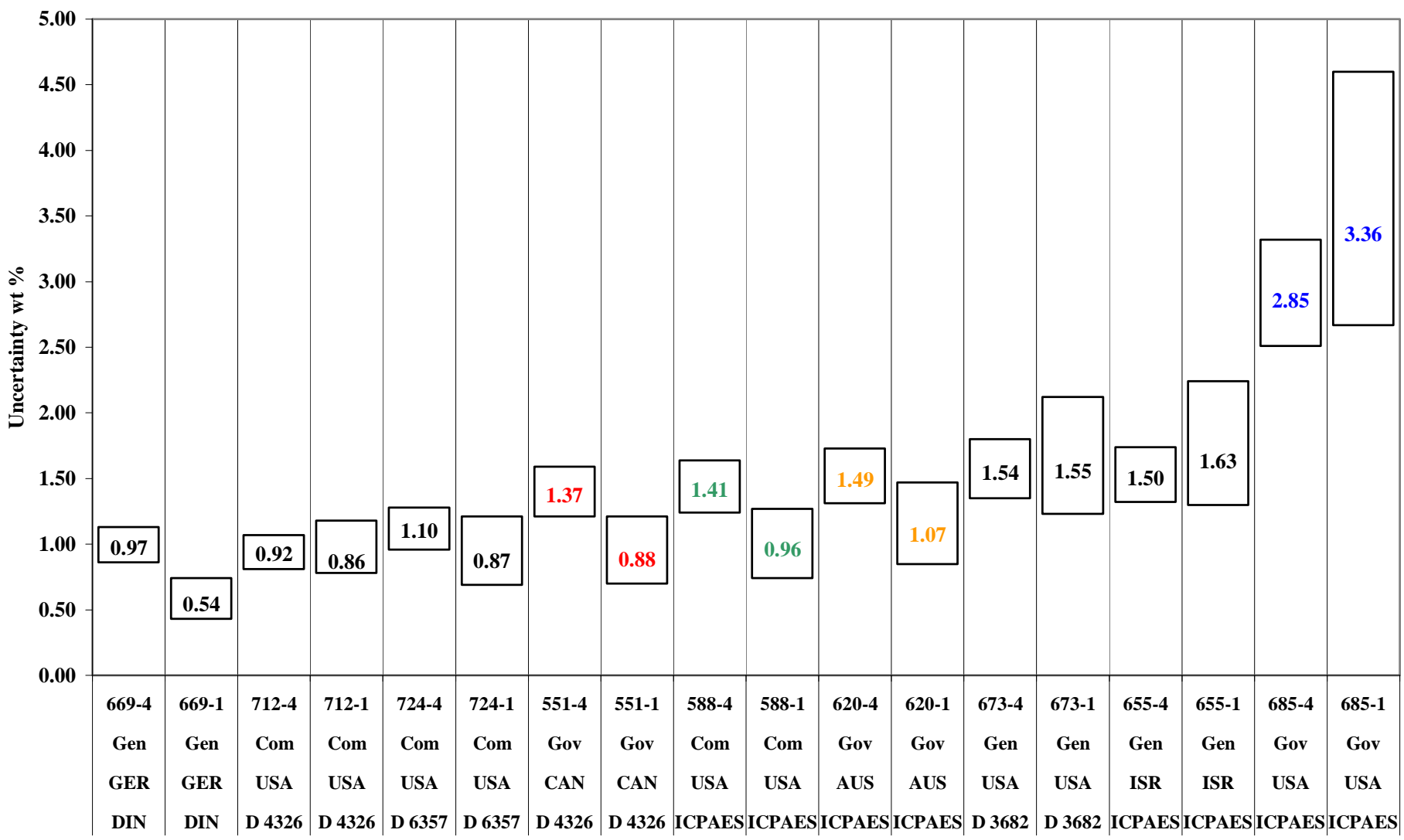

\begin{tabular}{|c|c|c|c|c|}
\hline USGS & Blue & Lab 685 & Gov & Government lab \\
\hline Geochemical & Green & Lab 588 & Prd & Coal producer \\
\hline
\end{tabular}

Canada Red Lab 551

Australlia Orange Lab $620 \quad$ Country code

Lab classification

Com Commercial lab

Edu University lab

Gen Utility lab

$\begin{array}{ll}\text { AUS } & \text { Australia } \\ \text { CAN } & \text { Canada } \\ \text { GER } & \text { Germany (DIN) } \\ \text { ISR } & \text { Israel } \\ \text { USA } & \text { United States of America }\end{array}$

Analytical Instruments: ICPAES: Inductively Coupled Plasma Argon Emission Spectroscopy; ICPMS: Inductively Coupled Plasma Mass Spectroscopy; ICPOES: Inductively Coupled Plasma Optical Emission Spectroscopy; XRF: X-Ray Fluorescence; IC: Ion Chromatography; ISE: Ion Selective Electrode

Figure A.1.X1.4. Silica expanded uncertainty (2001 - 2004) 


\section{Vanadium Expanded Uncertainty 1999-2004}

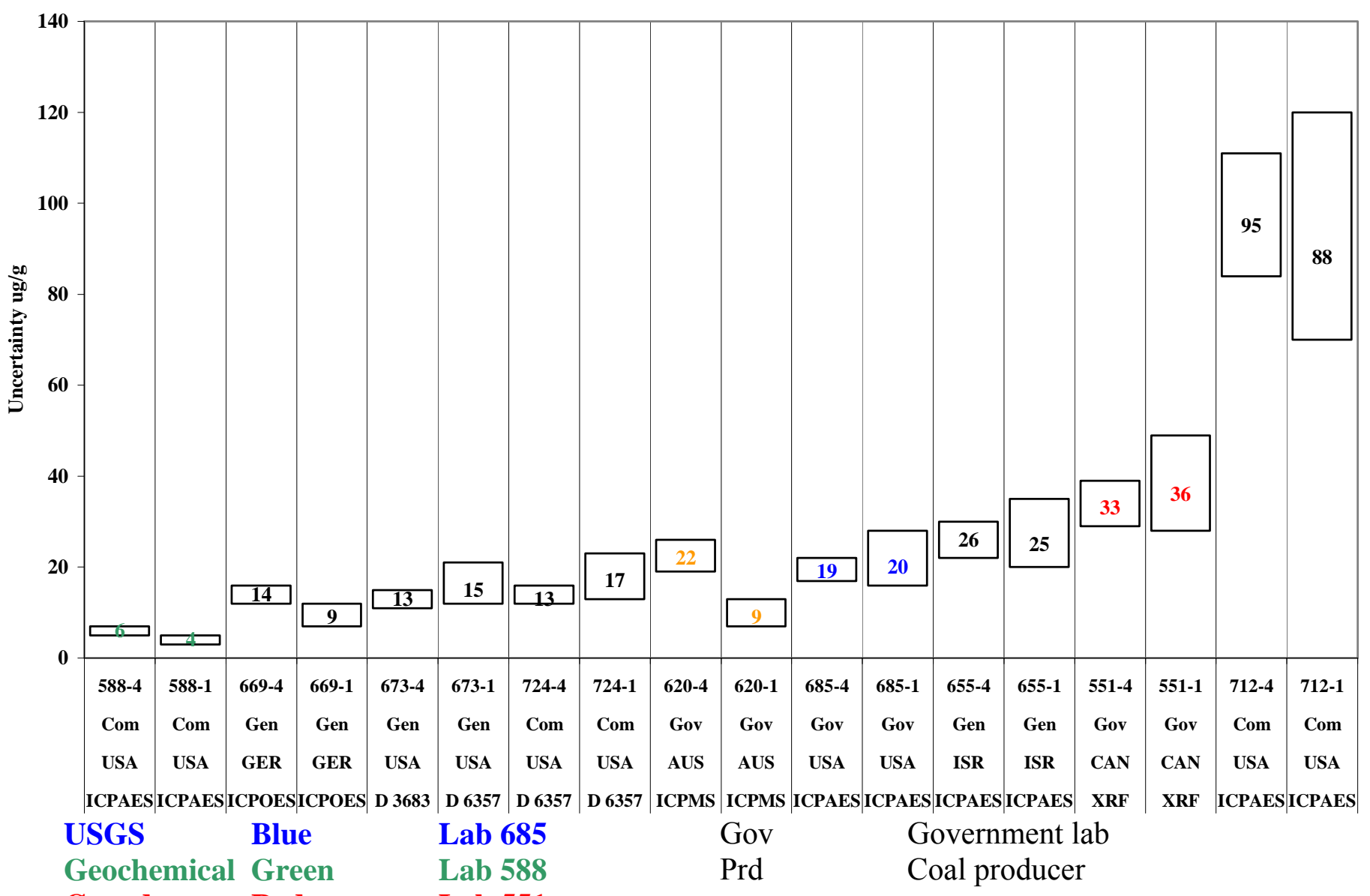

Canada Red Lab 551

Australia Orange Lab 620

\section{Country code}

\section{Lab classification}

Com Commercial lab

Edu University lab

Gen Utility lab
AUS
Australia
CAN
Canada
GER
ISR
Germany
Israel
USA

Analytical Instruments: ICPAES: Inductively Coupled Plasma Argon Emission Spectroscopy; ICPMS: Inductively Coupled Plasma Mass Spectroscopy; ICPOES: Inductively Coupled Plasma Optical Emission Spectroscopy; XRF: X-Ray Fluorescence; IC: Ion Chromatography; ISE: Ion Selective Electrode

Figure A.1.X1.5. Vanadium expanded uncertainty $(2001-2004)$ 


\section{Appendix A.2}

\section{Phase 1: Preliminary Evaluation of Quality System and Recommendations, Final Report}

\section{Performance Audit of U.S. Geological Survey Inorganic Geochemistry and Contract Laboratories}

Requisition \#3-2920-1052

September 10, 2004

Louis Janke, President

Quality Associates International ${ }^{\circledR}$, LDT.

P.0. Box 117

Douglas, ON KOJ 1 SO

Canada

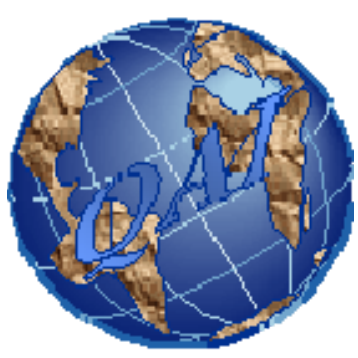




\section{Executive Summary}

Periodic external audits to verify that operations comply with the requirements of a QMS are a basic principle for sound laboratory management. The ultimate goal is to maintain a high level of confidence that the U.S. Geological Survey, Energy Resources Program, Inorganic Geochemical Laboratory (IGL) continues to produce data that are of the requisite accuracy. To that end, a performance audit of the IGL and its contract laboratory was conducted by Quality Associates International ${ }^{\circledR}$ Ltd. (QAI). This audit compared USGS results with laboratories representing government agencies, coal producers, utilities and third part testing laboratories worldwide each of which analyzes at least 2000 coal and coal derived samples a year.

The recommendations in this report, which require only a modest investment in equipment and materials will improve analytical reliability, increase productivity, lower consumable costs (Appendix X2), and improve safety conditions. Specific recommendations are emphasized in the body of the report.

The IGL facility is one of the two top included in this assessment for the determination of trace analytes in coal-derived ash. Through minor changes to in-house preparation procedures, this level of performance can be maintained and conducted in a more cost effective and safe manner while at the same time significantly improving performance for the determination of major and minor components in coal derived ash.

The recommendations made in the preliminary audit for the IGL to expand the panel of Certified Reference Materials (CRMs) and Reference Materials (RMs) for sulfur and mercury analysis as well as to convert to ASTM D 6721 for chlorine analysis, including the purchase of a direct combustion instrument for chlorine are confirmed in this assessment.

The USGS contract laboratory Geochemical Testing achieved the highest level of performance in this assessment for all contract parameters.

A reassessment of the performance of the Denver laboratory shall be conducted by December 31 2004 with a view to documenting the recommendations of the preliminary audit. This assessment should not only improve the overall efficiency of in-house capabilities, but also the reliability of analytical results.

\section{Introduction}

As part of a continuing effort to demonstrate government accountability the U.S. Geological Survey, Geologic Discipline, Energy Resources Team (ERT), is conducting an operating audit of the U.S. Geological Survey (USGS), Energy Resources Program, Inorganic Geochemistry Laboratory (IGL). Per ISO/IEC Guide 17025 General Requirements for the Competence of Testing and Calibration Laboratories, a basic tenet of sound laboratory management is a formal audit by an external examiner at appropriate intervals to verify that its operations comply with the requirements of the quality management system (QMS). 
In recognition of the need of the USGS to maintain a high degree of credibility both domestically and internationally, Quality Associates International ${ }^{\circledR}$ Ltd. (QAI) was contracted to conduct a performance-based audit that complies with the requirements of ISO Guide 17025. Properly structured, this approach permits an objective assessment of laboratory performance on a continuing basis as well as confirmation of any improvement in the reliability of analytical results. To ensure a comprehensive assessment of all analytical values reported by the U.S. Geological Survey (USGS), Inorganic Geochemistry Laboratory (IGL), the audit includes the IGL as well as the contract analytical laboratory, Geochemical Testing, Somerset PA.

\section{Approach}

ISO Guide 17025 General Requirements for the Competence of Testing and Calibration Laboratories, clause 5.4 accepts data from the analysis of Certified Reference Materials (CRMs), Reference Materials (RMs) and proficiency testing programs (PTP) as a basis for validating the capability of a laboratory to generate technically credible results. This performance based assessment approach for evaluating laboratory competence is continuing to gain prominence with regulatory (Environmental Protection Agency) as well as voluntary consensus standards writing organizations (SWOs) worldwide (ASTM International, ISO). The performance audit was conducted in two phases, preliminary recommendations and this final report.

The preliminary audit of the IGL provided recommendations to increase both the reliability and efficiency of procedures related to the use of CRMs and RMs for performance based assessment. The next phase, addressed in this report, involves a detailed assessment of proficiency test data submitted to CANSPEX ${ }^{\mathrm{TM}}$ by the USGS and its contract laboratory covering 15 samples over the period of December 2000 to July 2004. CANSPEX ${ }^{\mathrm{TM}}$ is proficiency service designed and administered by QAI that promotes competency in the coal-testing laboratory. Most PTPs assimilate results from their participants and return nothing more than a statistical analysis of the data. In the testing environment of today this approach is no longer adequate. CANSPEX ${ }^{\mathrm{TM}}$ provides much more than just basic statistics by notifying the laboratory on factors that affect both short and long-term quality control. This is accomplished through publication of the CANSPEX ${ }^{\mathrm{TM}}$ Method Manual, which is updated on a yearly basis. The manual draws upon reports from participants as well as interlaboratory studies (ILS) that have been specifically designed to identify factors, which have a critical impact on the reliability of analytical results. ILS programs usually involve a minimum of 8 different laboratories and include samples that cover sample composition and physical characteristics that would normally be encountered in the laboratory. This approach guards against excessively sanitized data by subjecting a method to a variety of sample types, operators, equipment, and environmental conditions. Currently 95 laboratories from 18 countries take part in the CANSPEX ${ }^{\mathrm{TM}}$ program.

The performance of the IGL and its contract laboratory is compared with laboratories representing government agencies, coal producers, utilities and third party testing laboratories worldwide, each of which analyzes at least 2,000 coal and coal derived samples a year. To provide an objective assessment of the CANSPEX ${ }^{\mathrm{TM}}$ PTP results, QAI employed the Horwitz function, which expresses an empirical relationship between sample concentration and multiple-laboratory standard deviation. This function, which applies over a wide range of test materials and analytes, as well as, physical principles underlying an analytical procedure, was developed from over 6,000 independent studies 
conducted worldwide. The Horwitz function is recognized by the International Union of Pure and Applied Chemists (IUPAC, Pure \& Appl. Chem., Vol. 62, No.1, pp. 149-162, 1990) and employed by the International Association of Geoanalysts in their GeoPT proficiency testing scheme as a fundamental fitness for purpose performance benchmark.

The Horwitz function can be employed to evaluate either the fitness for purpose of a method using interlaboratory study (ILS) data as prescribed by IUPAC or of a laboratory by examining proficiency test results over a series of samples. Dividing the standard deviation of a method ILS or of laboratory PTP results over a series of samples, by that predicted by the function, yields a Horwitz performance ratio. A low Horwitz performance ratio is an indicator of highly reliable analytical results. QAI recognizes several levels of performance. Class 1, which is appropriate for certified analysis, constitutes a performance ratio of 1 or less. Class 2, which is appropriate for referee (reference) analysis, constitutes a performance ratio of less than or equal to 2 but greater than 1. Class 3, which is appropriate for routine analysis, constitutes a performance ratio of less than or equal to 3 but greater than 2. Ratios greater than 3 indicate either that the laboratory or that the method employed by the laboratory is not capable of consistently producing suitable results. For this reason the evaluations in this document include the evaluation of the "best" current state of the art ASTM (reference) standard for a given measurement.

\section{Performance Tables}

This report includes a series of performance tables designed to provide the ability to determine the capability of a laboratory "at a glance". The Horwitz PTP performance ratio for each laboratory as well as the Horwitz method ILS performance ratio for the best state of the art ASTM standard is listed. A blue performance ratio indicates the laboratory or method is capable of producing certified results (maximum relative analytical error of $1 \%$ at $100 \%$ concentration). A green performance ratio indicates the laboratory or method is capable of producing reference results (maximum relative analytical error of $2 \%$ at $100 \%$ concentration). An orange performance ratio indicates the laboratory or method is capable of producing routine results (maximum relative analytical error of $3 \%$ at $100 \%$ concentration).

\section{ASTM Standards}

The objective of ASTM International is to produce standards that are suitable for routine analysis in the global coal testing community. ASTM conducts an ILS to establish the agreement of results can that expected within a laboratory (repeatability) and between laboratories (reproducibility). Both of these figures of merit appear in the precision statement of the respective ASTM standard and can be compared with the Horwitz function to determine the performance ratio of the standard.

\section{Laboratory Performance}

The goal of a laboratory should be to achieve a performance ratio at least equivalent to the reference standard. It is possible for a laboratory to achieve a lower performance ratio than the reference standard by establishing more rigorous control over environmental, sample preparation and instrumental conditions than specified in the standard. The following discussion provides examples of how an improved performance ratio (lower ratio) can be attained. 
The ASTM method for the determination of sulfur in coal D 4239 requires the measurement device to be calibrated with certified reference material (CRM) coals. Because the standard is employed worldwide for the determination of sulfur in coal, no restriction is placed on the source or composition of the CRMs. Prior to use for calibration, the certified values of the sulfur in the CRM coals, which is expressed on a dry basis, must be converted to the as determined basis by determining the moisture content of the CRM coal. The standard specifies, "CRM's must be stable with respect to moisture". Some laboratories control the relative humidity of the laboratory environment to remain in the range of $45 \%$ to $\% 55$ year round. Others do not control this environmental factor. In this case the relative humidity can range from as low as $25 \%$ in the winter months to as much as $80 \%$ in the summer months. The moisture content of CRM samples tracks the relative humidity of the laboratory environment. In the case where the humidity is controlled as described above, there will be negligible change in the as determined values of the CRM samples. In the case where humidity is not controlled, the change in relative humidity can create significant and undetected calibration shifts that adversely affect the reliability of results. As a result, a laboratory that controls relative humidity can be expected to achieve a lower (better) performance ratio for sulfur than one that does not.

ASTM D 4239 specifies “the CRM's must be must be mixed thoroughly before each use”, but does not explicitly state the same requirement for test samples. The amount of coal sample normally employed for the determination of sulfur in coal is $150 \mathrm{mg}$ to $200 \mathrm{mg}$. Since coal is by its very nature a heterogeneous material that tends to segregate on sitting, to ensure a representative and homogeneous test portion is taken for analysis mixing is a critical step in the preparation not only of calibration but also of test samples. Laboratories that have a uniform procedure for mixing all samples prior to taking a test portion for analysis can be expected to achieve a better performance ratio than those that do not. In fact, performance can be further improved by mixing all calibration samples after a test portion has been extracted for analysis to ensure the coal remaining equilibrates with the atmosphere in the bottle.

ASTM D 4239 states "follow the calibration procedure recommended by the manufacturer". Instruments that comply with ASTM D 4239 produce a peak that resembles a bell shape. This peak has two fundamental properties, height and area. Instrument manufacturers provide the option of calibrating by peak height or peak area. In the majority of cases, instrument peak height can, and does vary more from measurement to measurement than does instrument peak area. This is because as peak height increases the peak base decreases and as peak height decreases the peak base increases. As a result, peak area tends to remain more stable. The time required to measure maximum peak height is less than that required to measure total peak area. Many laboratories calibrate and measure according to peak height to increase sample throughput. However, laboratories that set the instrument condition to accumulate peak area can be expected to achieve a better performance ratio.

The USGS IGL is laboratory 135 and the USGS contract laboratory Geochemical Testing is laboratory 38 in the following tables and discussion.

\section{$\underline{\text { Trace Analysis in Coal Derived Ash }}$}


A comparison of the trace element results from the IGL (135) and 7 other laboratories is presented in table A.2.1.

Table A.2.1. Trace element performance summary table

\begin{tabular}{|c|c|c|c|c|c|c|c|c|c|}
\hline Laboratory & ASTM D 6357 & $\mathbf{1 3 5}$ & $\mathbf{3 0 0}$ & $\mathbf{7 0}$ & $\mathbf{1 0 5}$ & $\mathbf{1 1 9}$ & $\mathbf{1 2 3}$ & $\mathbf{1 4 6}$ & $\mathbf{1 7 4}$ \\
\hline Country & International & USA & USA & AUS & ISR & GER & USA & CHN & USA \\
\hline Class & Reference & Gov & Com & Gov & Gen & Gen & Gen & Gov & Com \\
\hline Arsenic & 2.6 & 1.9 & 2.6 & 1.8 & 2.8 & 2.8 & 2.7 & 2.2 & 1.8 \\
\hline Beryllium & 2.0 & 2.2 & 2.6 & 1.1 & 1.9 & 2.5 & 2.1 & & 1.8 \\
\hline Cadmium & 2.4 & 1.8 & $\mathbf{9 . 7}$ & $\mathbf{4 . 1}$ & $\mathbf{4 . 6}$ & $\mathbf{4 . 1}$ & 2.4 & $\mathbf{9 . 7}$ & 1.7 \\
\hline Cobalt & 2.0 & 2.2 & $\mathbf{5 . 2}$ & $\mathbf{7 . 2}$ & $\mathbf{4 . 1}$ & $\mathbf{4 . 8}$ & 2.4 & $\mathbf{4 . 1}$ & $\mathbf{4 . 9}$ \\
\hline Chromium & 2.1 & 2.0 & $\mathbf{0 . 9}$ & $\mathbf{3 . 9}$ & 2.2 & $\mathbf{1 . 6}$ & $\mathbf{1 . 8}$ & $\mathbf{6 . 3}$ & 2.2 \\
\hline Copper & 2.5 & 2.1 & 1.5 & $\mathbf{4 . 7}$ & 1.9 & 1.3 & 2.3 & 1.4 & 2.1 \\
\hline Manganese & 2.3 & 1.4 & $\mathbf{1 . 3}$ & $\mathbf{0 . 9}$ & $\mathbf{3 . 5}$ & $\mathbf{1 . 5}$ & $\mathbf{5 . 2}$ & $\mathbf{1 . 8}$ & 1.4 \\
\hline Nickel & 2.3 & 1.6 & $\mathbf{1 . 9}$ & 3.0 & 2.5 & $\mathbf{4 . 8}$ & 2.5 & 2.9 & 2.1 \\
\hline Lead & 2.8 & $\mathbf{3 . 6}$ & $\mathbf{1 0 . 2}$ & $\mathbf{3 . 6}$ & $\mathbf{3 . 9}$ & $\mathbf{5 . 8}$ & 2.4 & $\mathbf{5 . 0}$ & $\mathbf{3 . 7}$ \\
\hline Antimony & $\mathbf{3 . 1}$ & 2.1 & & $\mathbf{3 . 7}$ & $\mathbf{7 . 6}$ & $\mathbf{1 0 . 5}$ & $\mathbf{1 4 . 8}$ & & 2.0 \\
\hline Vanadium & 2.7 & 2.7 & $\mathbf{0 . 7}$ & 1.5 & 2.8 & 1.2 & 2.9 & 2.7 & 1.9 \\
\hline Zinc & 2.2 & $\mathbf{1 5 . 8}$ & $\mathbf{1 8 . 0}$ & $\mathbf{1 . 5}$ & 2.3 & $\mathbf{1 . 7}$ & $\mathbf{3 . 1}$ & 2.3 & 1.0 \\
\hline
\end{tabular}

Australia (AUS), China (CHN), Germany (GER), Israel (ISR), United States of America (USA)

Commercial Laboratory (Com), Utility (Gen), Government (Gov), Producer (Prd)

Green: Certified; Orange: Reference; Blue: Routine; Black: >3\% analytical error;

BLANK: Not analyzed.

\section{ASTM Standard}

In the case of trace element analysis ASTM has met the goal of producing a standard (ASTM D 6357) that is suitable for routine analysis. Most experts would recognize that the single exception antimony, which approaches the routine benchmark, presents substantial challenges to the analyst in a matrix as complex as coal ash.

\section{Inorganic Geochemistry Laboratory Trace Analysis}

The two laboratories that achieve the highest level of performance overall for trace element parameters with respect to the reference standard are laboratory 174 and laboratory 135, the IGL (table A.2.1). This can easily be discerned from the table as these two laboratories have more trace parameters that qualify as certified, reference and routine than do the other labs. The numerical procedure involves discarding the best and worst scores (something like Olympic gymnastics) and adding the remaining scores. When this is done Laboratories 135 and 174 achieve the best scores. In fact, if the two best and two worst scores are discarded laboratories $\quad 135$ and 174 still achieve the best performance overall. Both laboratories employ acid digest procedures. The difference between the two procedures is that the laboratory 174 digest, based on ASTM D 6357, uses nitric, hydrochloric, hydrofluoric acids, and a hot block, while the IGL procedure resorts to 
nitric, hydrochloric, sulfuric, perchloric acids and a Teflon digestion vessel. Use of perchloric acid can pose additional safety hazards. It is an analytical fact that each step or chemical employed in a test increases the overall variability of the results obtained.

\section{Recommendation 1: Equivalency Test for Sample Digestion Procedures}

Taking into account the above observations along with the difficulties of maintaining and designing a system for the safe use of perchloric acid, the IGL should conduct an equivalency test employing the 6357 acid mix with a hot block digest. The test would be performed by conducting duplicate analysis of CANSPEX ${ }^{\mathrm{TM}}$ ash samples 2000-4 to 2004-2 on two separate days.

A notable exception to the performance of laboratory 135 is zinc. The performance for zinc is so out of line with the other parameters that ambient contamination is suspected. This can be confirmed by running samples on the both the ICP-AES and ICP-MS. If both instruments produce erratic results, contamination is the most likely cause.

\section{Major and Minor Analysis in Coal derived Ash}

A comparison of the major and minor element results from the IGL (135) and 7 other laboratories is presented in table A.2.2.

Table A.2.2. Major and minor element performance summary table.

\begin{tabular}{|c|c|c|c|c|c|c|c|c|c|}
\hline Laboratory & ASTM D 4326 & 135 & 300 & 1 & 70 & 105 & 119 & 144 & 174 \\
\hline Country & International & USA & USA & CAN & AUS & ISR & GER & USA & USA \\
\hline Class & Reference & Gov & Com & Gov & Gov & Gen & Gen & Prd & Com \\
\hline $\mathrm{Na}_{2} \mathrm{O}$ & 2.7 & 3.2 & 24.8 & 3.8 & 1.8 & 1.5 & 2.0 & 1.9 & 2.7 \\
\hline MgO & 3.4 & 2.0 & 1.9 & 2.0 & 1.3 & 1.5 & 1.0 & 0.8 & 1.1 \\
\hline $\mathbf{A l}_{2} \mathbf{O}_{3}$ & 3.4 & 2.8 & 2.6 & 2.2 & 1.2 & 1.5 & 0.9 & 1.6 & 1.6 \\
\hline $\mathrm{SiO}_{2}$ & 2.9 & 3.6 & 1.7 & 1.6 & 1.3 & 1.2 & 0.8 & 0.9 & 1.2 \\
\hline $\mathbf{P}_{2} \mathbf{O}_{5}$ & 2.7 & 5.7 & 4.1 & 2.6 & 3.9 & 7.0 & 3.8 & 1.9 & 4.3 \\
\hline $\mathrm{SO}_{3}$ & 8.3 & 8.7 & 11.3 & 14.2 & 11.6 & 4.9 & 5.6 & 6.0 & 5.1 \\
\hline $\mathbf{K}_{2} \mathbf{O}$ & 2.7 & 5.2 & 2.4 & 1.9 & 2.2 & 3.0 & 2.5 & 2.4 & 1.2 \\
\hline $\mathrm{CaO}$ & 2.3 & 2.4 & 3.2 & 6.4 & 1.2 & 1.4 & 1.2 & 1.1 & 1.4 \\
\hline $\mathrm{TiO}_{2}$ & 2.6 & 1.8 & 1.3 & 1.6 & 1.0 & 1.6 & 1.2 & 1.7 & 1.0 \\
\hline $\mathrm{Fe}_{2} \mathrm{O}_{3}$ & 2.2 & 4.8 & 2.1 & 1.5 & 1.5 & 1.0 & 0.8 & 1.4 & 1.0 \\
\hline
\end{tabular}

Australia (AUS), Canada (CAN), Germany (GER), Israel (ISR), United States of America (USA) Commercial Laboratory (Com), Utility (Gen), Government (Gov), Producer (Prd)

Green: Certified; Orange: Reference; Blue: Routine; Black: $>3 \%$ analytical error.

\section{ASTM Standard}

In the case of major and minor analysis ASTM has met or approaches the goal of producing a standard (ASTM D 4326) that is suitable for routine analysis. ASTM D 4326 employs a fluxing 
agent to fuse the sample followed by an X-Ray Fluorescence (XRF) finish. The most notable exception to an acceptable performance rating of 3 or less for $\mathrm{D} 4326$ is $\mathrm{SO}_{3}$. This rating actually reflects the impact of the fusion preparation technique on the recovery of sulfur. A certain amount of $\mathrm{SO}_{3}$ is always lost in the fusion step. Because different laboratories use different fluxing agents and sample weights, the amount of $\mathrm{SO}_{3}$ lost varies significantly from laboratory to laboratory resulting in the poor performance ratio. This variable loss of $\mathrm{SO}_{3}$ does not affect the other analytes as loss on fusion is taken into account in the X-Ray corrections.

Examining the performance ratios of D 4326 for the remaining major and minor analytes suggests a trend to better performance with increasing atomic number as would be expected for XRF.

It is also notable that Laboratory 1, which employs XRF, does not perform as well as laboratories $70,105,119,144$ and 174, all of which use an ICP finish. ICP would be expected to perform better than XRF for low atomic number analytes. It is also interesting that laboratories employing ICP, which can be notorious for producing variable $\mathrm{K}_{2} \mathrm{O}$, do not perform as well as laboratory 1 for $\mathrm{K}_{2} \mathrm{O}$.

Essentially, the major and minor element results from table A.2.2 shows the various finish techniques perform exactly the way they would be expected to perform with respect to their underlying physical and chemical principles.

\section{Inorganic Geochemistry Laboratory Major and Minor Analysis}

Excluding sulfur for the reasons stated above and $\mathrm{Na}_{2} \mathrm{O}$, which is determined from another preparation step, the IGL (135) does not meet the performance goal for 5 of the eight remaining major and minor elements in coal derived ash. This trend was initially identified for $\mathrm{SiO}_{2}$ weight percent in the preliminary audit (Appendix A.1).

The laboratories achieving the highest level of performance are 144, 119, 174 and 70 . All of these laboratories use an ICP finish similar to that employed by the USGS. Of these four labs, laboratory 144 and laboratory 174 use the nitric, hydrochloric and hydrofluoric acid mix described in ASTM D 6357 followed by a hot block digestion.

Using the same acid hot block digestion procedure Laboratory 174 achieved the highest level of performance for trace element analysis along with the IGL 135, which also employs an acid digest for trace elements.

This supports the observation in the preliminary audit that the IGL sinter preparation procedure produces inconsistent recovery of certain major and minor constituents from coal derived ash, most likely due to the very low temperature $\left(450^{\circ} \mathrm{C}\right)$ at which the sinter is conducted.

\section{Recommendation 2: Modification of Sample Digestion Procedure}

The IGL should convert to the acid mix prescribed in ASTM D 6357, followed by hot block digestion for dissolution of coal-derived ash. This would create a single digestion procedure adequate for major, minor and trace elements significantly reducing operator time and consumables while, at the same time, improving the safety of the preparation step. During commissioning of this 
method, the IGL should conduct duplicate analysis of CANSPEX ${ }^{\mathrm{TM}}$ ash samples 2000-4 to 2004-2 on two separate days. These results can be used to reevaluate the performance of the IGL for major and minor element analysis.

\section{Coal Analysis}

A comparison of the major and minor element results from the IGL (135), Geochemical Testing (38), and 7 other laboratories is presented in table A.2.3.

Table A.2.3. Coal analysis performance ratios.

\begin{tabular}{|c|c|c|c|c|c|c|c|c|c|c|c|c|c|c|}
\hline Laboratory & ASTM & $\mathbf{1 3 5}$ & $\mathbf{3 8}$ & $\mathbf{1}$ & $\mathbf{7 0}$ & $\mathbf{1 1 7}$ & $\mathbf{1 1 9}$ & $\mathbf{1 2 2}$ & $\mathbf{1 4 4}$ & $\mathbf{1 4 6}$ & $\mathbf{1 5 1}$ & $\mathbf{1 5 9}$ & $\mathbf{1 7 4}$ & $\mathbf{1 7 6}$ \\
\hline Country & International & USA & USA & CAN & AUS & USA & GER & USA & USA & CHN & USA & USA & USA & NLD \\
\hline Class & Reference & Gov & Com & Gov & Gov & Edu & Gen & Edu & Prd & Gov & Com & Gen & Com & Com \\
\hline Ash & 1.1 & & $\mathbf{0 . 6}$ & 0.4 & $\mathbf{0 . 4}$ & & 0.3 & & 0.8 & 0.8 & & & 0.5 & 0.5 \\
\hline Volatile & 1.5 & & 0.7 & 0.9 & & & 0.6 & & 1.5 & 1.0 & $\mathbf{9 . 1}$ & & 1.3 & 1.9 \\
\hline Btu/lb & 2.2 & & 0.9 & 1.6 & & & 1.6 & & 2.5 & 1.7 & $\mathbf{3 . 2}$ & & 1.2 & 2.4 \\
\hline Carbon & 1.3 & & 0.5 & 0.4 & & & 0.4 & & 0.6 & 0.5 & 1.4 & & 1.1 & 1.0 \\
\hline Hydrogen & 2.8 & & 1.1 & 1.1 & & & 0.7 & & 1.5 & 1.4 & 2.4 & & 2.1 & 1.6 \\
\hline Nitrogen & $\mathbf{3 . 6}$ & & 1.8 & 1.4 & & & 1.2 & & $\mathbf{4 . 1}$ & 1.8 & $\mathbf{4 . 6}$ & & 2.5 & 1.3 \\
\hline Sulfur & 2.3 & 1.9 & 1.6 & 0.8 & & & 1.1 & & 1.0 & 2.1 & 2.2 & & 1.1 & 2.2 \\
\hline Chlorine & 1.3 & $\mathbf{2 2 . 6}$ & $\mathbf{8 . 2}$ & $\mathbf{4 . 8}$ & 1.9 & & $\mathbf{3 . 7}$ & & $\mathbf{6 . 2}$ & & 1.9 & & 1.9 & \\
\hline Mercury & $\mathbf{0 . 7}$ & 1.8 & 1.7 & & $\mathbf{0 . 9}$ & 1.3 & & 0.9 & 1.5 & & & $\mathbf{0 . 6}$ & 1.8 & \\
\hline
\end{tabular}

Australia (AUS), Canada (CAN), Germany (GER), Israel (ISR), United States of America (USA) Commercial Laboratory (Com), Utility (Gen), Government (Gov), Producer (Prd), University Research (Edu)

Green: Certified; Orange: Reference; Blue: Routine; Black: >3\% analytical error; BLANK: Not analyzed.

\section{ASTM Standards}

With the exception of nitrogen, it is evident the ASTM reference standards meet the requirement of being suitable for routine analysis. A cooperative study between ASTM and ISO is to be undertaken in 2005 to further improve the reliability of methods for carbon, hydrogen, and nitrogen analysis.

\section{Inorganic Geochemistry Laboratory Coal Analysis}

\section{$\underline{\text { Sulfur in Coal }}$}

The IGL (135) achieved a reference quality level of performance for sulfur well within the performance rating of the ASTM reference standard. The Canadian lab, which achieved by far the highest level of performance for sulfur employs certified reference materials (CRMs) and reference materials (RMs) from at least two independent sources for calibration of the sulfur analyzer. This laboratory also exercises all of the precautions cited in the section on Laboratory Performance that 
describes how to control environmental, sample preparation, and instrument conditions to achieve a low performance ratio for sulfur. A recommendation to further improve the reliability of sulfur analysis through the use of calibrants from independent sources was made to the USGS in the preliminary audit report (Appendix A.1). This recommendation, which has been implemented, should result in the IGL approaching or performing at the certified level.

\section{Chlorine in Coal}

Studies conducted by The Electric Power Institute (EPRI) and the International Organization for Standardization (ISO) have demonstrated the Eschka ignition method employed by the IGL for preparation of coal samples for chlorine analysis yields highly erratic and inconsistent recovery. This is reflected in the extremely high performance ratio of 22.6 (table A.2.3).

ASTM D 6721 is the benchmark method for chlorine. ASTM D 6721, published for use in late 2001, consistently produces chlorine results of reference quality. Standards that predate D 6721 (D 2361 and D 4208) are not capable of producing results of even routine quality. The performance table A.2.3 covers a period during which laboratories were constrained to use standards similar to D 2361 and D 4208. Laboratories 1, 38 and 144 employ ASTM D 4208. Laboratories 151 and laboratory 174 have converted to, or are employing methods similar to D 6721. Both of these laboratories are approaching the desired performance goal. The Australian laboratory 70 employs XRF.

\section{Recommendation 3: Conversion to ASTM D 6721 for Chlorine Analysis}

The preliminary audit (Appendix A.1) recommended that IGL convert to ASTM D 6721. During commissioning of this method, the IGL should conduct duplicate analysis of CANSPEX ${ }^{\mathrm{TM}}$ coal samples 2000-4 to 2004-2 on two separate days. These results can be used to reevaluate the performance of the IGL for chlorine analysis.

\section{Mercury in Coal:}

The IGL consistently produces reference quality mercury results. Laboratory 122 and laboratory 159 , which employ the ASTM reference method for mercury, D 6722 produce certified quality data, which meets or approaches that of the ASTM reference standard. The preliminary IGL audit (Appendix A.1) and this more extensive assessment are based on IGL results from a procedure based on wet oxidation of the test sample that complies with ASTM D 6414. Laboratories 117 and 144 employ an acid extraction method that complies with ASTM D 6414. The Australian laboratory 70 employs a variation of method D 6414 that promotes uniform and continuous refluxing of the sample to ensure complete extraction of mercury. The IGL has recently purchased a digestion apparatus that promotes uniform continuous acid reflux of the test sample. The purchase of this digestion apparatus along with implementation of recommendations with respect to selection and use of CRM coals should allow the IGL to produce certified quality results similar to the reference ASTM standard.

\section{Recommendation 4: Conversion to the acid extraction procedure per ASTM D 6414 for Mercury Analysis}


The IGL should convert to the acid extraction procedure described in ASTM D 6414 employing a hot block digestion for mercury analysis.

\section{Contract Coal Analysis: USGS Contract Laboratory Performance}

The contract laboratory (38) performs ash, volatile matter, Btu/lb, carbon, hydrogen, nitrogen, and sulfur analysis for the USGS (table A.2.3).

\section{Recommendation 5: The USGS Contract Laboratory Achieved the Highest Level of Performance for the Contract Parameters}

Table A.2.3 shows the USGS contract laboratory (38) easily meets the performance goal for all contract parameters. In fact, laboratory 38 achieved the highest level of performance for the contract parameters overall along with laboratory 1 from Canada and Laboratory 119 from Germany. The USGS should continue to monitor all contract laboratory analyses.

\section{APPENDIX A.2.X1: Cost Analysis Summary}

\section{Recommendations}

The recommendations provided in this report require a total capital investment of approximately $\$ 30,000$. In addition to significantly increasing the reliability of results, it is anticipated the USGS will recover the capital investment within 1 year and will realize an increased man-hour and consumable margin equivalent to $\$ 100,000$ over a period of 4 years, as well as achieving a safer operating environment. This was revised upward from the original total estimate of $\$ 85,720$ in table A.1.2 after final capital costs were finalized.

These estimates are summarized in the table A.2.X1.1.

Table A.2.X1.1. Estimated cost savings over a four year period for all recommendations.

\begin{tabular}{|c|c|c|c|c|c|c|}
\hline Recommendation & Description & Year $\mathbf{1}$ & Year $\mathbf{2}$ & Year $\mathbf{3}$ & Year 4 & Totals \\
\hline 3,4 & CRM/RM & $\$ 1,185$ & $\$ 645$ & $\$ 645$ & $\$ 645$ & $\mathbf{\$ 3 , 1 2 0}$ \\
\hline 3 & Analyzer (per ASTM D6721) & $\$ 11,850)$ & $\$ 13,150$ & $\$ 13,150$ & $\$ 13,150$ & $\mathbf{\$ 2 7 , 6 0 0}$ \\
\hline 1,2 & Hot Block & $\$ 15,250$ & $\$ 18,250$ & $\$ 18,250$ & $\$ 18,250$ & $\mathbf{\$ 7 0 , 0 0 0}$ \\
\hline Net Savings & & $\mathbf{\$ 4 , 5 8 5}$ & $\mathbf{\$ 3 2 , 0 4 5}$ & $\mathbf{\$ 3 2 , 0 4 5}$ & $\mathbf{\$ 3 2 , 0 4 5}$ & $\mathbf{\$ 1 0 0 , 7 2 0}$ \\
\hline
\end{tabular}

CRM: Certified Reference Material.

RM: Reference Material.

Negative values in parentheses.

Note: Year 1 for recommendations 1 and 2, and 3 include the purchase of an analyzer (per ASTM D6721) for chlorine and Hot Block for \$25,000 and \$3,000 respectively. 


\section{Appendix B}

\section{Phase 3: Reassessment Analyses, and On-site Audit Final Report}

Appendix B.1: Evaluation of Reassessment Results from Chlorine Determinations, March 19, 2005

Appendix B.2: Evaluation of Reassessment Results of IGL Digestion Procedures for Major Oxides, April 04, 2005

Appendix B.3: On-Site Evaluation of USGS IGL September 12- 14, 2005: October 10,2005

Appendix B.4: References for Cited Standards and Organizations

The following appendices do not conform to USGS form and style. They also contain multiple reference citations to standard methods and other contacts. To facilitate review of the documents the reference was not provided every time a standard test method or organizational contacts were cited. Information regarding these citations is provided Appendix B.4. 


\section{Appendix B.1 \\ Phase 3: Evaluation of Reassessment Results from Chlorine Determinations}

\section{Performance Audit of U.S. Geological Survey Inorganic Geochemistry and Contract Laboratories}

Requisition \#3-2920-1052

March 19, 2005

Louis Janke, President

Quality Associates International ${ }^{\circledR}$, LDT.

P.0. Box 117

Douglas, ON KOJ 1 SO

Canada

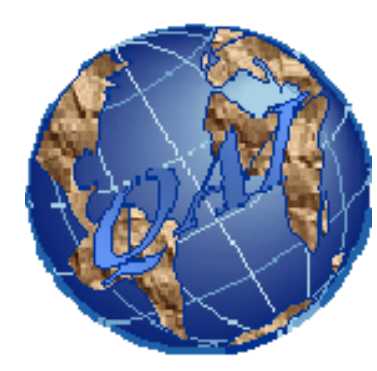




\section{Quality Associates International (QAI) Findings: (Lou Janke)}

The U.S. Geological Survey (USGS), Inorganic Geochemistry Laboratory (IGL produced chlorine (Cl) results employing ASTM D 6721 for 20 samples distributed through CANSPEX ${ }^{\mathrm{TM}}$ from 2000 to 2004 that exhibit a marked improvement in accuracy without any degradation in precision particularly, for samples with less than $500 \mu \mathrm{g} / \mathrm{g} \mathrm{Cl}$. The CANSPEX ${ }^{\mathrm{TM}}$ samples cover a wide range of coal rank and grade and represent coals from 9 different countries. No other CANSPEX ${ }^{\mathrm{TM}}$ laboratory achieved as high a level of performance for these 20 CANSPEX ${ }^{\mathrm{TM}}$ samples. The results of this assessment are summarized in tables B.1.1 and B.1.2.

\section{USGS Inorganic Geochemistry Laboratory (IGL) Findings: (John Bullock)}

To obtain an initial $\mathrm{Cl}$ estimate use a $10 \mathrm{mg}$ test portion of coal.

Employ $100 \mathrm{mg}$ of tungsten promoter for low weight, high $\mathrm{Cl}$ samples and $200 \mathrm{mg}$ tungsten promoter for high weight low $\mathrm{Cl}$ samples. Intimate mixing of the promoter with the coal is recommended.

The method blank is carried out on $200 \mathrm{mg}$ of tungsten. The blank can be adjusted for lower weights of tungsten based on the $200 \mathrm{mg}$ blank.

For low $\mathrm{Cl}$ samples, take care in mixing the tungsten promoter with the coal sample as loss of material can occur. If this occurs, then the sample must be reweighed.

The current instrument plumbing results in the buildup of latent moisture, which appears to generate a residual signal that adds as much as 5 minutes to the total analysis time. The IGL is reconfiguring instrument plumbing to minimize this problem. The same 20 CANSPEX ${ }^{\mathrm{TM}}$ samples shall be rerun with the new configuration to confirm that the accuracy and precision are not adversely affected.

\section{Data evaluation:}

Duplicate results were reported by the IGL for the 20 samples (Table B.1.1).

The precision and accuracy of the IGL results were evaluated using the CANSPEX ${ }^{\mathrm{TM}}$ most likely value standard deviation (MLV 1S) derived from all $\mathrm{Cl}$ results reported to CANSPEX ${ }^{\mathrm{TM}}$. The MLV 1S takes into account sample inhomogeneity as well as the diverse methods and control materials employed by CANSPEX ${ }^{\mathrm{TM}}$ laboratories for the determination of chlorine.

A result that agrees with the CANSPEX ${ }^{\mathrm{TM}}$ value within the MLV 1S is green and is considered to be certified quality. A result that agrees with the CANSPEX ${ }^{\mathrm{TM}}$ value within 2 times the MLV 1S is blue and is considered to be reference quality. A result that agrees with the CANSPEX ${ }^{\mathrm{TM}}$ value within 3 times the MLV 1S is orange and is considered to be routine quality. A value greater than 3 times the MLV 1S estimate is red and is considered suspect. 
Similarly, precision that is less than or equal to the CANSPEX ${ }^{\mathrm{TM}}$ MLV $1 \mathrm{~S}$ is green and is considered to be certified quality. Precision that is less than or equal to 2 times the CANSPEX ${ }^{\mathrm{TM}}$ MLV is blue and is considered to be reference quality. Precision that is less than or equal to 3 "times the CANSPEXTM MLV 1S is orange and is considered to be routine quality. Precision greater than 3 times the MLV $1 \mathrm{~S}$ is red and is considered suspect.

Table B.1.1. USGS IGL raw chlorine data.

\begin{tabular}{|c|c|c|c|c|c|c|c|c|}
\hline CANSPEX $^{\mathrm{TM}}$ & $\begin{array}{l}\text { CANSPEX } \\
\text { Ash Value }\end{array}$ & $\begin{array}{c}\text { CANSPEX } \\
\text { S Value } \\
\end{array}$ & $\begin{array}{c}\text { CANSPEX } \\
\text { CI Value }\end{array}$ & MLV 1S & \begin{tabular}{|c|} 
USGS \\
D6721 \\
Accuracy \\
\end{tabular} & \begin{tabular}{|c|} 
USGS D \\
6721 \\
Precision
\end{tabular} & \begin{tabular}{|c|} 
USGS \\
Eschka/IC \\
Accuracy \\
\end{tabular} & $\begin{array}{c}\text { USGS } \\
\text { Eschka/IC } \\
\text { Precision }\end{array}$ \\
\hline 2004-4 Australia mvb & 13.50 & 0.31 & 100 & 20 & 86 & 4 & & \\
\hline 2004-3 Indonesia hvCb & 7.34 & 0.37 & 37 & 12 & 17 & 1 & & \\
\hline 2004-2 Australia hvAb & 10.71 & 0.52 & 213 & 21 & 230 & 2 & 295 & 17 \\
\hline 2004-1 ISGS hvBb & 9.54 & 4.31 & 135 & 17 & 116 & 4 & & \\
\hline 2003-4 Venezuela hvAb & 5.44 & 0.67 & 214 & 24 & 200 & 4. & 341 & 14 \\
\hline 2003-3 USA hvAb & 8.51 & 0.92 & 1483 & 53 & 1568 & 40 & 1480 & 28 \\
\hline 2003-2 Canada subA & 24.32 & 0.25 & 67 & 22 & 12 & 1 & & \\
\hline 2003-1 Canada ligA & 21.17 & 0.92 & 92 & 30 & 16 & 1 & 292 & 13 \\
\hline 2002-4 NIST 2693 mvb & 9.43 & 0.46 & 384 & 30 & 373 & 5 & 898 & 17 \\
\hline 2002-3 UK hvAb & 19.18 & 1.90 & 4854 & 156 & 5444 & 80 & 4662 & 263 \\
\hline 2002-2 UK hvAb & 18.38 & 2.67 & 2317 & 71 & 2357 & 34 & 2321 & 205 \\
\hline 2002-1 USGS mvb & 6.28 & 1.54 & 1093 & 68 & 1045 & 30 & 1255 & 82 \\
\hline 2001-4 USA hvAb & 8.10 & 0.74 & 1900 & 114 & 1928 & 8 & 1838 & 64 \\
\hline 2001-3 USA hvAb & 9.66 & 0.77 & 2000 & 79 & 2054 & 6 & 2132 & 38 \\
\hline 2001-2 USA hvAb & 8.28 & 1.30 & 1963 & 78 & 2044 & 4 & 2090 & 5 \\
\hline 2001-1 Spain hvCb & 6.82 & 3.58 & 66 & 16 & 22 & 1 & $<150$ & \\
\hline 2000-4 Germany mvb & 7.00 & 0.70 & 1172 & 59 & 1117 & 8 & 1126 & 9 \\
\hline 2000-3 China an & 13.04 & 0.12 & 569 & 33 & 568 & 9 & & \\
\hline 2000-2 NIST 2692b hvAb & 7.89 & 1.17 & 1601 & 80 & 1575 & 33 & & \\
\hline 2000-1 ISGS IBC 105 & 17.96 & 4.27 & 877 & 39 & 811 & 23 & & \\
\hline
\end{tabular}

Green: Less than or equal to the CANSPEX ${ }^{\mathrm{TM}}$ MLV 1S

Blue: Less than or equal to 2 times the CANSPEX ${ }^{\mathrm{TM}}$ MLV $1 \mathrm{~S}$

Orange: Less than or equal to 3 times the CANSPEX ${ }^{\mathrm{TM}}$ MLV 1S

Red: Precision greater than 3 times the MLV 1S

BLANK: Not analyzed

The IGL precision for all 20 samples is green and can be considered of certified quality. Of the 20 samples reported by the IGL, 11 exhibit certified accuracy(green), 5 reference accuracy (orange), 3 routine accuracy (blue) and 1 sample 2002-3 is suspect (red). No other CANSPEX ${ }^{\mathrm{TM}}$ laboratory achieved this high a level of performance for these 20 CANSPEX $^{\mathrm{TM}}$ samples. The results submitted by the IGL using the former Eschka ignition Ion Chromatography (IC) finish are provided for comparison purposes.

The ash and sulfur content of each CANSPEX ${ }^{\mathrm{TM}}$ sample is listed. These two characteristics are known to have a critical impact on the precision and accuracy of chlorine results from other 
commonly employed methods including XRF, bomb decomposition with an ISE, or IC finish, and Eschka ignition with an ISE, or IC finish. There does not appear to be any relationship between these parameters and the determination of chlorine by D 6721.

Method D 6721 is calibrated and controlled employing an aromatic organochlorine compound. Many laboratories reporting $\mathrm{Cl}$ results to $\mathrm{CANSPEX}{ }^{\mathrm{TM}}$ employ a variety of certified reference material (CRM) coals from different certifying agencies for calibration and control. Different calibration and control materials can introduce a bias into laboratory results.

Most likely value estimation was applied to the raw chlorine data submitted by the IGL to estimate and apply a correction for calibration and control bias. This correction has no effect on laboratory precision. The results are summarized in table B.1.2.

Table B.1.2. USGS IGL Chlorine results corrected for calibration and control bias.

\begin{tabular}{|c|c|c|c|c|c|c|c|c|}
\hline CANSPEX $^{\mathrm{TM}}$ & $\begin{array}{l}\text { CANSPEX } \\
\text { Ash Value }\end{array}$ & $\begin{array}{l}\text { CANSPEX } \\
\text { S Value }\end{array}$ & $\begin{array}{l}\text { CANSPEX } \\
\text { CI Value }\end{array}$ & $\begin{array}{c}\text { MLV } \\
1 S\end{array}$ & $\begin{array}{c}\text { USGS D } \\
6721 \\
\text { Accuracy }\end{array}$ & $\begin{array}{c}\text { USGS D } \\
6721 \\
\text { Precision }\end{array}$ & \begin{tabular}{|c} 
USGS \\
Eschka/IC \\
Accuracy
\end{tabular} & \begin{tabular}{|c} 
USGS \\
Eschka/IC \\
Precision
\end{tabular} \\
\hline 2004-4 Australia mvb & 13.50 & 0.31 & 100 & 20 & 99 & 4 & & \\
\hline 2004-3 Indonesia hvCb & 7.34 & 0.37 & 37 & 12 & 25 & 1 & & \\
\hline 2004-2 Australia hvAb & 10.71 & 0.52 & 213 & 21 & 244 & 2 & 295 & 17 \\
\hline 2004-1 ISGS hvBb & 9.54 & 4.31 & 135 & 17 & 128 & 4 & & \\
\hline 2003-4 Venezuela hvAb & 5.44 & 0.67 & 214 & 24 & 216 & 4 & 341 & 14 \\
\hline 2003-3 USA hvAb & 8.51 & 0.92 & 1483 & 53 & 1603 & 40 & 1480 & 28 \\
\hline 2003-2 Canada subA & 24.32 & 0.25 & 67 & 22 & 26 & 1 & & \\
\hline 2003-1 Canada ligA & 21.17 & 0.92 & 92 & 30 & 36 & 1 & 292 & 13 \\
\hline 2002-4 NIST $2693 \mathrm{mvb}$ & 9.43 & 0.46 & 384 & 30 & 393 & 5 & 898 & 17 \\
\hline 2002-3 UK hvAb & 19.18 & 1.90 & 4854 & 156 & 5547 & 80 & 4662 & 263 \\
\hline 2002-2 UK hvAb & 18.38 & 2.67 & 2317 & 71 & 2404 & 34 & 2321 & 205 \\
\hline 2002-1 USGS mvb & 6.28 & 1.54 & 1093 & 68 & 1091 & 30 & 1255 & 82 \\
\hline 2001-4 USA hvAb & 8.10 & 0.74 & 1900 & 114 & 2003 & 8 & 1838 & 64 \\
\hline 2001-3 USA hvAb & 9.66 & 0.77 & 2000 & 79 & 2106 & 6 & 2132 & 38 \\
\hline 2001-2 USA hvAb & 8.28 & 1.30 & 1963 & 78 & 2095 & 4 & 2090 & 5 \\
\hline 2001-1 Spain hvCb & 6.82 & 3.58 & 66 & 16 & 33 & 1 & $<150$ & \\
\hline 2000-4 Germany mvb & 7.00 & 0.70 & 1172 & 59 & 1156 & 8 & 1126 & 9 \\
\hline 2000-3 China an & 13.04 & 0.12 & 569 & 33 & 590 & 9 & & \\
\hline 2000-2 NIST 2692b hvAb & 7.89 & 1.17 & 1601 & 80 & 1628 & 33 & & \\
\hline 2000-1 ISGS IBC 105 & 17.96 & 4.27 & 877 & 39 & 837 & 23 & & \\
\hline
\end{tabular}

Green: Less than or equal to the CANSPEX ${ }^{\mathrm{TM}}$ MLV $1 \mathrm{~S}$

Blue: Less than or equal to 2 times the CANSPEXTM MLV 1S

Orange: Less than or equal to 3 times the CANSPEX ${ }^{\mathrm{TM}}$ MLV 1S

Red: Precision greater than 3 times the MLV 1S

BLANK: Not analyzed

Of the 20 samples reported by the IGL 9, exhibit certified accuracy (green), 8 reference accuracy (blue), 2 routine accuracy (orange) and 1 sample (2002-3) remains suspect (red). 
At first glance there does not appear to be a significant change in the performance of the IGL with respect to accuracy. However, closer examination reveals that there is better agreement of the IGL value for samples with less than $500 \mu \mathrm{g} / \mathrm{g}$ chlorine. This suggests a discrepancy between D 6721 calibrated and controlled with the organochlorine compound and other methods calibrated and controlled with CRM coals. It is notable that the majority of CRM coals employed to calibrate and control chlorine measurements are in the order of $1,000 \mu \mathrm{g} / \mathrm{g}-2,000 \mu \mathrm{g} / \mathrm{g}$ chlorine $(\mathrm{Cl})$. 


\section{Appendix B.2 \\ Phase 3: Evaluation of Reassessment Results of USGS Digestion Procedures for Major Oxides}

Performance Audit of U.S. Geological Survey Inorganic Geochemistry and Contract Laboratories

Requisition \#3-2920-1052

April 04, 2005

Louis Janke, President

Quality Associates International ${ }^{\oplus}$, LDT.

P.0. Box 117

Douglas, ON KOJ 1 SO

Canada

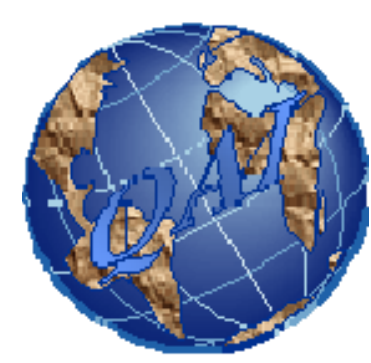




\section{Introduction}

Evaluation of CANSPEX ${ }^{\mathrm{TM}}$ data resulted in a recommendation that the U.S. Geological Survey (USGS), Inorganic Geochemistry Laboratory (IGL convert from a sinter-acid digestion procedure for decomposition and dissolution of coal derived ash to the mixed-acid decomposition and dissolution recommended in ASTM D 6349 with modifications recommended by CONSOL Research and Development during the development of ASTM D 6349.

The IGL performed the mixed-acid digestion on four separate test portions of $21 \mathrm{CANSPEX}^{\mathrm{TM}}$ samples covering the period of 1999 to 2004.

Evaluation of major oxide results from the mixed-acid digestion suggests significant solution-tosolution instability in the inductively coupled plasma (ICP) emission intensities is affecting the precision and accuracy of the major oxide results. The evaluation is summarized in this report.

\section{Summary of Approach}

Of the 21 samples subjected to the recommended mixed-acid digestion procedure, 18 are samples prepared by Quality Associates International ${ }^{\circledR}$ Ltd. (QAI). The remaining 3 are certified reference materials (CRMs) from three independent certifying bodies, the Canadian Certified Reference Materials Program (CCRMP), the National Institute of Standards and Technology (NIST) USA, and the USGS. These CRMs are employed world wide for the calibration and control of procedures employed for the determination of major oxides. The homogeneity of all three CRMs has been verified by the respective certifying agencies. To eliminate any objections concerning the homogeneity of the QAI samples, this evaluation is limited to results from the 3 CRMs.

\section{Data Evaluation}

This evaluation compares the results from the sinter-acid digestion procedure employed to produce the original CANSPEX ${ }^{\mathrm{TM}}$ results with results from the mixed-acid digestion procedure. The original CANSPEX ${ }^{\mathrm{TM}}$ samples were not ignited by the IGL prior to digestion. The samples subjected to mixed-acid digestion were subjected to a uniform ignition procedure by the IGL prior to digestion.

Values provided on the certificates issued by the respective certifying bodies were employed to calculate expected major oxide totals for the unignited and ignited CRM samples. These totals are summarized in Table B.2.1.

Table B.2.1. Expected major oxide totals (weight percent) for the unignited and ignited CRM samples.

\begin{tabular}{|c|c|c|c|}
\hline Source & Sample & $\begin{array}{c}\text { Expected Unignited } \\
\text { Total }\end{array}$ & $\begin{array}{c}\text { Expected Ignited } \\
\text { Total }\end{array}$ \\
\hline CCRMP & SY-4 & 94.75 & 99.27 \\
\hline NIST & $1633 b$ & 96.39 & 99.79 \\
\hline USGS & GSP-2 & 98.75 & 98.75 \\
\hline
\end{tabular}


The IGL confirmed all samples subjected to the mixed-acid digestion did not contain any visible residue. This suggests the entire sample is taken into solution by the mixed-acid digestion procedure. The IGL ran the 4 separate test portions of the each sample employing the following protocol.

Day 1

Sample 1 Portion 1, .....Sample 21, Portion 1.

Sample 1 Portion 2,......Sample 21, Portion 2.

Day 2

Sample 1 Portion 1, Sample 1 Portion 2, .....Sample 21, Portion 1, Sample 21, Portion 2.

The major oxide total was calculated for each sample test portion. These totals are summarized for the three CRMs in Table B.2.2 below.

Table B.2.2. The major oxide totals (weight percent basis).

\begin{tabular}{|c|c|c|c|c|c|c|c|c|}
\hline Source & CRM & $\begin{array}{c}\text { Digestion } \\
\text { Method }\end{array}$ & Ignited & Total 1 & Total 2 & Total 3 & Total 4 & $\begin{array}{c}\text { Expected } \\
\text { Total }\end{array}$ \\
\hline CCRMP & SY-4 & $\begin{array}{c}\text { Mixed- } \\
\text { Acid }\end{array}$ & Yes & 100.75 & 101.66 & 96.72 & 92.10 & 99.27 \\
\hline CCMRP & SY-4 & $\begin{array}{c}\text { Sinter- } \\
\text { Acid }\end{array}$ & No & 102.02 & 100.16 & 104.04 & 100.70 & 94.75 \\
\hline NIST & $1633 b$ & $\begin{array}{c}\text { Mixed- } \\
\text { Acid }\end{array}$ & Yes & 99.45 & 113.37 & 102.38 & 93.22 & 99.79 \\
\hline NIST & $1633 b$ & $\begin{array}{c}\text { Sinter- } \\
\text { Acid }\end{array}$ & No & 93.75 & 96.52 & 97.29 & 86.13 & 96.39 \\
\hline USGS & GSP-2 & $\begin{array}{c}\text { Mixed- } \\
\text { Acid }\end{array}$ & Yes & 99.87 & 102.29 & 100.37 & 97.90 & 98.75 \\
\hline USGS & GSP-2 & $\begin{array}{c}\text { Sinter- } \\
\text { Acid }\end{array}$ & Yes & 104.59 & 103.03 & 95.34 & 103.86 & 98.75 \\
\hline
\end{tabular}

The notable feature of this summary is that several totals in the table significantly exceed the expected total. This suggests sample-to-sample instrument drift in the measuring device (ICP) employed to determine the oxide values.

To assess whether instrument drift has an impact on the reliability of results, a correction was applied to each reported oxide value. The correction is applied as follows.

Corrected Oxide Value $=($ Reported Oxide Value $) \times[($ Total $) /($ Expected Total $)]$ 
If instrument drift is a contributing factor, the corrected oxide values should exhibit significantly improved precision (reduced spread in the test portion results) and acceptable accuracy (agreement with the certified value) for each test portion result.

The comparisons of reported and corrected oxide values $\left(\mathrm{SiO}_{2}, \mathrm{Al}_{2} \mathrm{O}_{3}, \mathrm{Fe}_{2} \mathrm{O}_{3}, \mathrm{CaO}, \mathrm{MgO}, \mathrm{Na}_{2} \mathrm{O}\right.$, $\mathrm{K}_{2} \mathrm{O}$ and $\mathrm{TiO}_{2)}$ for the $3 \mathrm{CRMs}$ are presented in figs. B.2.1-8. the x-axis of the graph specifies the oxide, the digestion method Acid (mixed-acid) or Sinter (sinter-acid). The results displayed are Rep (reported oxide value) or Corr (corrected oxide value), the CRM source and designation, and the year sequence the CRM was originally distributed through CANSPEX ${ }^{\mathrm{TM}}$. A green circle on the graph with a value listed in green to the left represents the certified oxide value. Vertical green bars accompany each green circle. These green bars are the acceptable accuracy limits that should been obtained under in-control routine analysis conditions. The horizontal blue bars are the day 1 (test portion 1 and test portion 2) results. The horizontal orange bars are the day 2 (test portion 3 and test portion 4) results.

\section{Observations:}

The conclusions below are based on the combined assessment of all of the graphs in figs. B.2.1-8. Table B.2.3 below summarizes whether the correction procedure described above yields improved precision and acceptable accuracy for the three CRM samples.

Table B.2.3. Comparison of precision and accuracy of corrected oxide vs. reported oxide values.

\begin{tabular}{|c|c|c|c|c|c|c|}
\hline \multirow{2}{*}{ Parameter } & \multicolumn{2}{|c|}{ Mixed-Acid } & \multicolumn{2}{c|}{ Sinter-Acid } & \multicolumn{2}{c|}{ Acid-Old } \\
\cline { 2 - 7 } & $\begin{array}{l}\text { Improved } \\
\text { Precision }\end{array}$ & $\begin{array}{c}\text { Acceptable } \\
\text { Accuracy }\end{array}$ & $\begin{array}{l}\text { Improved } \\
\text { Precision }\end{array}$ & $\begin{array}{l}\text { Acceptable } \\
\text { Accuracy }\end{array}$ & $\begin{array}{l}\text { Improved } \\
\text { Precision }\end{array}$ & $\begin{array}{l}\text { Acceptable } \\
\text { Accuracy }\end{array}$ \\
\hline $\mathbf{S i O}_{2}$ & Yes All & Yes All & Yes All & Yes All & & \\
\hline $\mathbf{A l}_{2} \mathbf{O}_{3}$ & Yes All & Yes All & No 1633b & No 1633b & & \\
\hline $\mathbf{F e}_{2} \mathbf{O}_{3}$ & Yes All & Yes All & Yes All & No 1633b & & \\
\hline $\mathbf{C a O}$ & Yes All & Yes All & $\begin{array}{c}\text { No } \\
1633 \mathrm{~b}, \text { SY-4 }\end{array}$ & $\begin{array}{c}\text { No } \\
1633 b, \text { SY-4 }\end{array}$ & & \\
\hline $\mathbf{M g O}$ & Yes All & Yes All & No 1633b & Yes All & & No \\
\hline $\mathbf{N a}_{2} \mathbf{O}$ & Yes All & Yes All & & & No & SY-4, GSP-2 \\
\hline $\mathbf{K}_{\mathbf{2}} \mathbf{O}$ & Yes All & Yes All & No 1633b & No SY-4 & & \\
\hline $\mathbf{T i O}_{2}$ & Yes All & No GSP-2 & Yes All & Yes All & & \\
\hline
\end{tabular}

It is evident from this table that there are significantly more quality exceptions for the sinter-acid and acid-old procedure than for the recommended mixed-acid digestion procedure. In particular, there are a significant number of exceptions for the NIST 1633b sample. The following explanations are offered for the trends observed in table B.2.3.

Of the three CRM samples NIST $1633 \mathrm{~b}$ is the only sample that contains combustible carbon. The amount is in the order of 3.4 weight percent. The NIST1633b test portions treated by the sinteracid digestion procedure were not preignited at a temperature sufficient to remove this combustible carbon. The IGL confirmed that the sinter-acid digestion solutions contained a visible gray residue. 
This residue not only has the potential to absorb soluble oxides but also to create erratic flow of the sample through the ICP nebulizer.

On the other hand, all three CRM samples were preignited at a temperature that not only eliminates combustible carbon, but also decomposes mineral carbonates, sulfides and hydrates prior to treatment by the recommended mixed-acid digestion procedure. Based on the above observation, all samples should be preignited as recommended in the section on preparation of ash in ASTM D $\underline{6349}$.

The original $\mathrm{Na}_{2} \mathrm{O}$ values reported to CANSPEX ${ }^{\mathrm{TM}}$ could not be obtained from the sinter-acid digestion as sodium peroxide $\left(\mathrm{Na}_{2} \mathrm{O}\right)$ is used in the sintering step. The $\mathrm{Na}_{2} \mathrm{O}$ values were obtained from an acid digestion procedure similar to the ASTM D 6349 mixed-acid digestion procedure with the exception the USGS acid digestion procedure which employs perchloric acid. This procedure is referred to as Acid-Old in this report. The Acid-Old $\mathrm{Na}_{2} \mathrm{O}$ values were determined on an entirely separate solution from all other oxides. However, the correction factor applied to the Acid-Old $\mathrm{Na}_{2} \mathrm{O}$ values is dominated by the total of oxides from the sinter-acid procedure. This amounts to extrapolation of a total from one sample to another and this can be dangerous.

On the other hand, all oxides are determined on the same solution prepared by the mixed-acid digestion procedure. As a result, it can be expected that the correction factor should be equally suitable for all oxides. This observation reveals a distinct advantage of a single mixed-acid digestion procedure over separate digestion procedures.

Finally, table B.2.3 above and the graphs in figs. B.2.1-8 that follow provide strong evidence that a significant shift in nebulization is occurring from sample to sample during the ICP analysis. This effect can be monitored and reconciled through the use of one or more internal standards added to each analysis solution.

\section{Follow up}

It is recommended that the IGL prepare two separate test portions of each ignited CRM material for ICP analysis using the recommended mixed-acid digestion procedure as well as the sinter-acid digestion procedure. The same internal standard should be added to each test solution. The test solutions should be run on two separate days in the following sequence.

Mixed-Acid Portion 1, Mixed-Acid Portion 2, Sinter-Acid Portion 1, Sinter-Acid Portion 2

The same analytical lines are to be used for all test solutions and oxide values, oxide intensities, and internal standard intensities should be reported for all test solutions. 


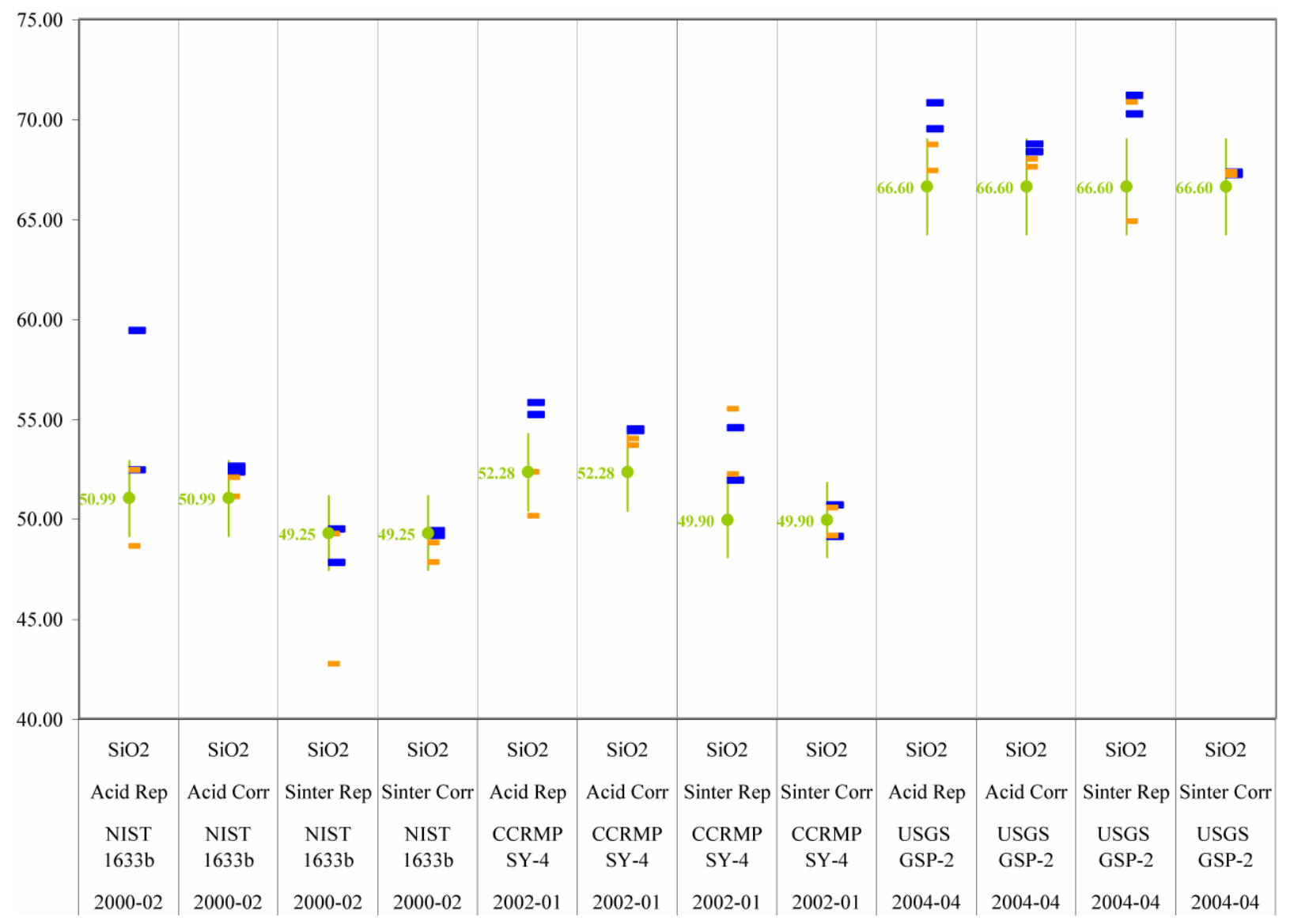

Figure B.2.1. The comparison of reported and corrected silica oxide values for the three certified reference materials. The $\mathrm{Y}$-axis is the weight percent concentration of the analyte. The X-axis of the graph specifies the oxide, the digestion method Acid (mixed-acid) or Sinter (sinter-acid), the results displayed Rep (reported oxide value) or Corr (corrected oxide value), the CRM source and designation and the year sequence the CRM was originally distributed.

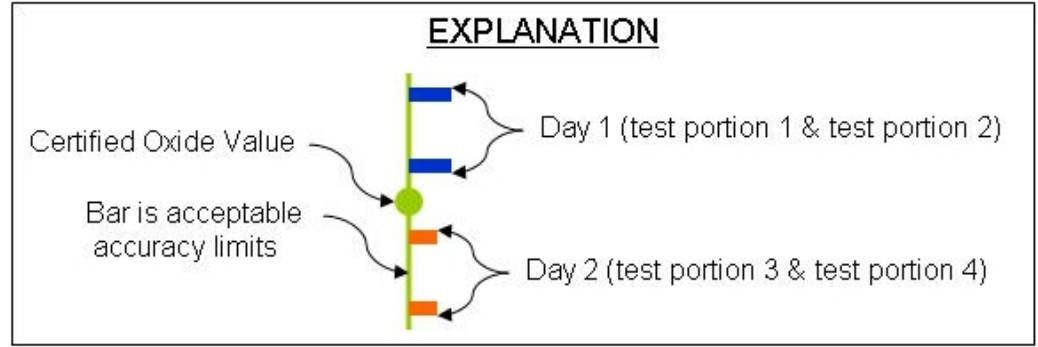




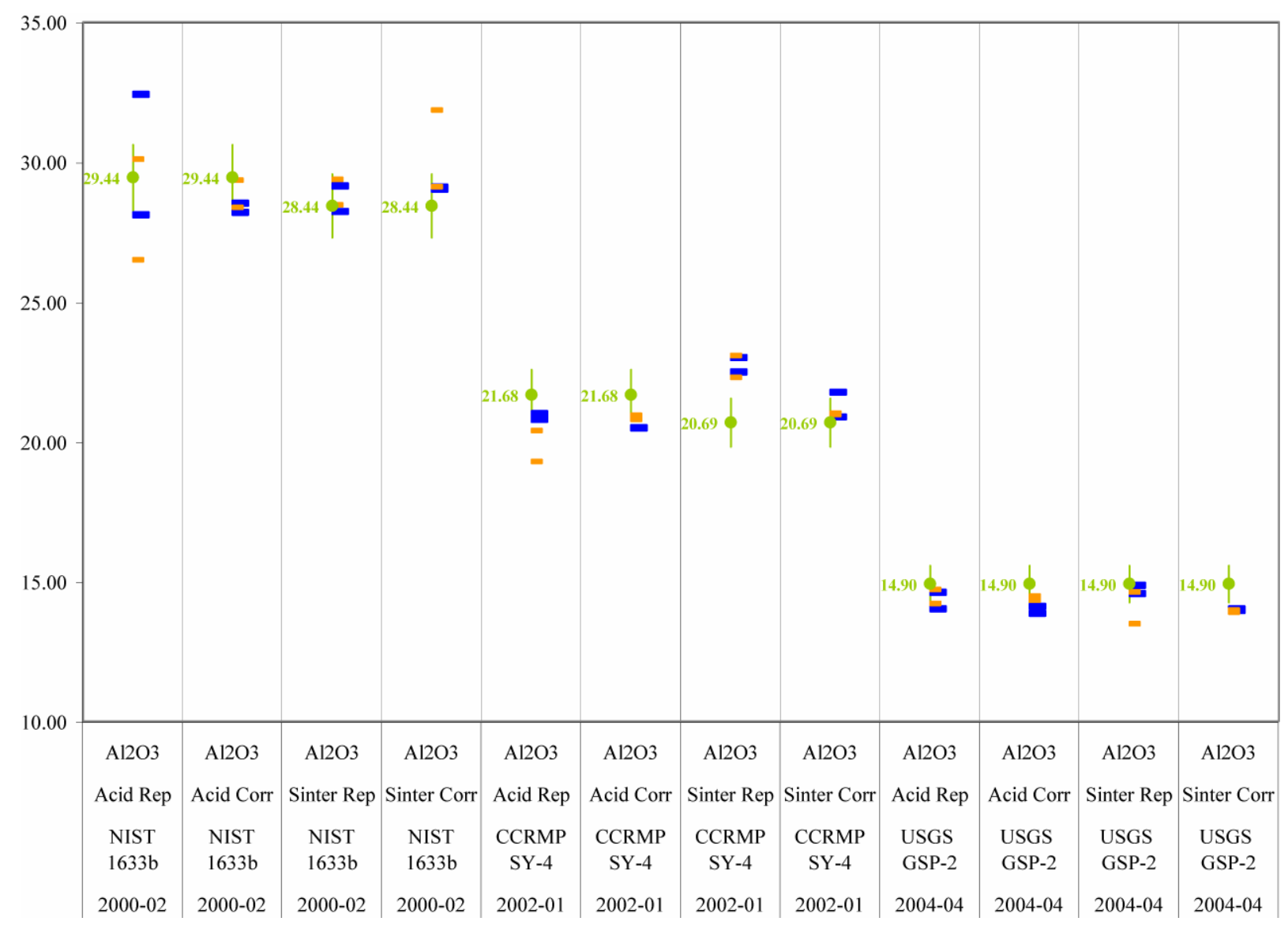

Figure B.2.2. The comparison of reported and corrected Aluminum oxide values for the three certified reference materials. The $\mathrm{Y}$-axis is the weight percent concentration of the analyte. The $\mathrm{x}-$ axis of the graph specifies the oxide, the digestion method Acid (mixed-acid) or Sinter (sinteracid), the results displayed Rep (reported oxide value) or Corr (corrected oxide value), the CRM source and designation and the year sequence the CRM was originally distributed.

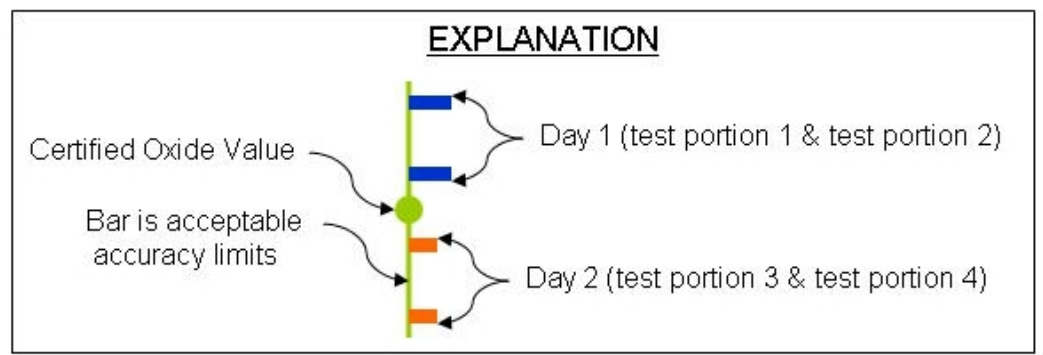




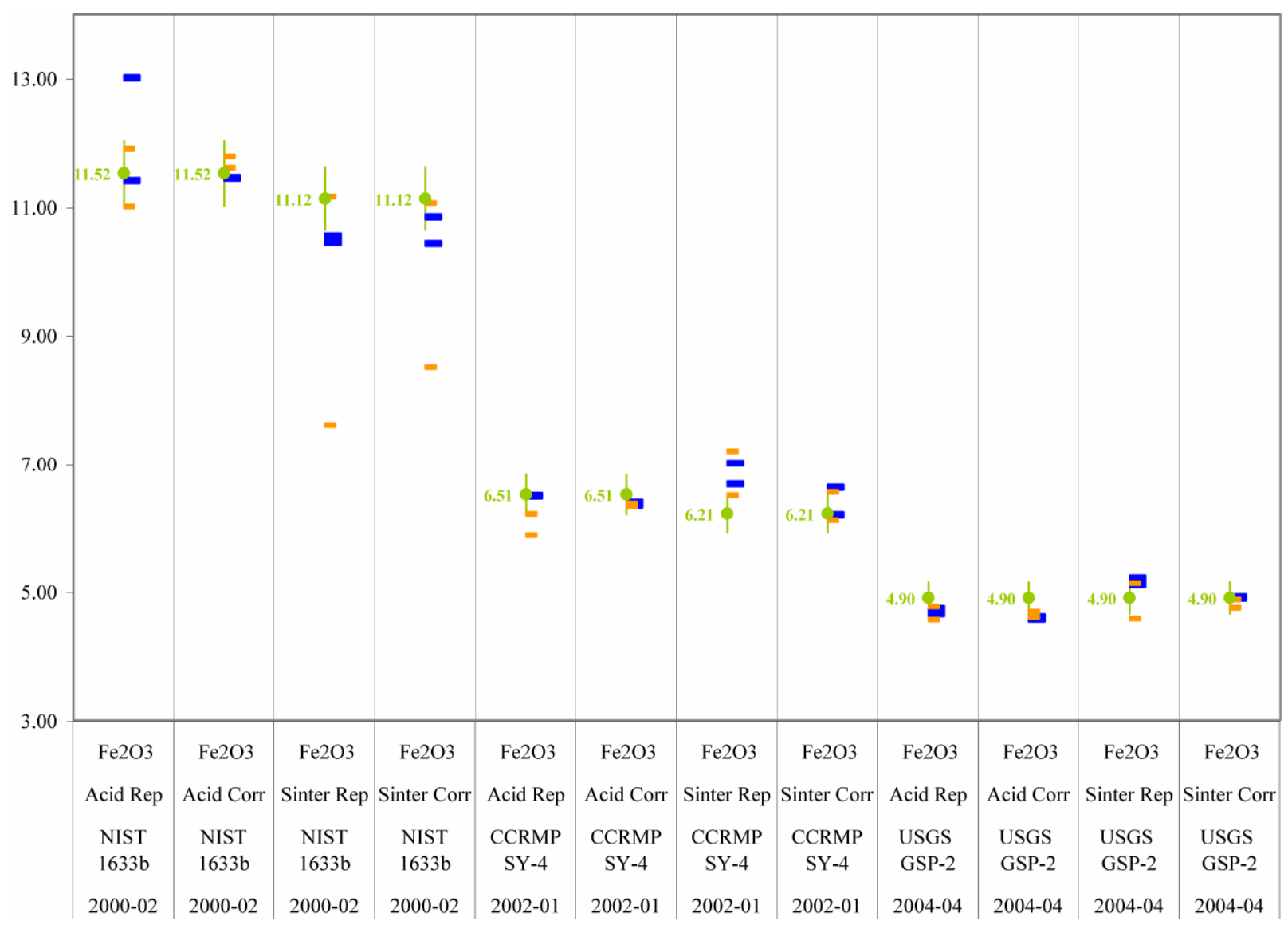

Figure B.2.3. The comparison of reported and corrected Iron oxide values for the three certified reference materials. The $\mathrm{Y}$-axis is the weight percent concentration of the analyte. The $\mathrm{x}$-axis of the graph specifies the oxide, the digestion method Acid (mixed-acid) or Sinter (sinter-acid), the results displayed Rep (reported oxide value) or Corr (corrected oxide value), the CRM source and designation and the year sequence the CRM was originally distributed.

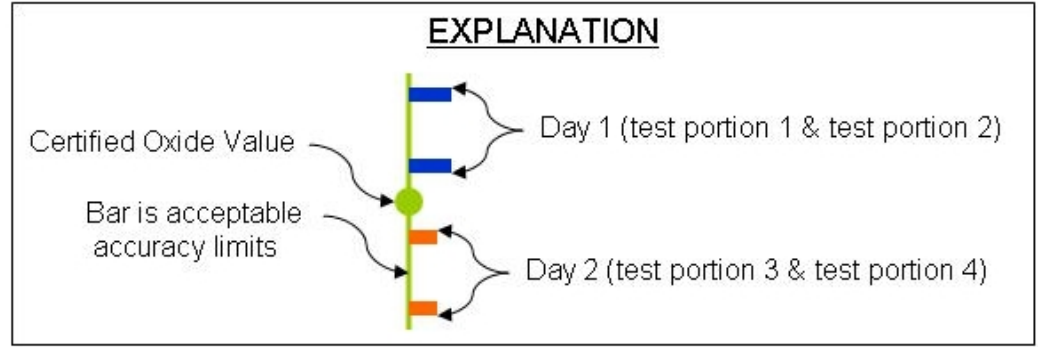




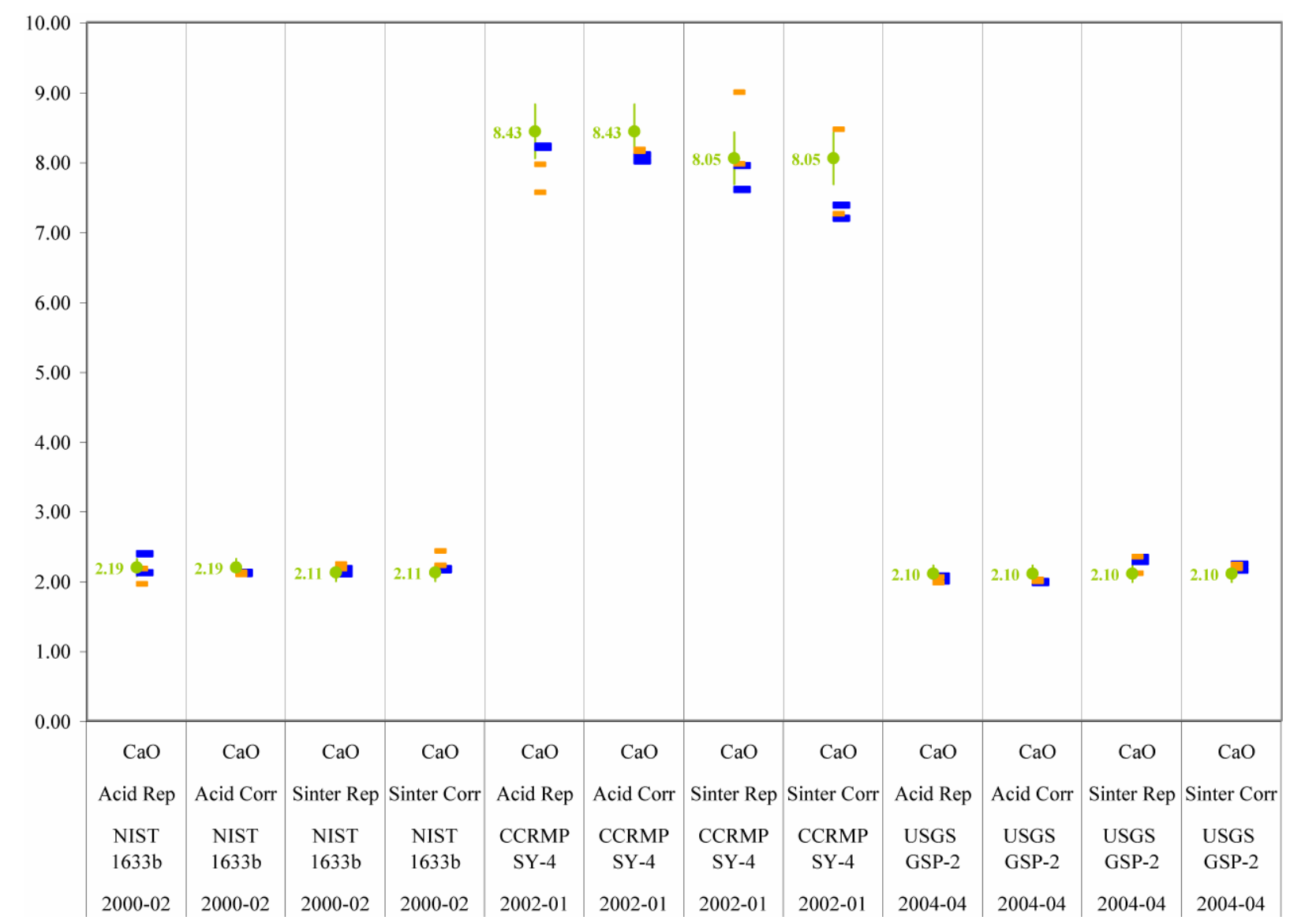

Figure B.2.4. The comparison of reported and corrected Calcium oxide values for the three certified reference materials. The Y-axis is the weight percent concentration of the analyte. The $\mathrm{x}-$ axis of the graph specifies the oxide, the digestion method Acid (mixed-acid) or Sinter (sinteracid), the results displayed Rep (reported oxide value) or Corr (corrected oxide value), the CRM source and designation and the year sequence the CRM was originally distributed.

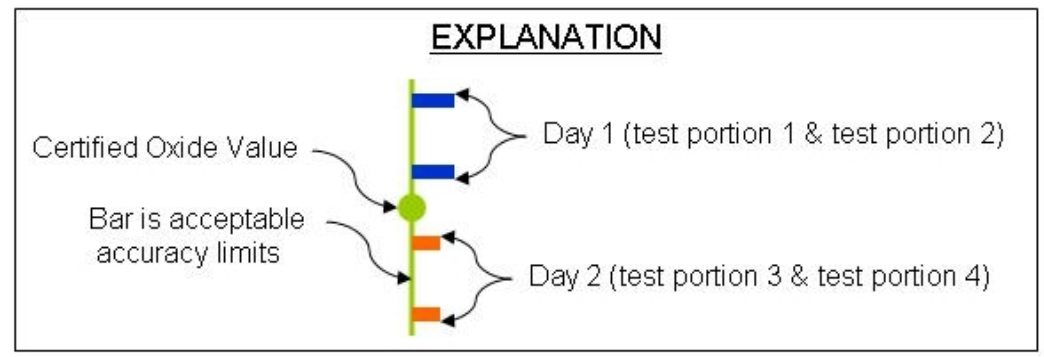




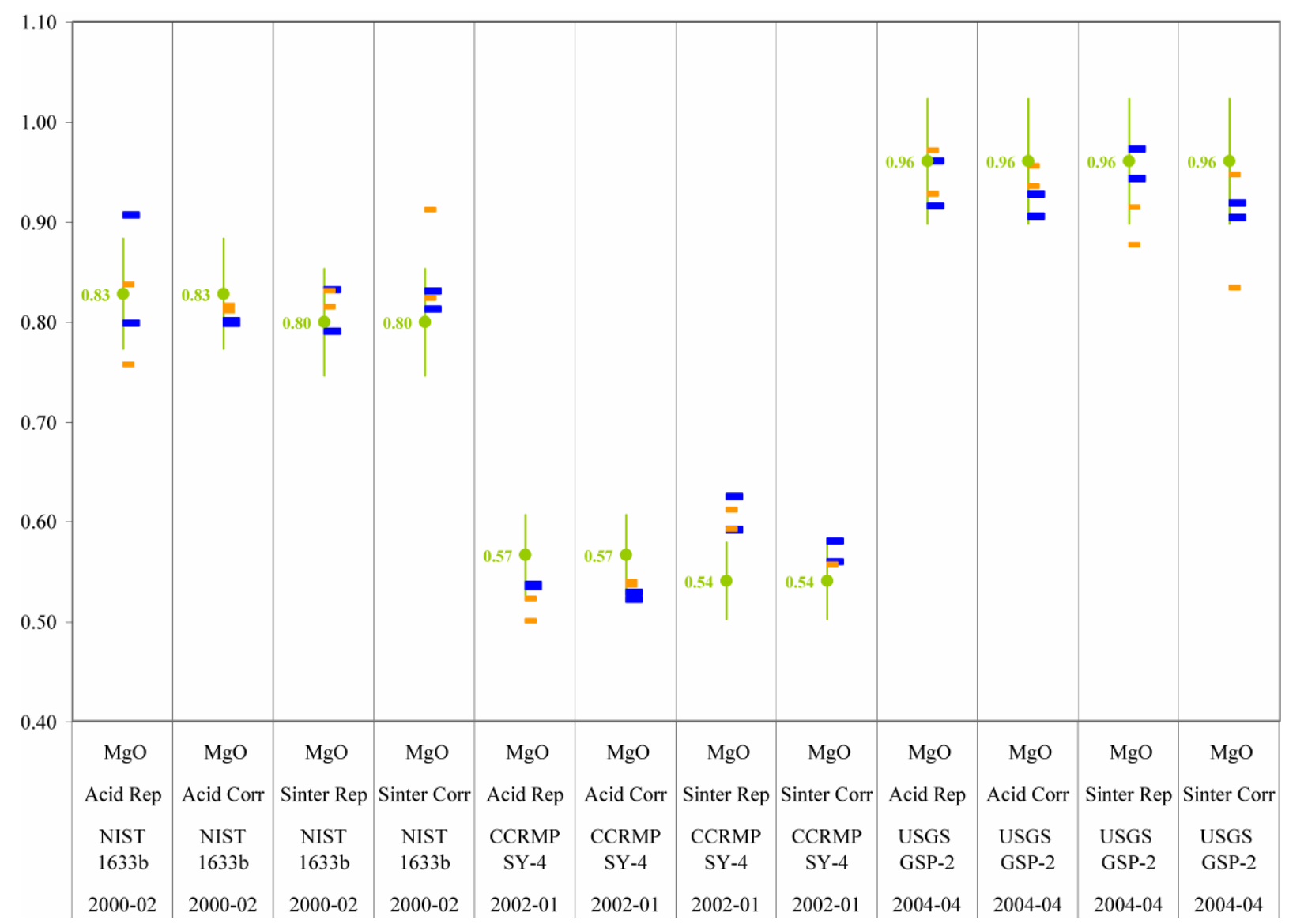

Figure B.2.5. The comparison of reported and corrected Magnesium oxide values for the three certified reference materials. The Y-axis is the weight percent concentration of the analyte. The $\mathrm{x}-$ axis of the graph specifies the oxide, the digestion method Acid (mixed-acid) or Sinter (sinteracid), the results displayed Rep (reported oxide value) or Corr (corrected oxide value), the CRM source and designation and the year sequence the CRM was originally distributed.

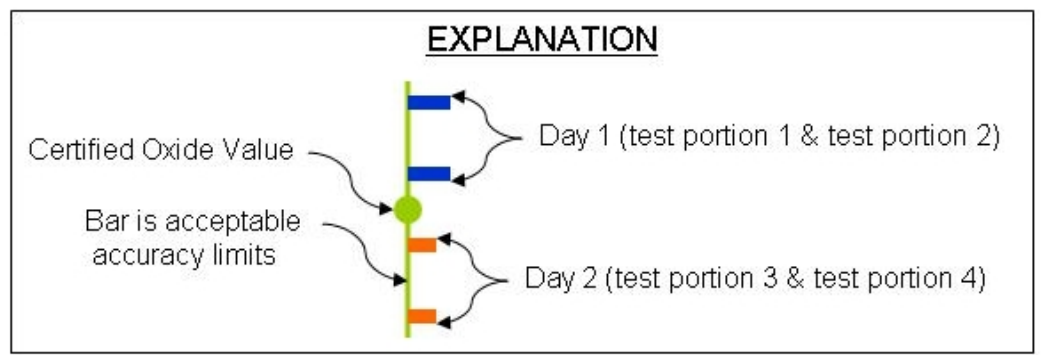




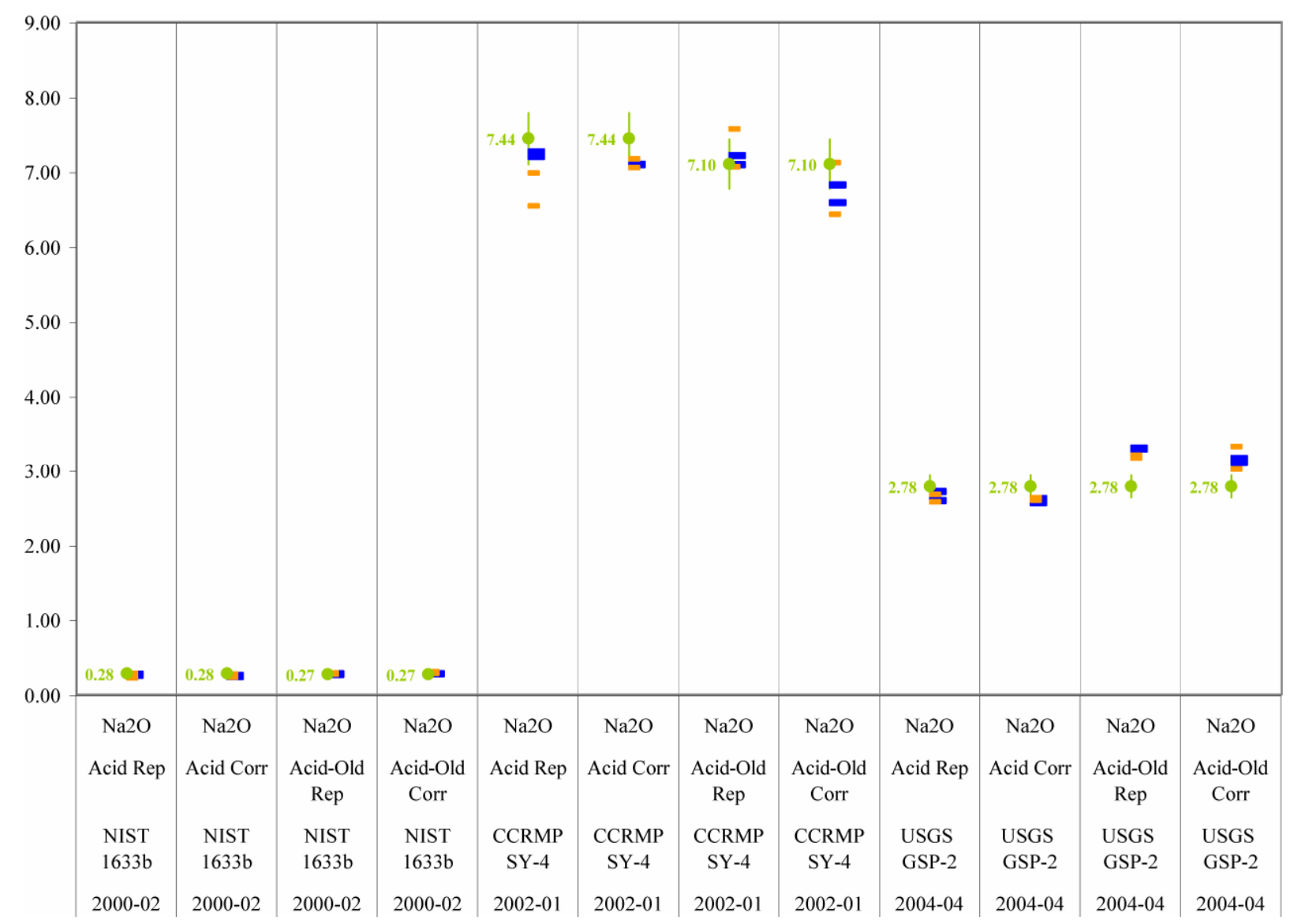

Figure B.2.6. The comparison of reported and corrected Sodium oxide values for the three certified reference materials. The $\mathrm{Y}$-axis is the weight percent concentration of the analyte. The $\mathrm{x}$ axis of the graph specifies the oxide, the digestion method Acid (mixed-acid) or Sinter (sinteracid), the results displayed Rep (reported oxide value) or Corr (corrected oxide value), the CRM source and designation and the year sequence the CRM was originally distributed.

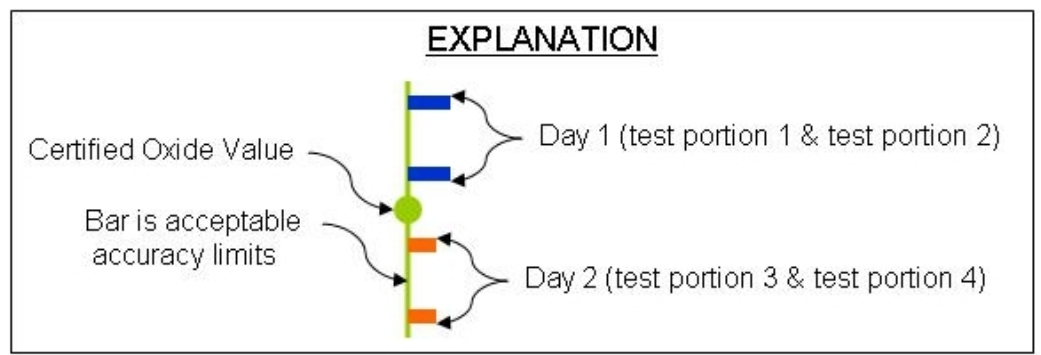




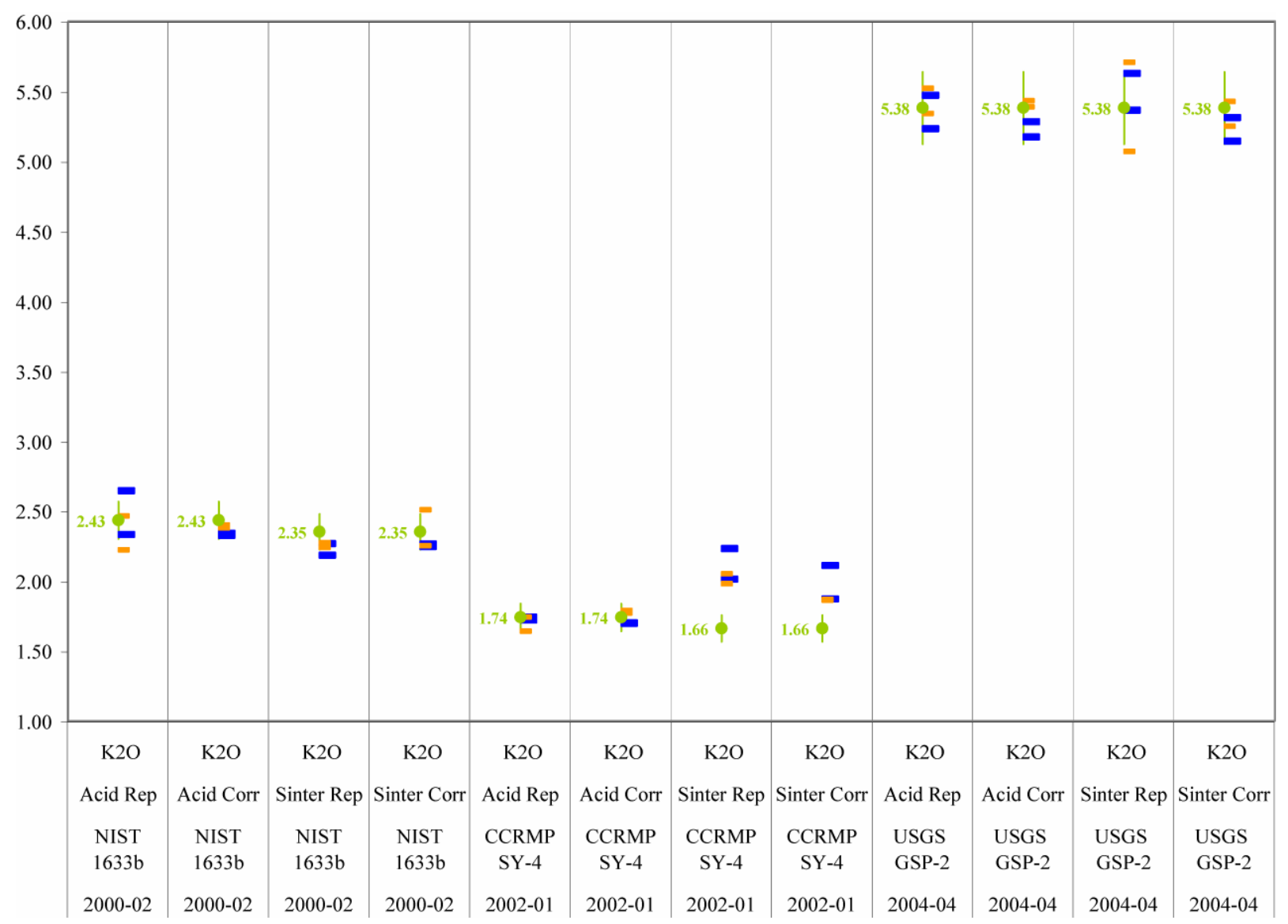

Figure B.2.7. The comparison of reported and corrected Potassium oxide values for the three certified reference materials. The $\mathrm{Y}$-axis is the weight percent concentration of the analyte. The $\mathrm{x}$ axis of the graph specifies the oxide, the digestion method Acid (mixed-acid) or Sinter (sinteracid), the results displayed Rep (reported oxide value) or Corr (corrected oxide value), the CRM source and designation and the year sequence the CRM was originally distributed.

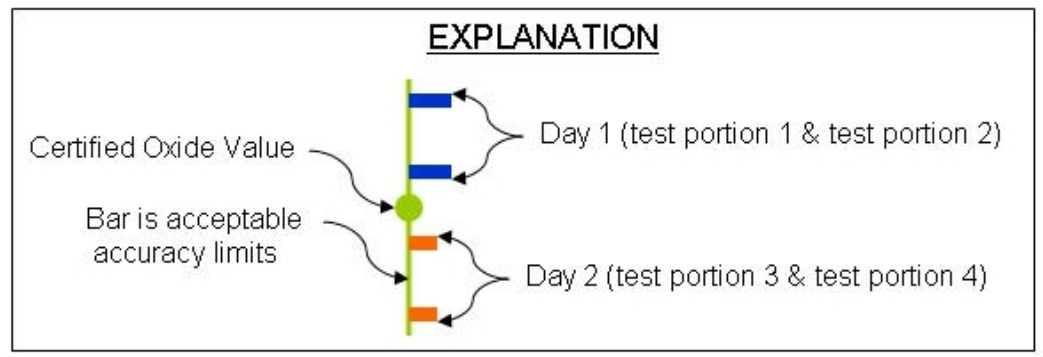




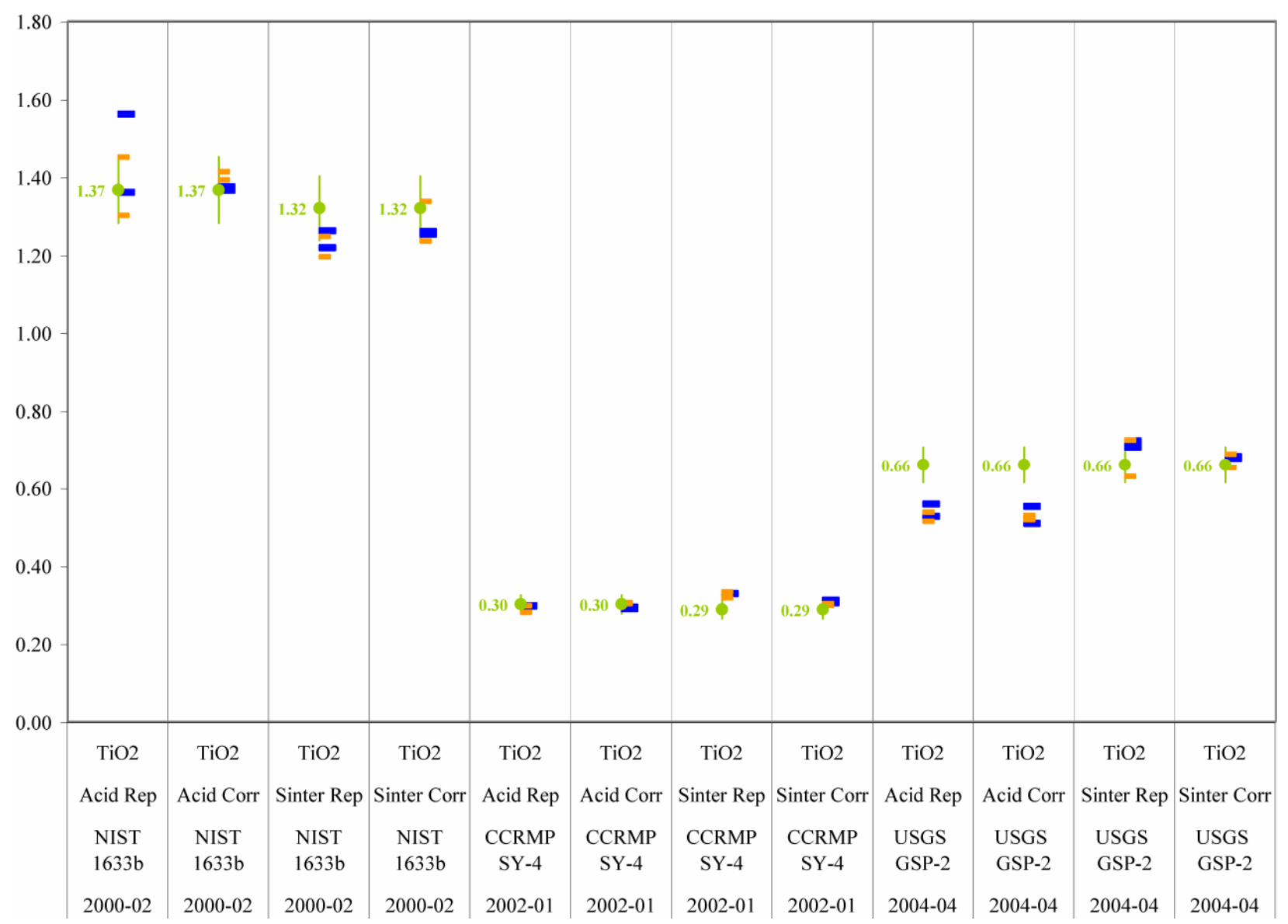

Figure B.2.8. The comparison of reported and corrected Titanium oxide values for the three certified reference materials. The Y-axis is the weight percent concentration of the analyte. The $\mathrm{X}$ axis of the graph specifies the oxide, the digestion method Acid (mixed-acid) or Sinter (sinteracid), the results displayed Rep (reported oxide value) or Corr (corrected oxide value), the CRM source and designation and the year sequence the CRM was originally distributed.

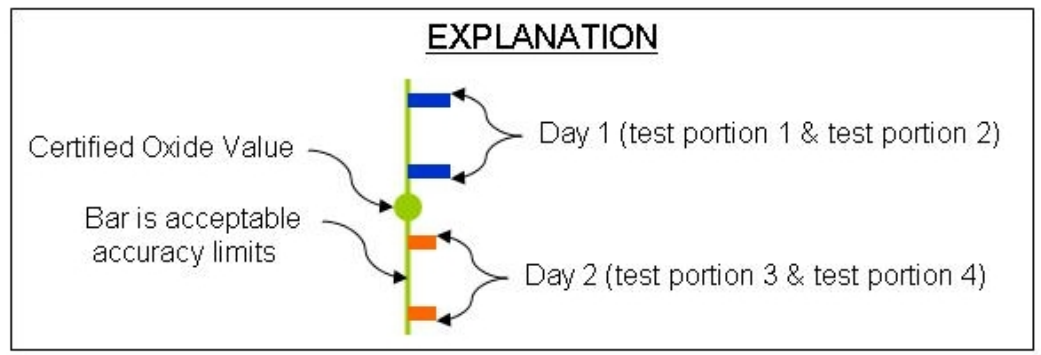




\section{Appendix B.3 \\ Phase 3: On-Site Evaluation of USGS IGL September 12- 14, 2005}

Performance Audit of U.S. Geological Survey Inorganic Geochemistry and Contract Laboratories

Requisition \#3-2920-1052

October 11, 2005

Louis Janke, President

Quality Associates International ${ }^{\oplus}$, LDT.

P.0. Box 117

Douglas, ON KOJ 1 SO

Canada

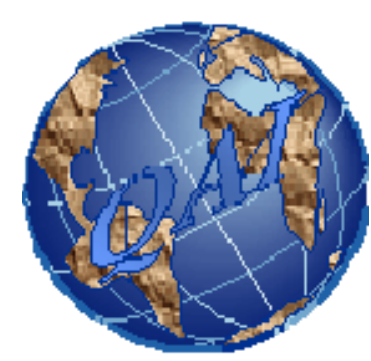




\section{Introduction}

An on-site of the USGS Inorganic Laboratory (IGL) was conducted September 11-14, 2005. This task had two primary goals. The main purpose was to verify that the recommendations made in Phase 1 for improving the analytical performance had been successfully implemented. Secondly, assistance in developing a standard operating procedure (SOP) for each analytical methodology employed by the IGL as part of developing a total quality management system was requested

\section{General Findings}

The on-site audit confirmed recommendations for analytical practices intended to improve the efficiency and reliability of test results have been implemented and are being monitored on an ongoing basis to substantiate the effectiveness of the recommendations. The recent implementation of a blinds testing program should provide the recommended ongoing, real time monitoring of laboratory performance.

There was not sufficient time to perform a detailed analysis of each analytical process so the remainder of this report contains a summary of best practices. Recommendations and examples included in this report do not constitute current or future practices or procedures employed at the U.S. Geological Survey (USGS), Inorganic Geochemistry Laboratory (IGL. It is the responsibility of USGS management and staff to review the recommendations and examples to decide whether they can be in whole or in part incorporated into current SOPs without adversely impacting the quality of results produced by the IGL.

One critical aspect of coal analysis that is fundamental to obtaining credible analytical results especially needs to be addressed. This is the concept of taking the proper steps to ensure that every sample taken is representative of the intended purpose. While this is ultimately outside the IGL's direct scope of responsibility, there needs to be close coordination between the sample collectors/submitters and the IGL personnel. Practices employed to collect samples should be compared with the procedures cited in this document. If it is not possible to implement comparable procedures, the IGL should implement procedures that can identify sources and causes of sample variability that could detract from the reliability of analytical results.

\section{Collection of Coal Samples}

According to ASTM D 2013 "Standard Practice for Preparing Coal Samples for Analysis", there are two groups into which coals fall:

Group A: Coals that have been cleaned in all sizes.

Group B: All other coals. Unknown coals are to be considered in group B.

Unless the USGS has information to the contrary, all coals submitted for analysis should be considered as being in group B. Table 1 of ASTM D 2013 stipulates a minimum mass of $4 \mathrm{~kg}$ of 4 mesh $(4.75 \mathrm{~mm})$. Group B coal is required for subdivision to produce a representative and homogeneous 60 mesh $(250 \mu \mathrm{m})$ analysis sample. The mass of the analysis sample shall not be less 
than $50 \mathrm{~g}$. To obtain the $4 \mathrm{~kg}$ of 4 mesh coal, a gross sample must be taken. Gross samples can be collected as mine samples or as commercial samples. Table B.3.1 lists the relevant ASTM standards for collection of mine samples and commercial samples.

Table B.3.1. The relevant ASTM standards for collection of mine samples and commercial samples.

\begin{tabular}{|c|c|c|c|c|c|c|}
\hline \multirow[b]{2}{*}{$\begin{array}{c}\text { ASTM } \\
\text { Standard }\end{array}$} & \multirow[b]{2}{*}{$\begin{array}{l}\text { Type of } \\
\text { Sample }\end{array}$} & \multirow[b]{2}{*}{$\begin{array}{c}\text { Source of } \\
\text { Sample } \\
\end{array}$} & \multirow[b]{2}{*}{ Minimum Increments } & \multicolumn{3}{|c|}{$\begin{array}{c}\text { Minimum Increment } \\
\text { Mass }\end{array}$} \\
\hline & & & & $\begin{array}{c}16 \mathrm{~mm} \\
(5 / 8 \\
\text { inch }) \\
\end{array}$ & $\begin{array}{l}50 \mathrm{~mm} \\
(2 \text { inch })\end{array}$ & $\begin{array}{l}150 \mathrm{~mm} \\
(6 \text { inch })\end{array}$ \\
\hline D 4596 & Mine & Channel & Specification A & $3 \mathrm{~kg}$ & $3 \mathrm{~kg}$ & $3 \mathrm{~kg}$ \\
\hline D 2234 & Commercial & Stopped belt & Specification B & $1 \mathrm{~kg}$ & $3 \mathrm{~kg}$ & $7 \mathrm{~kg}$ \\
\hline D 2234 & Commercial & Full Stream & Specification B & $1 \mathrm{~kg}$ & $3 \mathrm{~kg}$ & $7 \mathrm{~kg}$ \\
\hline D 2234 & Commercial & Part Stream & Specification B & $1 \mathrm{~kg}$ & $3 \mathrm{~kg}$ & $7 \mathrm{~kg}$ \\
\hline D 6609 & Commercial & Part Stream & Specification B & $1 \mathrm{~kg}$ & $3 \mathrm{~kg}$ & $7 \mathrm{~kg}$ \\
\hline D 6883 & Commercial & $\begin{array}{c}\text { Railroad Cars } \\
\text { Barges } \\
\text { Trucks } \\
\text { Stockpiles } \\
\end{array}$ & Specification B & $1 \mathrm{~kg}$ & $3 \mathrm{~kg}$ & $7 \mathrm{~kg}$ \\
\hline D 4916 & Commercial & Auger & Specification B & $1 \mathrm{~kg}$ & $3 \mathrm{~kg}$ & $7 \mathrm{~kg}$ \\
\hline
\end{tabular}

Specification A: One increment $29 \mathrm{~cm}$ high by $10 \mathrm{~cm}$ wide by $8 \mathrm{~cm}$ deep for each $30 \mathrm{~cm}$ of seam thickness. For seams of less than $40 \mathrm{~cm}$ thickness multiple channel samples are required to produce the minimum $4 \mathrm{~kg}$ of 4 mesh $(4.75 \mathrm{~mm})$

Specification B: $\mathrm{N}=35 \times \sqrt{M g / 908}$, where $\mathrm{Mg}$ is mega-grams of coal. The minimum amount of coal to be sampled is 908 mega-grams. Each sampling standard provide guidance on geometrical and temporal spacing of increments.

Examples:

Six barges contain $1362 \mathrm{Mg}$ (1500 tons) of raw coal each. The entire lot comprises $8292 \mathrm{Mg}$. According to ASTM D 6883 the total number of increments is calculated according to specification $\mathrm{B}$,

$\mathrm{N}=35 \times \sqrt{8292 / 908}=105$ increments. This is 17.5 increments per barge or 18 rounded off. The total gross sample would be top size $16 \mathrm{~mm} 108 \mathrm{~kg}$, top size $50 \mathrm{~mm} 324 \mathrm{~kg}$, and top size 150 $\mathrm{mm} 756 \mathrm{~kg}$.

A coal seam is $174 \mathrm{~cm}$ thick. According to ASTM D 4596, the total sample taken would be 174 $\mathrm{cm}$. thick by $10 \mathrm{~cm}$ wide by $8 \mathrm{~cm}$ deep. This gives a total volume of coal of $13,920 \mathrm{~cm}^{3}$. At a density of approximately $1.3 \mathrm{~g} / \mathrm{cm}^{3}$ this yields approximately $18 \mathrm{~kg}$ of coal. 


\section{Collection of Ash Samples}

Coal-derived ash falls into two groups, laboratory ash and solid combustion residues (utility ash). Utility ash can consist of, but is not limited to, bottom ash, bed ash, super heater tube ash, fly ash, bag house ash, and scrubber sludge. Collection of a representative and homogeneous sample of utility ash requires specialized probes that can be inserted in the ash stream. It is recommended that not less than $3 \mathrm{~kg}$ of utility ash is collected for analysis. Prepare laboratory ash according to the section on preparation of ash samples for analysis.

\section{Sample Preparation, Storage and Handling}

\section{Preparation of coal samples for analysis}

While awaiting preparation, store gross samples in containers that prevent a change in the moisture condition of the gross sample.

Gross samples normally require air-drying to properly feed through size reduction (crushing) and dividing equipment. Air dry gross samples in accordance with ASTM D 3302. Do not air-dry coal samples at temperatures in excess of $30^{\circ} \mathrm{C}$, as all coals are subject to some oxidation at temperatures in excess of $30^{\circ} \mathrm{C}$.

Employ equipment for size reduction that minimizes either moisture loss or gain during the reduction stage.

After each stage of reduction, employ an enclosed riffle to split the coal sample. The chutes and riffle slots shall have a slope of at least $60^{\circ}$. The sample shall be fed into the riffle employing a scoop with straight sides and a width equal to the effective width of the riffle. To generate splits as close to equal mass as possible, ensure sufficient sample is produced after each stage of reduction to fill the riffle scoop. Table B.3.2 lists the recommended riffle slot sizes for particle sizes at each stage of reduction.

Table B.3.2. The recommended riffle slot sizes for particle sizes at each stage of sample reduction

\begin{tabular}{|c|c|c|c|}
\hline Particle size & Mesh & Riffle slots (inches) & Riffle slots (mm) \\
\hline $4.75 \mathrm{~mm}$ & 4 & $0.75-1.00$ & $18-25$ \\
\hline $2.36 \mathrm{~mm}$ & 8 & $0.75-1.00$ & $18-25$ \\
\hline $0.250 \mathrm{~mm}$ & 60 & $0.25-0.375$ & $6-10$ \\
\hline
\end{tabular}

Employ figure 3 of ASTM D 2013 to plan and carry out the preparation of the 60 mesh $(250 \mu \mathrm{m})$ analysis sample. Transfer a minimum of $50 \mathrm{~g}$ of coal (Note 1) to a closed container. Do not fill the container to more than $2 / 3$ of total capacity. Take an equivalent quantity reserve at the same time.

Verify once a month that an internally prepared sample passes $100 \%$ through a 60 mesh $(250 \mu \mathrm{m})$ sieve and post as internal sample verified and the date of verification prominently in the sample preparation area. 
Verify once a month that an externally prepared sample passes $100 \%$ through a 60 mesh $(250 \mu \mathrm{m})$ sieve and post the source of the sample and the date of verification prominently in the sample preparation area.

Note 1 - Since all test portions for analysis are to be taken from the same bottle of coal, it is necessary to calculate the amount of coal required for all tests. In the case of the IGL, the amount required allowing for duplicates, repeats and blinds is $30 \mathrm{~g}$ for a coal of $10 \%$ ash content.

\section{Preparation of ash samples for analysis}

The procedures described below are suitable for the preparation of laboratory ash from coal or the ignition of utility ash. Ashes prepared according to the procedure below should be immediately treated for analysis. Since ash can absorb moisture or carbon dioxide from the atmosphere, reignite ash that is stored for subsequent analysis or ash that has been received from an outside source according to the conditions specified below.

\section{Equipment}

Muffle furnace, with unexposed elements and a sheathed thermocouple. The furnace shall be equipped to allow for 2 to 4 air changes a minute. The furnace shall be capable of being programmed to heat from approximately $3{ }^{\circ} \mathrm{C}$ per minute to $8{ }^{\circ} \mathrm{C}$ per minute. The final soak temperature of the working surface of the furnace shall be maintained within $450-500{ }^{\circ} \mathrm{C}$ for preparation of ash for trace analysis and within $700-750{ }^{\circ} \mathrm{C}$ for preparation for major and minor analysis.

Ignition crucible, quartz, porcelain or fused silica crucibles. The crucible shall be of sufficient capacity to produce $2 \mathrm{~g}$ of ignited sample. The sample to be ignited is not to exceed $6 \mathrm{~mm}(1 / 4$ inch) in depth. Do not employ crucibles with a pitted or flaked interior surface.

\section{Procedure}

Clean the muffle furnace with a vacuum or air hose prior to use.

At no time during the preparation of laboratory ash from coal should the sample be allowed to ignite. Should ignition occur, the temperature in the sample is likely to be significantly higher than the one to which the muffle is controlled, resulting in the loss of volatile trace elements.

Remove ignited samples while the furnace is still at the final soak temperature. Do not allow ignited samples to cool down in the furnace. The interior surfaces of muffle furnaces are subject to spalling (flaking or crumbling) during cool down. This can result in contamination of the ash sample and is one of the primary reasons for cleaning the muffle prior to use.

An ash sample prepared according to the conditions specified for Ignition of Samples for Trace Analysis can be treated starting at Stage 2 of Ignition for Samples Major and Minor analysis. 


\section{Ignition of Samples for Trace Analysis}

Stage 1 - Weigh a quantity of sample that will yield not less than $2 \mathrm{~g}$ of ash, into an ignition crucible. Place the ignition crucible in the working surface of a muffle at ambient temperature. Program the furnace so that it reaches a temperature of $300^{\circ} \mathrm{C}$ in 1 hour $\left(\sim 4^{\circ} \mathrm{C} / \mathrm{min}\right)$. Hold at this temperature until all evidence of smoking has ceased.

Stage 2 - Program the furnace so that it reaches a temperature of $500{ }^{\circ} \mathrm{C}\left(\sim 3{ }^{\circ} \mathrm{C} / \mathrm{min}\right)$ in another hour. Hold at the final soak temperature for not less than 2 hours. Remove the sample and cool to ambient at conditions that minimize absorption of water or carbon dioxide. Stir the sample. If carbonaceous material is present (Note 2), place the sample back in the muffle at the final soak temperature and ignite for an additional of 4 hours. Remove the sample and cool to ambient at conditions that minimize absorption of water or carbon dioxide (Note 3). Immediately weigh test portions for subsequent treatment for analysis. Store and retain unused ash in sealed containers for repeat, blind or major and minor analysis. The containers shall minimize the opportunity for contamination or loss of trace analytes as well as the absorption of water or carbon dioxide.

Note 2-In the case of laboratory ash prepared from coal, no carbonaceous material should remain after a total ignition time of 6 hours at the final soak temperature. In the case of solid combustion residues from utility source, is it is possible that some carbonaceous material can persist. This indicates the presence of "graphitic" carbon that is unlikely to decompose at a temperature of $500^{\circ} \mathrm{C}$.

Note-3- Some samples can have a composition that promotes the formation of a low melting eutectic, causing the ash sample to partially fuse at the final soak temperature. If this occurs, grind the ignited sample in a non-contaminating (alundum) mortar and pestle and screen through a 200 mesh (75 $\mu \mathrm{m})$ kevlar sieve.

\section{Ignition of Samples for Major and Minor Analysis}

Stage 1-Weigh a quantity of sample that will yield not less than $2 \mathrm{~g}$ of ash, into an ignition crucible. Place the ignition crucible in the working surface of a muffle at ambient temperature. Program the furnace so that it reaches a temperature of $500^{\circ} \mathrm{C}$ in 1 hour $\left(\sim 8^{\circ} \mathrm{C} / \mathrm{min}\right)$. Hold at this temperature until all evidence of smoking has ceased.

Stage 2-Program the furnace so that it reaches a temperature of $750{ }^{\circ} \mathrm{C}\left(\sim 4{ }^{\circ} \mathrm{C} / \mathrm{min}\right)$ in another hour. Hold at the final soak temperature for not less than 2 hours. Remove the sample and cool to ambient at conditions that minimize absorption of water or carbon dioxide. Stir the sample. If carbonaceous material is present, place the sample back in the muffle at the final soak temperature and ignite for an additional 4 hours (Note 2). Remove the sample and cool to ambient temperature at conditions that minimize absorption of water or carbon dioxide (Note 3). Immediately weigh test portions of the sample for subsequent treatment for analysis. Store and retain unused ash in sealed containers for repeat or blind analysis. The sealed containers will minimize the opportunity for contamination, as well as the absorption of water or carbon dioxide. 


\section{Sample Storage}

Establish a common area for the storage of all reserve samples, quality control samples, and blind samples not currently in use.

Quality control materials can be categorized as conditioning samples, calibration samples, or control samples. These samples can be pure substances, certified reference materials, external reference materials, or internal reference materials. Do not use a quality control material that is removed from the laboratory for internal control purposes.

Keep a copy of all certificates provided by the suppliers of pure substances, certified reference materials, and external reference materials. Mark the date of receipt on the certificate. Mark the date of receipt and, if appropriate, the date of expiry on the control material container.

Mark all internal reference materials with the date of preparation.

Mark each control material container with a replacement line $1 / 4$ of the height of the sample in the container.

When the level of an active quality control material reaches the replacement line bring a substitute container of the same or an alternative quality control material into the laboratory for verification. Run the substitute quality control material as an unknown to verify the material meets acceptance limits. Mark the date of verification on the control material.

Blind samples can be provided by external or internal sources. Analyze blind samples with a routine batch of samples within 2 weeks of receipt. Run duplicate test portions of the blind sample, unless otherwise specified by the submitter. Report blind results to the submitter within 24 hours of completion of the analysis. Verify and report all relevant quality control data (in control and out of control) with the blind results.

\section{Quality Control}

\section{Instrument Maintenance}

Instrument maintenance sheets shall be posted on or immediately adjacent to each instrument. Specific maintenance criteria are specified in each method SOP.

\section{Validated Operators}

The IGL shall only report results produced by validated operators. Each validated operator shall be capable of conducting all instrument set up, conditioning, and quality control checks.

The IGL shall initially verify individual analysts as validated operators by having the analyst conduct blind analysis of selected control materials that cover the normal expected range of materials analyzed in the laboratory. The results and date of initial verification of each analyst shall be recorded in the instrument operating manual kept at the instrument station. 
On-going verification of validated operators shall occur through the analysis of external and internal blind samples.

\section{Instrument Conditioning}

Each method SOP shall specify requirements for instrument conditioning. At a minimum, the instrument conditioning runs shall produce results that do not exceed the maximum expected repeatability standard deviation specified for the test parameter in the relevant SOP. Conditioning runs shall be identified as conditioning.

\section{Acceptance Limits for Calibration and Control Samples}

Establish acceptance limits for each conditioning, calibration, and control material (CM). Label each CM with these limits.

According to the ISO “Guide for Uncertainty Measurement" (GUM), the total uncertainty of a measurement is made up of the components of uncertainty that can impact the measurement result. The uncertainty of a measurement conducted on a CM can be expressed in equation 1 below.

Equation 1:

$\mu T_{C M}=\sqrt{\mu_{\text {homogeneityCM }}{ }^{2}+\mu_{\text {stability } C M}{ }^{2}+\mu_{\text {bias } C M}{ }^{2}+\mu_{\text {precisionCM }}{ }^{2}+\mu_{\text {precisionLabMethod }}^{2}}$

Where;

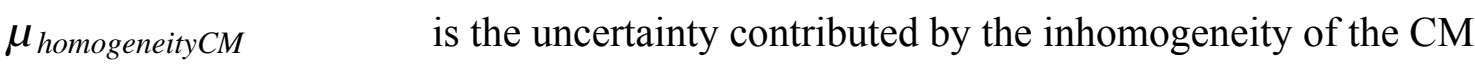

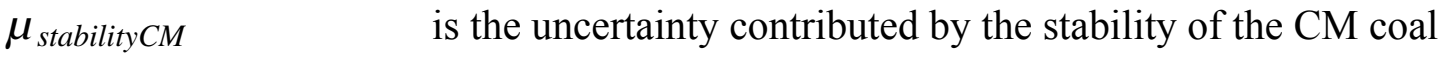

$\mu_{\text {bias } C M} \quad$ is the uncertainty contributed by bias of the CM measurement process

$\mu_{\text {precisionCM }} \quad$ is the uncertainty contributed by the precision of the $\mathrm{CM}$ measurement process

$\mu_{\text {precisionLabMethod }}$ is the uncertainty contributed by the precision of the laboratory method

In the case of a $\mathrm{CM} \mu_{\text {biasCM }}$ is assumed to be 0 and $\mu_{\text {homogeneityCM }}, \mu_{\text {stability } C M}, \mu_{\text {precisionCM }}$ can be combined into $\mu_{C M}$.

So for a CM the GUM (equation 2) becomes:

Equation 2

$\mu T=\sqrt{{\mu_{C M}^{2}+\mu_{\text {precisionLabMethod }}^{2}}^{2}}$

In a laboratory operating in a state of control under repeatability conditions, the precision of the laboratory method should not exceed the repeatability standard deviation of the method (equation $3)$. 
Equation 3:

$\mu_{\text {precisionLabMethod }}=\sqrt{\mu_{r}^{2} / n}$

Where:

$\mu_{r}$ is the repeatability standard deviation of the method

$\mathrm{n}$ is the number of measurements made on the standard coal

The total uncertainty is shown in equation 4.

Equation 4:

$\mu T=\sqrt{\mu_{R M}^{2}+\mu_{r}^{2} / n}$

This equation indicates that the limits employed to accept or reject a calibration or control point are a function of two factors: 1.) the uncertainty of the CM material; and 2.) the uncertainty of the laboratory method. Three values are required to make use of equation 4 , the value of the CM (CMvalue), the limits of the CM (CMlimits) and the repeatability of the laboratory method (Ir). Assume the following National Institute of Standard Testing (NIST) sulfur standards are employed for calibration of method D 4239c. The values below are from NIST certificates.

NIST $1632 \mathrm{c}$ sulfur $1.462 \% \pm 0.051 \%$

NIST $2684 \mathrm{~b}$ sulfur $3.076 \% \pm 0.031 \%$

NIST $2685 \mathrm{~b}$ sulfur $4.730 \% \pm 0.068 \%$

Calculate $\mu_{C M}$ for each standard employing equation 5 below.

Equation 5:

$\mu_{C M}=$ CMlimits $/ 2$

For each standard $\mu_{R M}$ is as follows.

NIST $1632 \mathrm{c}=0.026$

NIST $2684 b=0.016$

NIST $2685 b=0.034$

Calculate the repeatability standard deviation for sulfur from ASTM D 4239c

This is equivalent to the repeatability interval (Ir) divided by 2.8 .

$\mathrm{Sr}=[0.02+0.03($ CMvalue $)] / 2.8$

NIST $1632 \mathrm{c}=0.023$

NIST $2684 \mathrm{~b}=0.040$

NIST $2685 b=0.058$ 
Multiply by the ISO 5725-1 factor (1.25) to obtain the maximum expected repeatability standard deviation.

NIST $1632 \mathrm{c}=0.029$

NIST $2684 b=0.050$

NIST $2685 b=0.072$

The total uncertainty for each calibration standard using $\mu T$ (equation 4) is:

NIST $1632 \mathrm{c}=0.038$

NIST $2684 \mathrm{~b}=0.053$

NIST $2685 b=0.080$

The 95\% expanded uncertainties are 2 times these values.

NIST $1632 \mathrm{c}=0.076$

NIST $2684 b=0.106$

NIST $2685 b=0.160$

The following are limits for accepting or rejecting a calibration point for each standard.

NIST $1632 \mathrm{c}$ sulfur $1.462 \% \pm 0.076 \%$

NIST $2684 \mathrm{~b}$ sulfur $3.076 \% \pm 0.106 \%$

NIST $2685 b$ sulfur $4.730 \% \pm 0.160 \%$

Compare this with the NIST certificate values only.

NIST $1632 \mathrm{c}$ sulfur $1.462 \% \pm 0.051 \%$

NIST $2684 \mathrm{~b}$ sulfur $3.076 \% \pm 0.031 \%$

NIST 2685 b sulfur $4.730 \% \pm 0.068 \%$

A calibration or control point cannot be "not accepted" or rejected on the basis of the limits of the $\mathrm{CM}$ only. The precision of the laboratory method must also be included in these limits. If this is not done, a laboratory will have a tendency to reject acceptable conditioning, calibration or control runs. A laboratory could establish a calibration, run a material as a check, and find that it appears to be out of control, and needlessly recalibrate an instrument or reject results. This cycle can go on repeatedly. As a result, a great deal of expense associated with operator time and supplies could be unnecessarily expended. This is a case where applying fundamental quality principles can save an enormous amount of expenditure.

\section{Calibration and calibration verification}


The number of standards used for calibration shall not be less than the degree of the calibration curve plus 2 and according to the AOAC International (AOAC) should not be less than the degree of calibration curve plus 5. Table B.3.3 summarizes these requirements:

Table B.3.3. The number of standards required by the type of calibration curve.

\begin{tabular}{|c|c|c|c|}
\hline $\begin{array}{c}\text { CURVE } \\
\text { TYPE }\end{array}$ & DEGREE & $\begin{array}{c}\text { MINIMUM NUMBER } \\
\text { OF STANDARDS }\end{array}$ & $\begin{array}{c}\text { AOAC RECOMMENDED } \\
\text { NUMBER OF STANDARDS }\end{array}$ \\
\hline LINEAR & 1 & 3 & 6 \\
\hline QUADRATIC & 2 & 4 & 7 \\
\hline CUBIC & 3 & 5 & 7 \\
\hline EXPONENTIAL & 2 & 4 & \\
\hline
\end{tabular}

Calculate the range of the standards as follows.

$\mathrm{C}_{\mathrm{u}} \sim 2 \times \mathrm{C}_{\mathrm{M}}$

Where: $C_{u}$ is the upper concentration standard

$\mathrm{C}_{\mathrm{M}}$ is the highest concentration control material employed for calibration verification

and,

$\mathrm{C}_{1}=\mathrm{C}_{\mathrm{u}} / 10$

Where: $C_{1}$ is the lower concentration standard

The highest concentration control material for sulfur analysis is $1.03 \mathrm{wt} \%$.

The upper calibration standard should be approximately $2.0 \%$.

The lower calibration standard should be approximately $0.2 \%$.

Space standards as equally as possible over the calibration range.

If $6(n=6)$ standards are to be used then a suitable distribution for the standards can be calculated from:

$$
\begin{aligned}
& \mathrm{D} \sim\left(\mathrm{C}_{\mathrm{u}}\right) /(\mathrm{n}-1) \\
& \mathrm{D} \sim(2) / 5 \sim 0.4 \\
& \mathrm{C}_{\mathrm{n}+1} \simeq \mathrm{C}_{\mathrm{n}}+\mathrm{D}
\end{aligned}
$$

A reasonable selection of standard concentrations would be:
$\mathrm{C}_{1} \quad 0.2$
$\mathrm{C}_{2} \quad 0.6$
$\mathrm{C}_{3} \quad 1.0$
$\mathrm{C}_{4} 1.4$
$\mathrm{C}_{5} \quad 1.8$
$\mathrm{C}_{6} \quad 2.0$ 
Unless otherwise specified in the method SOP, verify the calibration a minimum of every ten samples after acceptance of the initial calibration and at the end of each batch of test samples. It is preferable that the calibration verification sample be a control material not used during calibration and has a value near the mid point of the calibration range.

Many instruments have built-in calibration software. It is advisable to conduct an independent verification of instrument generated calibration coefficients. This can be accomplished by employing Excel functions to plot instrument response versus mass of calibrant.

\section{Establishment and Use of Control Charts}

Establish control charts for each control material.

Establish three sets of control lines on each control chart.

The first set corresponds to the acceptance limits calculated according to equation 4 in the section on acceptance limits for calibration and control samples of this report. These limits should be shown in green. The second set corresponds to twice the acceptance limits calculated according to equation 4 . These limits should be shown in yellow. The third set corresponds to three times the acceptance limits calculated according to equation 4 . These limits should be shown in red.

Plot control results on the control charts as the control results are generated.

Values on or inside the green limits indicate the measurement system is in an optimum state of control, values on or inside the yellow limits indicate the system is in an acceptable state of control, and values outside the yellow limits require corrective action.

If a value falls on or below the red limits, but above the yellow limits, run the control material in duplicate. If both duplicate runs fall below the yellow limits, analysis can proceed. The operator shall make note of any possible assignable cause for the quality excursion.

Otherwise, reject all values back to the last acceptable control point. The operator shall take and make note of appropriate corrective action with respect to instrument maintenance, conditioning, and/or calibration.

If a value falls above the red limits, run the control material in duplicate. If both duplicate runs fall below the green limits, analysis can proceed. The operator shall make note of any possible assignable cause for the quality excursion.

Otherwise, reject all values back to the last acceptable control point. The operator shall take and make note of appropriate corrective action with respect to instrument maintenance, conditioning, and/or calibration. 
Within one year of implementation of each control chart, summarize the number of points inside the green limits, inside the yellow limits, and inside the red limits. Use the information to determine whether the control limits can be adjusted.

\section{Method Specific Standard Operating Procedures}

\section{Moisture}

International, Regional and National standards for Moisture are:

AS 1038

ASTM D3173

ASTM D 5142

BS 1016

DIN 51718

GB/T212

ISO 589

ISO 11722

ISO 5068

SABS 925

The USGS IGL procedure for the determination of residual moisture content is based on ASTM D 3173 "Standard Test Method for Moisture in the Analysis Sample of Coal and Coke". This SOP describes factors that are known to affect the measurement of moisture in the analysis sample. Critical maintenance requirements are prefaced with an [M]. The measurement characteristic(s) precision and/or accuracy affected by the factor appear in brackets.

\section{Condition of test sample (Accuracy)}

Standards normally specify two alternatives for extracting a test portion for analysis. Procedure A involves mixing the sample in the bottle and extracting a test portion from the bottle for analysis. Procedure B involves mixing the sample in the bottle, extracting sufficient material for the test, allowing the material to equilibrate with the laboratory atmosphere, and then conducting analysis on test portions from the equilibrated material. Samples treated by procedure B can lose or pick up moisture depending on the ambient humidity of the laboratory. As a result, laboratories employing procedure B can produce residual moisture results that are either lower or higher than that produced by procedure A. For this reason, as well as the obvious practical limitations of ensuring the moisture condition of test samples exchanged by laboratories does not change, comparing residual moisture results determined on the analysis sample from different laboratories has absolutely no technical validity.

\section{Type of Purging Atmosphere (Accuracy)}

Studies have shown nitrogen will produce higher moisture results than air conditioned to the same requirements. Since the residual moisture value is employed to calculate other parameters to a dry basis, nitrogen as a purging atmosphere produces higher dry basis estimates for other parameters than air. 


\section{Dryness of Purging Atmosphere (Precision \& Accuracy)}

[M-Monthly or after any repair] Control the dryness of the purging atmosphere to the requirement specified in the standard. Verify this dryness requirement is met by passing the drying atmosphere through a suitable desiccant and then through a tube containing magnesium perchlorate for a fixed period of time. Remove the tube after a fixed period of time and weigh. By knowing the flow rate, the amount of moisture in the dried purging atmosphere in $\mathrm{mg} / \mathrm{L}$ can be calculated.

\section{Insufficient Drying Time (Precision \& Accuracy)}

Low rank coals have the capacity to hold significantly more moisture than higher rank coals. A low rank coal may not lose all of this moisture by the end of a one-hour drying period. Place low rank coal samples in the drying apparatus for additional half hour periods until a minimum change in mass is reached. The term "minimum change in mass" is used because excessive drying can result in oxidation of low rank coals. Studies have shown that most low rank coals will achieve a minimum change in mass after 1.5 to 2 hours. The example below lists the weight of $1 \mathrm{~g}$ of low rank coal after an initial one hour drying period and then after each additional half hour drying period. The minimum mass is indicated in bold.

1 hour.: $0.8256 \mathrm{~g}, 1.5$ hour: $0.8149 \mathrm{~g}, 2$ hour: $0.8156 \mathrm{~g}, 2.5$ hour: $0.8270 \mathrm{~g}$

This low rank coal has residual moisture content of $18.51 \mathrm{wt} \%$.

\section{Concurrent Drying Coals of Significantly Different Rank (Precision)}

If a low rank coal is dried in a batch with higher rank coals, the coals can exchange moisture in an unpredictable way. Do not dry coals of significantly different rank together.

\section{Cooling and Weighing of Samples (Precision \& Accuracy)}

[M-daily] On the same day as test samples are to be analyzed, heat empty capsules or crucibles and lids under the conditions at which the sample is to be dried. Cool the capsules and lids in a desiccator.

Some laboratories process a large number of samples at a time in one batch. Before the latter samples are weighed, they can pick up moisture from the desiccator environment, particularly if the samples are not covered with a suitable lid. This occurs because coal can act as a better desiccant than certain chemical agents. Cover the sample with a lid to minimize the pick up of moisture from the desiccator environment as well as from other coal samples in the desiccator. Dry samples in batches of 6 to 8 to further minimize these effects. Once the initial batch is put in the drying apparatus, another batch can be weighed out no less than 15 minutes later and placed in the drying apparatus. Remove samples in each batch sequence from the drying apparatus at the required time interval, cool, and weigh.

\section{Ash Content}


International, Regional and National standards for Ash are:

AS 1038

ASTM D3174

ASTM D 5142

BS 1016

DIN 51719

$\mathrm{GB} / \mathrm{T} 212$

ISO 1171

The USGS IGL procedure for the determination of ash content is based on ASTM D 3174

"Standard Test Method for Ash in the Analysis Sample of Coal and Coke from Coal". This SOP describes factors that are known to affect the measurement of ash in the analysis sample. Critical maintenance requirements are prefaced with an [M-frequency]. The measurement characteristic(s) precision and/or accuracy affected by the factor appear in brackets.

\section{Incineration of the sample (Precision)}

[M-Monthly or after any repair] Verify the airflow calibration of the muffle furnace is 2 to 4 air exchanges per minute according to figure 2 of ASTM D 3174 . Verify the muffle furnace temperature calibration according to the section on Temperature Calibration in the standard. If there is no section on Temperature Calibration, the section on Temperature Calibration in ASTM D 3174 is recommended.

Do not place ignition crucibles closer than 1 inch to the muffle furnace door. Standards prescribe heating a specified weight of coal sample in a muffle furnace with a specified number of air changes per minute to an initial transition point within a period of 1 hour and then to a final soak temperature within the next hour. The sample is held at the soak temperature for a specified period of time.

Interpreting the heating periods for each stage of ignition to mean the specified temperatures can be set to reach either 1 hour limit within any time up to and including the 1 hour, although literally correct, can produce erratic ash results. This is particularly true if the sample ignites during either ignition stage. Should this occur, the temperature in the sample will not be anything remotely similar to the one displayed on the temperature control display of the furnace.

Program the muffle to rise uniformly from ambient to the initial transition point $\left(500^{\circ} \mathrm{C}\right.$ ASTM D $3174)$ in 1 hour $\left(\sim 8^{\circ} \mathrm{C} / \mathrm{min}\right.$.) and then uniformly to the final soak point $\left(750^{\circ} \mathrm{C}\right.$ ASTM D 3174) in the second hour $\left(\sim 5^{\circ} \mathrm{C} / \mathrm{min}\right.$.). Programming the furnace to hold at the initial transition point until all evidence of smoking has ceased can further improve the precision of results. This hold period is normally about 1 hour.

\section{Final Soak Temperature (Precision \& Accuracy)}

Standards specify final soak temperatures that range from $700{ }^{\circ} \mathrm{C}$ to as high as $825^{\circ} \mathrm{C}$. Ash results determined at the higher temperatures can be significantly less than those determined at lower temperatures. Studies have shown that the removal of the water of crystallization from clay 
minerals and the decomposition of carbonate minerals approach or reaches completion at temperatures in excess of $800{ }^{\circ} \mathrm{C}$. For this reason, tighter precision can also be obtained for coals containing minerals with high water of crystallization content or carbonate minerals by determining the ash content at higher temperatures.

\section{Concurrent Ashing Coals of Significantly Different Rank (Precision)}

If a low rank coal is ashed with higher rank coals, sulfur can transpose from the higher rank coals to the low rank coal in an unpredictable way. This occurs for two reasons. As much as $80 \%$ of the sulfur in high rank coals can be present as pyrites $\left(\mathrm{Fe}_{\mathrm{x}} \mathrm{S}_{\mathrm{y}}\right)$ and organic sulfur. These compounds readily decompose to form sulfur oxides. Most low rank coals contain appreciable quantities of alkali $\left(\mathrm{Na}_{2} \mathrm{O}, \mathrm{K}_{2} \mathrm{O}\right)$ and alkaline $(\mathrm{CaO}, \mathrm{MgO})$ earth compounds. These compounds readily react with sulfur oxides to form alkali and alkaline sulfates. The extent to which these reactions occur can be dictated by the proximity of the low rank coal to a high rank coal. Avoid ashing low rank coals together with other coals.

\section{Cooling and weighing of Samples (Precision \& Accuracy)}

Ash programs set to 4 to 6 hours often finish late at night or in the early morning hours. The furnace cools down and the ash samples are ready to weigh. Although this may be convenient, it can produce high or erratic ash values as some coal ash can pick up moisture and or carbon dioxide on cooling. In addition, the interior surfaces of muffle furnaces are subject to spalling (flaking or crumbling) during cool down. This can result in contamination of the ash sample with vagrant material. To minimize these affects, set the ash furnace to complete the final soak temperature phase just before the ash samples are to be weighed. This has the added benefit of identifying whether a power failure has occurred. Do not allow an ash furnace to reset after a power failure. Even if a furnace is designed to "recover" the reactions that occur during the recovery are likely to be entirely different from those that would have occurred if initial ignition sequence had not been interrupted.

Remove the sample and cool to ambient temperatures at conditions that minimize absorption of water or carbon dioxide. If upon cooling and weighing results appear to be erratic, immediately stir the ash sample to check for carbonaceous residue or fused ash. [M-As required] If the majority of samples exhibit one or both of these characteristics check the furnace for a burned out element or an open thermocouple.

If repeat results for a single sample are erratic, stir the ash sample to check for carbonaceous residue. If carbonaceous residue is detected, place the samples in a muffle heated to the final soak temperature and reignite for an additional 2 hours [M- As required] If the results are still erratic, screen the original coal sample for oversize (plus 60 mesh material). If plus 60 mesh material is detected, report the finding to the laboratory supervisor and the submitter of the sample.

\section{Ash Sequence for Thermo Gravimetric Analysis (Accuracy)}

Conventional standards specify heating a coal sample in a furnace in the presence of air. Some standards allow the use of semi-automated or automated instruments that can be programmed to 
heat the sample in nitrogen at $105{ }^{\circ} \mathrm{C}-110{ }^{\circ} \mathrm{C}$ to determine moisture, then in nitrogen to $900{ }^{\circ} \mathrm{C}-950$ ${ }^{\circ} \mathrm{C}$ to determine volatile, and finally in air at $700{ }^{\circ} \mathrm{C}-815^{\circ} \mathrm{C}$ to determine ash. Heating a coal in this fashion can affect the decomposition of the mineral matter in such a way that less sulfur is retained in the ash than the coal heated in air. As a result, the ash content measured employing this approach in many cases is less than that obtained for samples ignited in air.

Assuming the results obtained using the thermogravimetric analysis (TGA) ash sequence described above can be made equivalent to that obtained by heating in air by calibrating a TGA with coals whose ash content has been determined in air is completely erroneous. Reactions that occur in the TGA can be significantly different from those that occur in muffle purged with air.

Consider the hypothetical case of two coals ignited in a muffle in the presence of air. The mineral composition of Coal A is $50 \% \mathrm{FeS}_{2}$ and $50 \% \mathrm{CaCO}_{3}$. The mineral composition of Coal $\mathrm{B}$ is $50 \%$ $\mathrm{Fe}_{2} \mathrm{O}_{3}$ and $50 \% \mathrm{CaCO}_{3}$. Under the muffle conditions Coal A will have a tendency to form an ash that contains significant amounts of $\mathrm{Fe}_{2} \mathrm{O}_{3}$ and $\mathrm{CaSO}_{4}$. Coal B will likely form an ash that contains $\mathrm{Fe}_{2} \mathrm{O}_{3}$ and $\mathrm{CaO}$. If these two coals are ashed according to the TGA sequence above they will both very likely react to form an ash that consists primarily of $\mathrm{Fe}_{2} \mathrm{O}_{3}$ and $\mathrm{CaO}$. Under the TGA ashing conditions specified above, Coal A ash will not be similar to that obtained in the muffle, while Coal $\mathrm{B}$ ash will, rendering the calibration meaningless.

Ash values of coal determined in muffle in air should be used to calibrate a TGA only if the TGA is run under conditions that closely approximate those specified for ignition in the muffle.

\section{Sulfur}

International, Regional and National standards for Sulfur are:

AS 1038

ASTM D 3177

ASTM D 4239

BS 1016

$\mathrm{GB} / \mathrm{T} 214$

ISO 351

The USGS IGL procedure for the determination of sulfur content is based on ASTM D 4239

'Standard Test Method for Sulfur in the Analysis Sample of Coal and Coke Using High temperature Tube Furnace Combustion Methods". This SOP describes factors that are known to affect the measurement of sulfur in the analysis sample. Critical maintenance requirements are prefaced with an $[\mathbf{M}]$. The measurement characteristic(s) precision and/or accuracy affected by the factor appear in brackets.

\section{Verification of the Operating Conditions (Precision \& Accuracy)}

[M-daily] The minimum temperature required to convert all sulfur present in coal sample to oxides of sulfur is $1350^{\circ} \mathrm{C}$. Verify that the instrument meets this minimum temperature requirement. Although most analyzers have provisions for internal temperature verification, it is a good practice to verify the temperature with a separate device that has been certified (NIST traceable) for the 
desired temperature range. The frequency with which this is done would depend on the number of samples analyzed but should not be less than once a month and whenever furnace maintenance occurs.

\section{Analyzer Calibration (Precision \& Accuracy)}

The instrument shall be calibrated to the AOAC requirements in the section on Calibration and Calibration Verification. There are two protocols that can be used for calibration of the analyzer.

These are:

Protocol 1:

The dry basis values of the CMs employed for calibration are adjusted to an as analyzed value employing the residual moisture value (Note 4) of each CM. The results produced by the analyzer represent the as analyzed results.

Protocol 2:

The dry basis values of the Control Materials (CMs) employed for calibration remain fixed in the instrument. The residual moisture value (Note 4) of each CM is entered into the instrument at the time of calibration. The residual moisture value of each test sample must also be entered. The results produced by the analyzer represent the dry basis results.

Note-4 Although determination of the residual moisture content of a CM each time the analyzer calibrated ensures results of the highest quality, it can result in rapid depletion of the CM. This requirement can be avoided by maintaining the laboratory environment at a constant $45 \%$ to $55 \%$ humidity and storing each sulfur CM without the opportunity for contamination in this humidity range in a exposed container in a layer not more than $6 \mathrm{~mm}$ thick. Measure residual moisture content of the CM after two days of exposure to the constant humidity condition. A less desirable approach is to place a relative humidity meter in the area where sulfur analysis is conducted. If the meter indicates a sustained change of $20 \%$ in relative humidity over a period of two or more days, it is necessary to verify the residual moisture content of each CM.

Some standards allow coals used for calibration during a normal production period to be predried. This practice can be badly abused, as normal production period can be subjectively interpreted. Either the quantity of CM coal to be used in the production period or even entire bottles of CM coal are predried. The assumption that storing the $\mathrm{CM}$ coal in a desiccator ensures the coal remains dry until the entire quantity of CM is used is erroneous. To verify this practice, it is not advisable to weigh a coal immediately after it is dried. Store the coal in a desiccator for 2 hours and then weigh it again. It is very likely that the weight will have changed. When a coal is dried and allowed to cool to room temperature, it can pick up moisture not only from the ambient laboratory environment, but also from the desiccator environment after a relatively short period of time. In the case of low rank coals, this can occur very quickly. Assuming that dried CM samples used for calibration remain dry will consistently produce sulfur results that trend high. 
Despite the fact some standards allow coals to be pre-dried, the practice can be unacceptable for another reason. It could invalidate the $\mathrm{CM}$. The user should check the $\mathrm{CM}$ certificate or with the $\mathrm{CM}$ provider to determine whether the $\mathrm{CM}$ was pre-dried to determine the certified $\mathrm{S}$ value. If not, then pre-drying for purposes of calibration is not acceptable.

A sulfur analyzer calibrated with a CM from one source will not necessarily produce an unbiased result for a $\mathrm{CM}$ from another source. To minimize biases caused by calibrating with a single $\mathrm{CM}$ from one source, or even by multiple CMs from one source, it is good practice, if possible, to employ CMs from at least two sources such as NIST and SABS.

\section{Premature Termination of Sulfur Analysis Cycle (Precision \& Accuracy)}

An instrument set to accumulate the sulfur response for 90 to 120 seconds can obtain low sulfur recovery particularly with coal high in components that readily react with sulfur. These components can react to form compounds or liquid slag that delays release of sulfur. The mechanisms by which these reactions take place can be extremely complex. Addition of a combustion aid or a mediator can minimize or prevent these reactions. Another alternative is to extend the analysis time to 300 seconds. Lignite and subbituminous coals tend to contain mineral components that can delay sulfur release.

\section{Chlorine}

International, Regional and National standards for Chlorine are:

ASTM D 2361

ASTM D 4208

ASTM D 6721

BS 1016

DIN 51727-B

EPA 9076

ISO 587

The USGS IGL procedure for the determination of chlorine content is based on ASTM D 6721

"Standard Test Method for Determination of Chlorine in Coal by Oxidative Hydrolysis Microcoulometry". This SOP describes factors that are known to affect the measurement of chlorine in the analysis sample. Critical maintenance requirements are prefaced with an [M]. The measurement characteristic(s) precision and/or accuracy affected by the factor appear in brackets.

Situation and Handling of Instrument Components and Samples (Precision \& Accuracy) Chlorine can be a prevalent contaminant in the environment. Do not locate the analyzer in an area where chlorine contamination is likely to occur, such as an area where hydrochloric acid is stored or in regular use. Wear chlorine free gloves to handle all instrument components and use platinum tipped tongs to handle the boats into which samples are to be weighed.

\section{Preparation of the Apparatus (Precision \& Accuracy)}


[M-daily] Clean the chlorine titration cell and electrodes. Add fresh electrolyte. Fill the hydration tower with chlorine free distilled water. Fill the dehydration tower with fresh sulfuric acid.

\section{Analyzer calibration (Precision \& Accuracy)}

The conditions specified in the section on recovery factor of ASTM D 6721 meet the AOAC requirements in the section on Calibration and Calibration Verification.

\section{Determination Chlorine Content (Precision \& Accuracy)}

Samples high in chlorine content $(>2000 \mu \mathrm{g} / \mathrm{g}$ ) can result in an over titration condition, indicated by a negative instrument response. This scenario results in an underestimation of chlorine content. The chlorine content of samples exhibiting this characteristic shall be corrected for the over titration.

\section{Limits of Application of Standard Methods (Precision \& Accuracy)}

A standard method calibrated, employing primary chemical substances, can be expected to produce results with minimal bias. In this case, compliance with the provisions of the standard method without modification should produce results with a precision at least equivalent to the repeatability of the method.

The repeatability of a standard method can be used to calculate the expected $\pm 2 \mathrm{~s}$ ( 2 standard deviation) uncertainty of a chlorine value at different levels of chlorine in coal. Assume a method should not be used to report a value with a \pm 2 s uncertainty that exceeds $20 \%$ of the measured value. The point at which the $\pm 2 \mathrm{~s}$ uncertainty of each standard method reaches $20 \%$ of the measured chlorine value is highlighted in bold in table B.3.4.

From table B.3.4, these standards as written and without modification can be used down to the following chlorine concentrations in coal:

ASTM D 2361, BS 1016, ISO 587: $1000 \mu \mathrm{g} / \mathrm{g} \mathrm{Cl}$

ASTM D 4208: $300 \mu \mathrm{g} / \mathrm{g} \mathrm{Cl}$

ASTM D 6721: $10 \mu \mathrm{g} / \mathrm{g} \mathrm{Cl}$

Table B.3.4. The point at which the \pm 2 s uncertainty of each standard method reaches $20 \%$ (in bold) of the measured chlorine value.

\begin{tabular}{|c|c|c|c|}
\hline Cl $\mu \mathrm{g} / \mathrm{g}$ & $\begin{array}{c} \pm \text { 2s Uncertainty ASTM } \\
\text { D2361, BS 1016, ISO 587 }\end{array}$ & $\begin{array}{c} \pm \text { 2s Uncertainty } \\
\text { ASTM D 4208 }\end{array}$ & $\begin{array}{c} \pm \text { 2s Uncertainty } \\
\text { ASTM D 6721 }\end{array}$ \\
\hline 2000 & $10 \%$ & $10 \%$ & $5 \%$ \\
\hline 1000 & $\mathbf{2 0 \%}$ & $15 \%$ & $5 \%$ \\
\hline 300 & $70 \%$ & $\mathbf{2 0 \%}$ & $5 \%$ \\
\hline 50 & $430 \%$ & $80 \%$ & $5 \%$ \\
\hline 20 & $1070 \%$ & $180 \%$ & $10 \%$ \\
\hline 10 & $2145 \%$ & $355 \%$ & $\mathbf{2 0 \%}$ \\
\hline
\end{tabular}


The limit of application of the ASTM D 2361, BS 1016 and ISO 587 titration method appears to be unreasonably high. Examination of the three methods reveals the equation for the calculation of chlorine content is:

$\mathrm{Cl}=3.545 \times \mathrm{N} \times(\mathrm{V} 2-\mathrm{V} 1) / \mathrm{m}$

Where:

$\mathrm{Cl}$ is the chlorine content in wt \%

$\mathrm{N}$ is the normality of the titration solution

V2 is the volume of titrant required to titrate the test solution

$\mathrm{V} 1$ is the volume of titrant require for the blank

$\mathrm{m}$ is the mass of the coal sample in grams

All three standards allow for a 0.025 normal titration solution. In this case, the equation above reduces to

$\mathrm{Cl}=886 \times(\mathrm{V} 2-\mathrm{V} 1) / \mathrm{m}$

Where: $\mathrm{Cl}$ is the chlorine content in $\mu \mathrm{g} / \mathrm{g}$

In other words, for a 1 gram sample of coal, a $1 \mathrm{~mL}$ difference between the volume required to titrate the test solution (V2), and the volume required to titrate the blank (V1) is equivalent to a concentration of $886 \mu \mathrm{g} / \mathrm{g}$ chlorine. A $0.1 \mathrm{~mL}$ difference is equivalent to equivalent to a concentration of $88.6 \mu \mathrm{g} / \mathrm{g}$ chlorine.

Clearly, to determine chlorine, the titration device must dispense titrant with very small volume errors. In addition, it is essential to keep the final volume of the solution to be titrated to $100 \mathrm{~mL}$ and preferably to $50 \mathrm{~mL}$ as the solubility product of silver chloride can restrict the lower quantitative limit. Add to this the increase in the solubility of silver chloride created by the diverse ion effect as a result of the presence of other salts that are most certainly generated during Eschka and ignition or bomb combustion and the determination of chlorine by ASTM D 2361, BS1016 and ISO 587, and this becomes a rather complex exercise in chemistry.

\section{Bomb Decomposition as a Preparation Technique (Precision \& Accuracy)}

Certain standards include a preparation method that involves igniting coal in a stainless steel bomb in an oxygen atmosphere. A solution is added to the bomb to absorb the chlorine compounds. The absorbing solution is treated to convert chlorine compounds to chloride in solution. Careful rinsing of all internal bomb surfaces, the crucible, electrodes, and valves is necessary to ensure complete recovery of chlorine and to prevent run-to-run memory effects. Chlorine can also be trapped in the bomb or crucible alloy, contributing to low recovery and run-to-run memory affects. Halide resistant bombs, platinum electrodes, and a platinum combustion crucible can minimize these effects. 
This method is generally unsuitable for samples that do not burn well, such as ashes and fuels of low reactivity. Although combustion aids can be used for ashes and low reactivity fuels, these materials must be free of chlorine.

\section{Mercury}

International, Regional and National standards For Mercury are:

ASTM D 3684

ASTM D 6414

ASTM D 6722

EPA 7473

GB/T16659

ISO 15237

The USGS IGL procedure for the determination of mercury content is based on ASTM D 6414 "Standard Test Method for Total Mercury in Coal and Coal Combustion Residues by Acid Extraction or Wet Oxidation/ Cold Vapor Atomic Absorption". This SOP describes factors that are known to affect the measurement of mercury in the analysis sample. Critical maintenance requirements are prefaced with an $[\mathbf{M}]$. The measurement characteristic(s) precision and/or accuracy affected by the factor appear in brackets.

\section{Acid Extraction/Wet Oxidation as a Preparation Technique (Precision \& Accuracy)}

ASTM D 6414 involves extracting up to $2 \mathrm{~g}$ of coal in a sealed container. The method can be adapted for samples of very high or very low mercury content by adjusting the weight of sample. The method is suitable for ash materials. The method may not be suitable for extraction of mercury from anthracitic coals and furnace or foundry coke. In the case of these materials, it is speculated mercury may be included in refractory carbon structures that do not readily decompose in the digestion process.

\section{Sample Digestion}

The USGS IGL employs a hot block for sample digestion. Significant deformation of the digestion tubes has been noted for certain coal samples. This can be attributed in part to the oxidation of organic coal structures by the nitric acid employed in the digestion step. The depletion of nitric acid associated with the reaction with coal could result in incomplete extraction of mercury from the coal matrix. In addition, the soluble organic compounds produced by oxidation of the coal could react with potassium permanganate added to the digestion to promote complete oxidation of mercury.

\section{Analyzer Calibration (Precision \& Accuracy)}

The instrument shall be calibrated to with the AOAC requirements in the section on Calibration and Calibration Verification.

\section{Limit of Application of Standard Methods (Precision \& Accuracy)}


A standard method calibrated employing primary chemical substances can be expected to produce results with minimal bias. Compliance with the provisions of the standard method without modification should produce results with a precision at least equivalent to the repeatability of the method.

The repeatability of a standard method can be used to calculate the expected $\pm 2 \mathrm{~s}$ ( 2 standard deviation) uncertainty of a mercury value at different levels of mercury in coal. Assume a method should not be used to report a value with a $\pm 2 \mathrm{~s}$ uncertainty that exceeds $20 \%$ of the measured value. The point at which the $\pm 2 \mathrm{~s}$ uncertainty of each standard method reaches $20 \%$ of the measured mercury value is highlighted in bold in Table B.3.5.

Table B.3.5. The point at which the \pm 2 s uncertainty of each standard method reaches $20 \%$ (bold) of the measured mercury value.

\begin{tabular}{|c|c|c|c|c|}
\hline Hg ng/g & $\begin{array}{c}\text { + 2s Uncertainty } \\
\text { ASTM D 3684 }\end{array}$ & $\begin{array}{c} \pm \text { 2s Uncertainty } \\
\text { ISO 15237 }\end{array}$ & $\begin{array}{c} \pm \text { 2s Uncertainty } \\
\text { ASTM D 6414 }\end{array}$ & $\begin{array}{c} \pm \text { 2s Uncertainty } \\
\text { ASTM D 6722 }\end{array}$ \\
\hline 250 & $10 \%$ & $15 \%$ & $10 \%$ & $5 \%$ \\
\hline 200 & $15 \%$ & $15 \%$ & $10 \%$ & $5 \%$ \\
\hline 140 & $\mathbf{2 0 \%}$ & $15 \%$ & $15 \%$ & $10 \%$ \\
\hline 100 & $25 \%$ & $20 \%$ & $15 \%$ & $10 \%$ \\
\hline 70 & $35 \%$ & $\mathbf{2 0 \%}$ & $\mathbf{2 0 \%}$ & $10 \%$ \\
\hline 40 & $65 \%$ & $25 \%$ & $30 \%$ & $\mathbf{2 0 \%}$ \\
\hline 20 & $130 \%$ & $40 \%$ & $50 \%$ & $35 \%$ \\
\hline
\end{tabular}

From this table the standard as written and without modification can be used down to the following mercury concentrations in coal:
ASTM D 3684
$140 \mathrm{ng} / \mathrm{g}$
ISO 15237
$70 \mathrm{ng} / \mathrm{g}$
ASTM D 6414
$70 \mathrm{ng} / \mathrm{g}$
ASTM D 6722
$40 \mathrm{ng} / \mathrm{g}$

\section{Bomb Decomposition as a Preparation Technique (Precision \& Accuracy)}

ASTM D 3684 and ISO 15237 involve igniting approximately $1 \mathrm{~g}$ of coal in a stainless steel bomb in an oxygen atmosphere. The lower limit of the method is constrained by the maximum weight of coal that can be burned. The method is generally unsuitable for samples that do not burn well such as ashes and fuels of low reactivity. Although combustion aids can be used for ashes and low reactivity fuels, these materials must be mercury free.

Careful rinsing of all internal bomb surfaces, the crucible, electrodes, and valves is necessary to ensure complete recovery of mercury and to prevent run-to-run memory effects. Mercury reacts readily with chlorine and can be trapped in the bomb or crucible alloy, contributing to low recovery and run-to-run memory affects. Halide resistant bombs, platinum electrodes and a platinum combustion crucible can minimize these effects. 
ISO 15237 requires the bomb washings and residues to be collected in a $100 \mathrm{~mL}$ volumetric flask. Prior to dilution to $100 \mathrm{~mL}, 0.5 \mathrm{~mL}$ of a $(50 \mathrm{~g} / \mathrm{L})$ potassium permanganate solution is added. The final solution is transferred to a mercury free vessel and heated at $90{ }^{\circ} \mathrm{C}$ for 60 minutes in a suitable digestion block. These additional precautions have been found to improve the recovery of mercury as well as the precision of analysis (see $\pm 2 \mathrm{~s}$ mercury, table B.3.5).

\section{Direct Combustion for the Analysis of Mercury (Precision \& Accuracy)}

ASTM D 6722 involves igniting a milligram quantity of coal in a combustion train and capturing the mercury in its elemental state on gold amalgam. The method can be adapted for samples of very high or very low mercury content by adjusting the weight of sample. The method is suitable for ash materials. Some samples can cause problems with uniform combustion depending on their moisture content or mineral composition. These samples may explode or "spark" in the combustion train, carrying material out of the combustion region before mercury is completely released.

Some evidence suggests high concentrations of selenium $(>4 \mu \mathrm{g} / \mathrm{g})$ in coal may cause incomplete and erratic recovery of mercury during direct combustion analysis. It has not been determined if the form of selenium in coal leads to this problem or, for that matter, how the selenium "interferes" with the collection and detection of a uniform species of mercury. If erratic results for a test sample are obtained, blanks should be run until the instrument stabilizes. Run a CRM or RM mercury standard that is known to produce results for acceptable precision to verify accuracy and stability. If the CRM and/or RM standard(s) are within acceptable limits, check the selenium value of the suspect test sample.

\section{Majors and Minor Elements}

International, Regional and National standards for Major and Minor Oxides are listed in table B.3.6.

Based on the law of propagation of errors, the expected total for the major and minor oxides listed in the table B.3.6 for an in control measurement system should be from 97.5 weight percent to 102.5 weight percent on an ignited basis. An oxide total outside these limits indicates the measurement system may not be in control, or the presence of an analyte in an amount not normally encountered in coal-derived ash.

Table B.3.6. The major and minor oxides normally determined in coal ash and the relevant applicable standards.

\begin{tabular}{|c|c|}
\hline Oxide & Relevant Standards \\
\hline $\mathrm{Na}_{2} \mathrm{O}$ & AS 1038, ASTM D 3682, ASTM D 6349, DIN 51729, GB/T4634 \\
\hline $\mathrm{MgO}$ & AS 1038, ASTM D 3682, ASTM D 6349, DIN 51729, GB/T4634 \\
\hline $\mathrm{Al}_{2} \mathrm{O}_{3}$ & AS 1038, ASTM D 3682, ASTM D 6349, DIN 51729, GB/T1574 \\
\hline $\mathrm{SiO}_{2}$ & AS 1038, ASTM D 3682, ASTM D 6349, DIN 51729, GB/T1574 \\
\hline $\mathrm{P}_{2} \mathrm{O}_{5}$ & AS 1038, ASTM D 2795, ASTM D 6349, DIN 51729, GB/T1574 \\
\hline $\mathrm{SO}_{3}$ & ASTM D 5016, DIN 51729, GB/T1574 \\
\hline
\end{tabular}




\begin{tabular}{|c|l|}
\hline $\mathrm{K}_{2} \mathrm{O}$ & AS 1038, ASTM D 3682, ASTM D 6349, DIN 51729, GB/T4634 \\
\hline $\mathrm{CaO}$ & AS 1038, ASTM D 3682, ASTM D 6349, DIN 51729, GB/T4634 \\
\hline $\mathrm{TiO}_{2}$ & AS 1038, ASTM D 3682, ASTM D 6349, DIN 51729, GB/T1574 \\
\hline $\mathrm{Fe}_{2} \mathrm{O}_{3}$ & AS 1038, ASTM D 3682, ASTM D 6349, DIN 51729, GB/T4634 \\
\hline $\mathrm{SrO}$ & AS 1038, ASTM D 3682, ASTM D 6349, DIN 51729 \\
\hline $\mathrm{BaO}$ & AS 1038, ASTM D 3682, ASTM D 6349, DIN 51729 \\
\hline
\end{tabular}

The USGS IGL procedure for the determination of major and minors is based on ASTM D 6349 "Standard Test Method for Determination of Major and Minor Elements in Coal, Coke and Solid Combustion Residues from Coal and Coke by Inductively Coupled Plasma-Atomic Emission Spectroscopy". This SOP describes factors that are known to affect the measurement of majors and minors in the prepared ash sample. Critical maintenance requirements are prefaced with an [M]. The measurement characteristic(s) precision and/or accuracy affected by the factor appear in brackets.

\section{Analyzer calibration (Precision \& Accuracy)}

The instrument shall be calibrated to the AOAC requirements in the section on Calibration and Calibration Verification.

\section{Trace Elements}

Table B.3.7 lists the trace constituents normally determined in coal ash and the relevant applicable standards. A standard method calibrated employing primary chemical substances can be expected to produce results with minimal bias. Compliance with the provisions of the standard method without modification should produce results with a precision at least equivalent to the repeatability of the method. The repeatability of a standard method can be used to calculate the expected $\pm 2 \mathrm{~s}(2$ standard deviation) uncertainty of a trace element at different levels of the trace element. The expected percent uncertainty of the measured value over the normally expected range of each trace element in ash is listed in table B.3.7.

Table B.3.7. The relevant applicable standards and expected percent uncertainty of the measured value over the normally expected range of each trace element normally determined in coal ash. Values with $\mathrm{a} \pm 2 \mathrm{~s}$ uncertainty that exceeds $20 \%$ of the measured value are shown in bold.

\begin{tabular}{|c|l|c|c|c|}
\hline $\begin{array}{c}\text { Trace } \\
\text { Analyte }\end{array}$ & \multicolumn{1}{|c|}{ Relevant Standards } & $\begin{array}{c} \pm \mathbf{2 s} \mathbf{\mu g} / \mathbf{g} \\
\text { AS 1038 }\end{array}$ & $\begin{array}{c} \pm \mathbf{2 s} \mathbf{\mu g} / \mathbf{g} \\
\text { ASTM D } \\
\mathbf{3 6 8 3}\end{array}$ & $\begin{array}{c}\mathbf{\pm 2 s} \mathbf{\mu g} / \mathbf{g} \\
\text { ASTM D } \\
\mathbf{6 3 5 7}\end{array}$ \\
\hline $\mathrm{Be}$ & AS 1038 ASTM D 3683 ASTM D 6357 & $10 \%$ & $\mathbf{3 5 \%}$ & $5 \%$ \\
\hline $\mathrm{V}$ & AS 1038 ASTM D 3683 ASTM D 6357 & $5 \%$ & $20 \%$ & $10 \%$ \\
\hline $\mathrm{Cr}$ & AS 1038 ASTM D 3683 ASTM D 6357 & $10 \%$ & $15 \%$ & $5 \%$ \\
\hline $\mathrm{Mn}$ & AS 1038 ASTM D 3683 ASTM D 6357 & $5 \%$ & $10 \%$ & $5 \%$ \\
\hline $\mathrm{Co}$ & ASTM D 6357 & & & $10 \%$ \\
\hline $\mathrm{Ni}$ & AS 1038 ASTM D 3683 ASTM D 6357 & $10 \%$ & $\mathbf{7 0} \%$ & $10 \%$ \\
\hline $\mathrm{Cu}$ & AS 1038 ASTM D 3683 ASTM D 6357 & $5 \%$ & $10 \%$ & $10 \%$ \\
\hline $\mathrm{Zn}$ & AS 1038 ASTM D 3683 ASTM D 6357 & $5 \%$ & $20 \%$ & $5 \%$ \\
\hline
\end{tabular}




\begin{tabular}{|c|l|c|c|c|}
\hline As & ASTM D 6357 & & & $10 \%$ \\
\hline $\mathrm{Mo}$ & ASTM D 6357 & & & $10 \%$ \\
\hline $\mathrm{Cd}$ & ASTM D 6357 & & & $20 \%$ \\
\hline $\mathrm{Sb}$ & ASTM D 6357 & & & $20 \%$ \\
\hline $\mathrm{Pb}$ & AS 1038 ASTM D 3683 ASTM D 6357 & $15 \%$ & $\mathbf{7 0} \%$ & $10 \%$ \\
\hline
\end{tabular}

The USGS IGL procedure for the determination of trace is based on ASTM D 6357 "Standard Methods for Determination of Trace Elements in Coal, Coke and Combustion Residues from Coal Utilization Processes by Inductively Coupled Plasma Atomic Emission Spectrometry, and Graphite Furnace Atomic Absorption Spectrometry". This SOP describes factors that are known to affect the measurement of trace in the prepared ash sample. Critical maintenance requirements are prefaced with an [M]. The measurement characteristic(s) precision and/or accuracy affected by the factor appear in brackets.

Assume a method should not be used to report a value with a \pm 2 s uncertainty that exceeds $20 \%$ of the measured value. Although the table B.3.7 is only a guide, it suggests ASTM D 3683 should not be used for $\mathrm{Be}, \mathrm{Ni}$, or $\mathrm{Pb}$. On the other hand both AS 1038 and ASTM D 6357 appear to be adequate for the entire suite of trace elements for which they are cited in the table. The uncertainty for Be and V by AA should be greater than ICP-AES, ICP-MS, while the uncertainty for analytes such as $\mathrm{Cr}, \mathrm{Mn}, \mathrm{Cu}$ should be similar for all finishes. Table B.3.7 tends to support this notion.

The standard AS 1038, which specifies conditions for preparation and selection of calibration standards that more rigorously comply with the fundamentals of calibration cited in the section Calibration and Calibration Verification, appears to be suitable for measuring significantly lower limits of trace elements than ASTM D3683.

\section{Analyzer calibration (Precision \& Accuracy)}

The instrument shall be calibrated to the AOAC requirements in the section on Calibration and Calibration Verification. 


\section{Appendix B.4}

\section{References for Cited Standards and Organizations}

The reports comprising Appendices A and B contain multiple reference citations to standard methods and other contacts. To facilitate review of the documents the reference was not provided every time a standard test method or organizational contacts was cited. Information regarding these citations is provided below:

\section{Standard Test Methods}

\section{ASTM D XXXX}

ASTM International, 2006, Annual book of ASTM Standards, Section 5, Petroleum products, lubricants and fossil fuels, vol. 05.05 Gaseous fuels; coal and coke: ASTM International, West Conshohocken, Pennsylvania, 705 p.; http://www.astm.org/

AS XXXX

Standards Australia Limited; Sydney, NSW, 2000; http://www.standards.org.au/

BS XXXX

BSI Group (British Standards); London, United Kingdom; http://www.bsi-global.com/en/

\section{DIN XXXX}

DIN Detaches Institute fur Norman e. V (German Institute for Standardization); Berlin

Germany; http://www2.din.de/index.php?lang=en

\section{GB XXXX}

Standardization Administration of the People's Republic of China; Beijing, China, Bulletin of Chinese Standards; http:/www.sac.gov.cn/english/home.asp

ISO XXXXX

International Organization for Standardization); Geneva, Switzerland; http://www.iso.org/iso/en/ISOOnline.frontpage

\section{SABS XXXX}

South African Bureau of Standards, Pretoria, South Africa, https://www.sabs.co.za/index.aspx

\section{Organizational Contacts}

AOAC International; Gaithersburg, Maryland 20877-2417 USA; http://www.aoac.org/

CANSPEX $^{\mathrm{TM}}$; Quality Associates International ${ }^{\circledR}$; Douglas ON K0J 1S0CANADA; http://www.qai-online.com/canspex.pdf

National Institute of Standards and Technology (NIST); Gaithersburg, MD USA; http://www.nist.gov/

Canadian Certified Reference Materials Project (CCRMP), Ottawa, Ontario K1A 0G1, http://www.nrcan.gc.ca/mms/canmet-mtb/mmsl-lmsm/ccrmp/ccrmp-e.htm 